ANA PRISCILA BATISTA

EFEITO DO HYPERICUM PERFORATUM, EM PREPARAÇÃO HOMEOPÁTICA E FITOTERÁPICA, SOBRE O DESAMPARO APRENDIDO EM RATOS

São Paulo

2006 


\section{ANA PRISCILA BATISTA}

EFEITO DO HYPERICUM PERFORATUM, EM

\section{PREPARAÇÃO HOMEOPÁTICA E FITOTERÁPICA,} SOBRE O DESAMPARO APRENDIDO EM RATOS

Dissertação apresentada ao Instituto de Psicologia da Universidade de São Paulo, como parte dos requisitos necessários para a obtenção do título de Mestre.

Área de concentração: Psicologia Experimental.

Orientadora: Prof ${ }^{\mathrm{a}}$. Dra. Maria Helena Leite Hunziker

São Paulo

2006 


\title{
EFEITO DO HYPERICUM PERFORATUM, EM PREPARAÇÃO HOMEOPÁTICA E FITOTERÁPICA, SOBRE O DESAMPARO APRENDIDO EM RATOS.
}

\author{
ANA PRISCILA BATISTA
}

BANCA EXAMINADORA

Elenice Aparecida Moraes Ferrari

Marcus Bentes de Carvalho Neto

Maria Helena Leite Hunziker

(Orientadora) 
A meus pais, Osmario e Ana, e ao Fabio 


\section{AGRADECIMENTOS}

A meus pais, Osmario e Ana, pelo amor e apoio incondicional, fundamental para que eu chegasse até aqui.

Aos meus irmãos, Jusiane e Junior, pelo incentivo e apoio.

À minha orientadora Maria Helena Leite Hunziker (Tatu), pelo incentivo, dedicação e excelente orientação, fundamentais para a minha formação acadêmica e ampliação do meu repertório teórico e prático.

À Flavia Cristina Goulart, pela disponibilidade e ajuda imprescindível para a realização desse trabalho.

À amiga, confidente, conselheira, companheira de casa e de mestrado, Emileane. Pela ótima e bem-humorada convivência de quase 24 horas por dia. Com certeza conviver com ela foi uma variável facilitadora da minha vida de mestranda em São Paulo.

Às companheiras e amigas de casa, Giovana e Izabela, pela amizade e pela boa e descontraída convivência, condições fundamentais para uma boa adaptação.

À amiga Angélica Capelari, sempre muito pronta a ajudar em todas as horas, pelos conselhos sempre tão úteis.

Ao Cristiano, pela ajuda sempre pronta em relação a discussões referentes a assuntos teóricos e práticos, em todas as horas.

À Angélica Yochi, pela ajuda na coleta inicial dos dados.

Ao pessoal do laboratório: Marcos, Mariana, Raquel, Desiree, Carol, Thrissy, Ingrid, e outros já citados anteriormente, à amizade, auxílio, companheirismo, boa convivência...

À secretária Sônia Kamisaki pela ajuda, esclarecimentos e atendimento sempre pronto em relação às questões formais.

À minha ex-professora e orientadora de iniciação científica, Verônica Bender Haydu, por ter me ensinado o gosto pela pesquisa em análise experimental do comportamento.

À Carol e a Esther, sempre amigas, companheiras, confidentes, conselheiras...

A todos que contribuíram de alguma forma com a realização desse trabalho.

Em especial ao Fabio, meu namorado, sempre incentivando, apoiando, compreendendo... Por ter suportado a distância e os longos períodos de ausência. Por essa grande prova de amor.

A mestranda teve, por período parcial, bolsa do Programa de Pós-Graduação em Psicologia $\begin{array}{lll}\text { Experimental/USP cedida } & \text { pelo }\end{array}$ 


\section{SUMÁRIO}

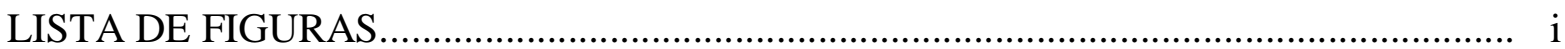

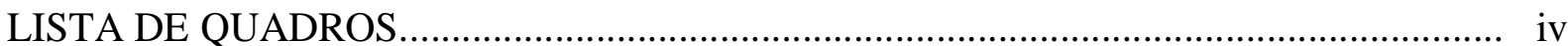

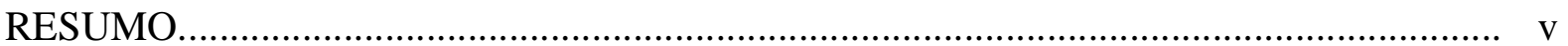

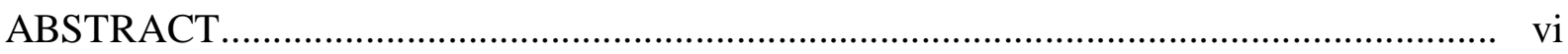

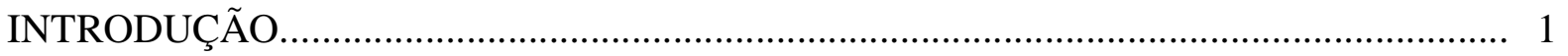

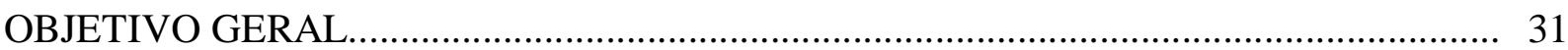

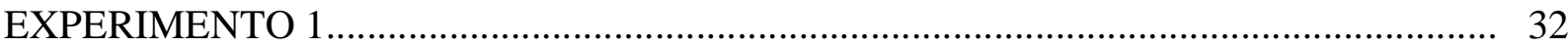

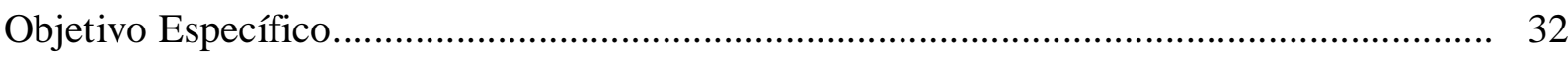

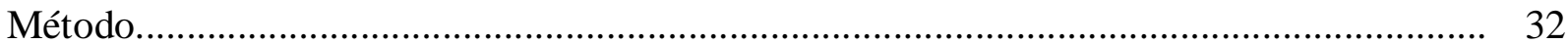

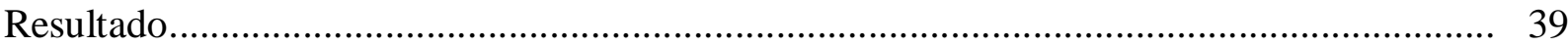

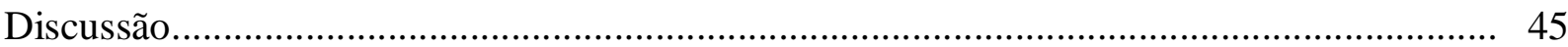

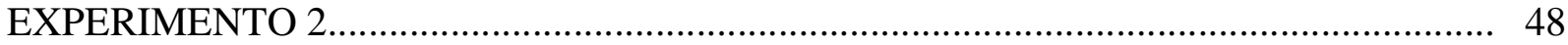

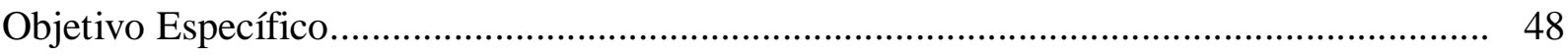

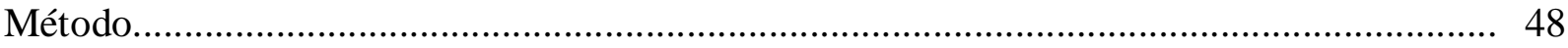

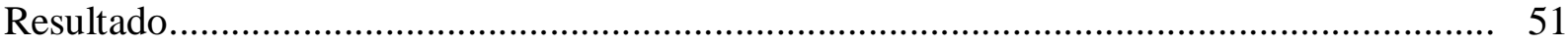

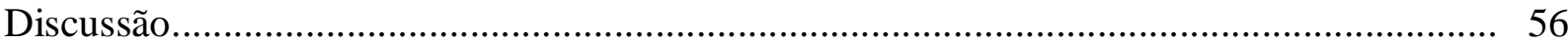

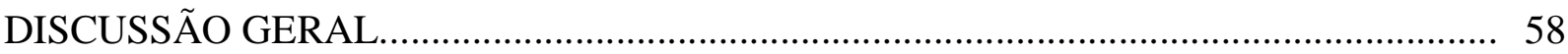

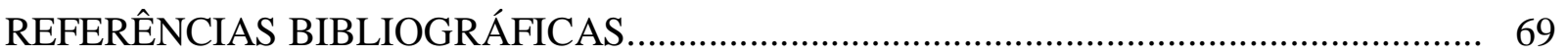

ANEXOS 


\section{LISTA DE FIGURAS}

Figura

Página

1. Médias das latências (em segundos) da resposta de fuga (saltar) na sessão de teste, em blocos de 5 tentativas, apresentadas pelos grupos $(\mathrm{N}=$ nenhum choque, $\mathrm{C}=$ choque controlável e $\mathrm{I}=$ choque incontrolável) de cada tríade (Sem droga - sd; Solução hidroalcóolica 5\% - 0CH; Hypericum perforatum 30CH - Hp30CH e Hypericum perforatum 200CH - Hp200CH).

2. Médias das latências (em segundos) da resposta de fuga (saltar) do primeiro e último blocos na sessão de teste, apresentadas pelos grupos $(\mathrm{N}=$ nenhum choque, $\mathrm{C}=$ choque controlável e $\mathrm{I}=$ choque incontrolável) de cada tríade (Sem droga - sd; Solução hidroalcóolica 5\% - 0CH; Hypericum perforatum $30 \mathrm{CH}-\mathrm{Hp} 30 \mathrm{CH}$ e Hypericum perforatum 200CH - Hp200CH).

3. Médias das latências (em segundos) da resposta de fuga (saltar) na sessão de teste, em blocos de 5 tentativas, apresentadas pelos sujeitos dos grupos que passaram por nenhum choque $(\mathrm{N})$, choque controlável (C) e choque incontrolável (I) da tríade que não recebeu droga (sd).

4. Médias das latências (em segundos) da resposta de fuga (saltar) na sessão de teste, em blocos de 5 tentativas, apresentadas pelos grupos que passaram por nenhum choque (N), choque controlável (C) e choque incontrolável (I) e que receberam as diferentes substâncias (Sem droga - sd; Solução hidroalcóolica $5 \%$ - 0CH; Hypericum perforatum 30CH - 30CH e Hypericum perforatum $200 \mathrm{CH}-200 \mathrm{CH})$.

5. Médias das latências (em segundos) da resposta de fuga (saltar) na sessão de teste, em blocos de 5 tentativas, apresentadas pelos grupos $(\mathrm{N}=$ nenhum choque, $\mathrm{C}=$ choque controlável e $\mathrm{I}=$ choque incontrolável) de cada tríade (Sem droga - sd; Solução hidroalcóolica 5\% - Hp 0mg/kg; Hypericum perforatum $15 \mathrm{mg} / \mathrm{kg}$ - Hp 15mg/kg e Hypericum perforatum 30mg/kg - Hp $30 \mathrm{mg} / \mathrm{kg})$.

6. Médias das latências (em segundos) da resposta de fuga (saltar) do primeiro e último $\left(6^{\circ}\right)$ blocos na sessão de teste, apresentadas pelos grupos $(\mathrm{N}=$ nenhum choque, $\mathrm{C}=$ choque controlável e $\mathrm{I}=$ choque incontrolável) de cada tríade (Sem droga - sd; Solução hidroalcóolica 5\% - Hp 0 mg/kg; Hypericum perforatum 15 mg/kg - Hp 15 mg/kg e Hypericum perforatum 30 mg/kg - Hp $30 \mathrm{mg} / \mathrm{kg})$. 
7. Médias das latências (em segundos) da resposta de fuga (saltar) na sessão de teste, em blocos de 5 tentativas, apresentadas pelos grupos que passaram por nenhum choque $(\mathrm{N})$, choque controlável (C) e choque incontrolável (I) e que receberam as diferentes substâncias (Sem droga - sd; Solução hidroalcóolica 5\% - Hp 0 mg/kg; Hypericum perforatum 15 mg/kg - Hp 15 mg/kg e Hypericum perforatum $30 \mathrm{mg} / \mathrm{kg}$ - Hp $30 \mathrm{mg} / \mathrm{kg}$ ).

8. Médias das latências (em segundos) da resposta de fuga (saltar) na sessão de teste, em blocos de 5 tentativas, apresentadas pelos sujeitos dos grupos que passaram por nenhum choque $(\mathrm{N})$, choque controlável (C) e choque incontrolável (I) da tríade que recebeu o veículo $(0 \mathrm{CH})$ - solução hidroalcóolica 5\%.

9. Médias das latências (em segundos) da resposta de fuga (saltar) na sessão de teste, em blocos de 5 tentativas, apresentadas pelos sujeitos dos grupos que passaram por nenhum choque $(\mathrm{N})$, choque controlável $(\mathrm{C})$ e choque incontrolável (I) da tríade que recebeu o Hypericum perforatum na dinamização 30CH (Hp30CH).

10. Médias das latências (em segundos) da resposta de fuga (saltar) na sessão de teste, em blocos de 5 tentativas, apresentadas pelos sujeitos dos grupos que passaram por nenhum choque $(\mathrm{N})$, choque controlável $(\mathrm{C})$ e choque incontrolável (I) da tríade que recebeu o Hypericum perforatum na dinamização 200CH (Hp200CH).

11. Médias das latências (em segundos) da resposta de fuga (saltar) na sessão de teste, em blocos de 5 tentativas, apresentadas pelos grupos que passaram por nenhum choque $(\mathrm{N})$, choque controlável (C) e choque incontrolável (I) da tríade que recebeu solução hidroalcóolica $5 \%$ e pelo Grupo I acoplado a essa tríade, mas que recebeu solução hidroalcóolica 5\% na dinamização $30 \mathrm{CH}$ (30CH).

12. Médias das latências (em segundos) da resposta de fuga (saltar) na sessão de teste, em blocos de 5 tentativas, apresentadas pelos sujeitos do grupo que passou por choque incontrolável (I), acoplado ao Grupo $\mathrm{C}$ da Tríade $0 \mathrm{CH}$, e que recebeu solução hidroalcóolica 5\% na dinamização 30CH (30CH).

13. Médias das latências (em segundos) da resposta de fuga (saltar) na sessão de teste, em blocos de 5 tentativas, apresentadas pelos sujeitos dos grupos que passaram por nenhum choque $(\mathrm{N})$, choque controlável $(\mathrm{C})$ e choque incontrolável (I) da tríade que recebeu o veículo - solução hidroalcóolica 5\% (0mg/kg). 
14. Médias das latências (em segundos) da resposta de fuga (saltar) na sessão de teste, em blocos de 5 tentativas, apresentadas pelos sujeitos dos grupos que passaram por nenhum choque $(\mathrm{N})$, choque controlável (C) e choque incontrolável (I) da tríade que recebeu o Hypericum perforatum na dose $15 \mathrm{mg} / \mathrm{kg}$ (Hp 15mg/kg).

15. Médias das latências (em segundos) da resposta de fuga (saltar) na sessão de teste, em blocos de 5 tentativas, apresentadas pelos sujeitos dos grupos que passaram por nenhum choque $(\mathrm{N})$, choque controlável $(\mathrm{C})$ e choque incontrolável (I) da tríade que recebeu o Hypericum perforatum na dose $30 \mathrm{mg} / \mathrm{kg}$ (Hp 30mg/kg).

16. Médias das latências (em segundos) da resposta de fuga (saltar) na sessão de teste, em blocos de 5 tentativas, apresentadas pelos grupos que passaram por nenhum choque $(\mathrm{N})$, choque controlável $(\mathrm{C})$ e choque incontrolável (I) da Tríade $0 \mathrm{mg} / \mathrm{kg}$ e pelo Grupo I acoplado a essa tríade, que recebeu salina (Sal).

17. Médias das latências (em segundos) da resposta de fuga (saltar) na sessão de teste, em blocos de 5 tentativas, apresentadas pelos sujeitos do grupo que passou por choque incontrolável (I), acoplado ao Grupo C da Tríade 0mg/kg, e que recebeu salina (Sal). 


\section{LISTA DE QUADROS}

Quadro

Página

1. Resumo esquemático do procedimento utilizado no Experimento 1, sendo: sd indicativo de "sem droga"; $0 \mathrm{CH}=$ solução hidroalcóolica a $5 \%$; Hp = hypericum perforatum; $\mathrm{CH}=$ dinamização, nos valores de 0,30 e $200 \mathrm{CH}$ O intervalo entre o final do tratamento com choques e o início do teste foi de 24 horas.

2. Resumo esquemático do procedimento utilizado no Experimento 2. Doses do hypericum perforatum: 0 (solução hidroalcóolica a 5\%), 15 ou $30 \mathrm{mg} / \mathrm{kg}$. O intervalo entre as sessões de choque e teste foi de 24 horas. Os três primeiros grupos, em itálico, são os mesmos utilizados no Experimento 1.

3. Resumo esquemático do procedimento utilizado como complemento do Experimento 1, com o acréscimo de um Grupo I que recebeu a solução hidroalcóolica 5\% na dinamização $30 \mathrm{CH}$, acoplado à Tríade $0 \mathrm{CH}$. Assim: 0CH $=$ solução hidroalcóolica a 5\%; 30CH = solução hidroalcóolica $5 \%$ na dinamização $30 \mathrm{CH}$. O intervalo entre o final do tratamento com choques e o início do teste foi de 24 horas.

4. Resumo esquemático do procedimento utilizado como complemento do Experimento 2, com o acréscimo de um Grupo I que recebeu salina, acoplado à Tríade $0 \mathrm{mg} / \mathrm{kg}$. Assim: $0 \mathrm{mg} / \mathrm{kg}$ = solução hidroalcóolica a 5\%; Sal = salina ou soro fisiológico. O intervalo entre as sessões de choque e teste foi de 24 horas. 


\section{RESUMO}

Batista, A. P. (2006) Efeito do Hypericum Perforatum, em preparação homeopática e fitoterápica, sobre o desamparo aprendido em ratos. Dissertação de Mestrado, Instituto de Psicologia, Universidade de São Paulo, São Paulo, 102p.

Tratamentos alternativos para a depressão humana vêm sendo realizados pela homeopatia e fitoterapia, por meio do Hypericum perforatum (Hp), dinamizado ou extrato, respectivamente. Experimentalmente, o desamparo aprendido é proposto como modelo animal de depressão, o que permite seu uso para o teste de substâncias potencialmente antidepressivas. Assim, foram realizados dois experimentos para verificar se o Hp em preparação homeopática e fitoterápica impediriam o desamparo aprendido em animais. No Experimento 1, foram utilizados 96 ratos Wistar, machos, distribuídos em doze grupos $(\mathrm{n}=8)$, expostos às fases choque e teste, separadas por 24h. Os grupos foram manipulados em tríades, tratados com choques $(60,1,0$ mA, VT 60s, 10s máx.) controláveis (C), incontroláveis (I) ou nenhum choque (N). Após esse tratamento, as tríades receberam 5 gotas, v.o. de: $\mathrm{Hp} 30 \mathrm{CH}, \mathrm{Hp} 200 \mathrm{CH}$ e $0 \mathrm{CH}$ (veículo solução hidroalcóolica a 5\%), três vezes, com intervalo de 0,19 e $23 \mathrm{~h}$ após o término da fase choque. A quarta tríade não recebeu substância (sd) e foi utilizada para comparação em ambos os experimentos. No teste, todos os sujeitos foram submetidos a uma contingência de fuga, com 30 choques, semelhantes aos anteriores, em uma shuttlebox. No Experimento 2, foram utilizados 72 ratos com as mesmas características, distribuídos em nove grupos $(n=8)$. Os equipamentos foram os mesmos e o procedimento foi semelhante ao do Experimento 1, com diferença apenas na fase de administração da droga, sendo que cada tríade recebeu extrato de Hp i.p., $1 \mathrm{ml} / \mathrm{kg}$, nas doses: $0 \mathrm{mg} / \mathrm{kg}$ (veículo - solução hidroalcóolica a 5\%), $15 \mathrm{mg} / \mathrm{kg}$ e 30 $\mathrm{mg} / \mathrm{kg}, 22$ horas após o término da fase choque. Os resultados mostraram que apenas o Grupo I da Tríade sd apresentou desamparo aprendido. No Experimento 1, as substâncias não produziram efeito sobre os grupos $\mathrm{N}$ e C, enquanto os grupos I tiveram redução das latências, sendo o efeito mais significativo com $\mathrm{Hp} 200 \mathrm{CH}$. O tratamento $0 \mathrm{CH}$ produziu uma pequena redução das latências gerais, embora não suficiente para abolir o desamparo. Os resultados do Experimento 2 mostraram que os grupos $\mathrm{N}$ e C não sofreram efeito das substâncias, enquanto os grupos I tiveram redução da suas latências, sendo o efeito maior com Hp $0 \mathrm{mg} / \mathrm{kg}$. Esses resultados sugerem que o veículo não era farmacologicamente inerte, comprometendo os demais resultados do Hp. Conclui-se que os efeitos de tratamentos da homeopatia e fitoterapia precisam ser mais investigados para que uma afirmação da sua eficácia tenha mais confiabilidade. 
Batista, A. P. (2006) Effect of Hypericum Perforatum, in homeopathic and phytotherapic preparation, upon learned helplessness in rats. Master Dissertation, Institute of Psychology, University of São Paulo, São Paulo, 102p.

\begin{abstract}
Alternative treatments for the human depression have been conducted in the homeopathy and phytoterapy, through Hypericum perforatum (Hp), dynamized or extract, respectively. Experimentally, learned helplessness is proposed as an animal model of depression, which permits its use to test the effects of potential antidepressants. Two experiments were conducted to investigate whether $\mathrm{Hp}$, either in homeophatic and or in phytotherapic preparation, can prevent the occurrence of learned helplessness in animals. In the Experiment 1, 96 male Wistar rats were divided into 12 groups $(\mathrm{n}=8)$ exposed to treatment and test phases, separated by 24 hours. Groups were divided into triads exposed to controllable shocks (C), uncontrollable shocks (I) or no shocks (N). After that, Hp was administered orally (five drops) to each triad in one of three dynamizations - 30CH, $200 \mathrm{CH}$ and $0 \mathrm{CH}$ (vehicle - hydroalcoholic solution 5\%) - three times: 0, 19, and 23 hours after treatment with shocks. The fourth triad didn't receive drug (sd) and it was used in both experiments. In the test phase, all the animals were exposed to an escape contingency in a shuttlebox. In the Experiment 2, 72 rats were divided into 9 groups $(\mathrm{n}=8)$. Equipments were the same and procedure was similar to Experiment 1, with the exception of drug administration. Extract of Hp was administered, i.p., $1 \mathrm{ml} / \mathrm{kg}$, in one of three concentrations for each triad - $0 \mathrm{mg} / \mathrm{kg}$ (vehicle - hydroalcoholic solution 5\%), $15 \mathrm{mg} / \mathrm{kg}$ and $30 \mathrm{mg} / \mathrm{kg}$ - 22 hours after treatment with shocks. Results showed that, among the groups that were not administered pharmacological treatment, only Group I did not learn to escape, an indication of learned helplessness. In Experiment 1, among the groups that were administered $\mathrm{Hp}$ in homeopathic preparation, groups $\mathrm{N}$ and $\mathrm{C}$ were not affected, while response latencies for groups I decreased, with a stronger effect with $200 \mathrm{CH}$. Treatment with $0 \mathrm{CH}$ caused a small reduction of general latencies, although it wasn't suficient to prevent helplessness. In Experiment 2, results showed that $\mathrm{Hp}$ in phytotherapic administration didn't affect groups $\mathrm{N}$ and C, while the latencies of Group I were reduced, with a stronger effect with $\mathrm{Hp} 0 \mathrm{mg} / \mathrm{kg}$. These data suggest that the vehicle wasn't inert pharmacologically, which casts doubt on the results that involved Hp. In conclusion, more studies will be necessary to attest the efficacy of homeopathic and phytotherapic treatment.
\end{abstract}


A observação da ação do ambiente sobre o organismo, da ação do organismo sobre o ambiente e as mudanças subseqüentes, faz parte do trabalho de cientistas comportamentais (Skinner, 1989/1991). Quando se observa um comportamento, identificamse as relações existentes entre propriedades do ambiente e propriedades do organismo. Uma análise experimental do comportamento determina que existem tipos de relações entre os estímulos e as respostas e como surgem essas relações (Catania, 1979/1999).

Deste modo, pode-se afirmar que o indivíduo modifica seu meio à medida que é modificado por ele, de forma que organismo e ambiente se relacionam reciprocamente. Skinner (1953/1998) define esse comportamento como “operante" e descreve que "as conseqüências do comportamento podem retroagir sobre o organismo. Quando isto acontece, podem alterar a probabilidade de o comportamento ocorrer novamente” (p. 65). Portanto, essa interdependência é a essência da análise do comportamento, que estuda como o aparecimento e a remoção de estímulos produzidos pelas respostas do sujeito modificam o comportamento do mesmo.

Uma forma de facilitar o estudo das relações entre eventos é o exame em ambiente controlado de laboratório, cuja simplicidade propicia a observação dos vários aspectos da aprendizagem (Catania,1979/1999). De acordo com Skinner (1953/1998), a ciência do comportamento estuda organismos relativamente simples, com histórias simples e sob condições simples. Assim, com o alcance do rigor necessário para uma análise científica em trabalhos desenvolvidos experimentalmente sobre comportamento animal em laboratório, pode-se identificar leis gerais que regem o comportamento, inclusive o humano.

A transposição do laboratório animal para a espécie humana não é direta. As espécies diferem entre si, cada uma tendo suas características próprias. Porém, parte-se do pressuposto que, a despeito dessas diferenças, elas tenham seus comportamentos controlados pelas mesmas leis naturais, selecionadas ao longo do seu processo evolutivo. Portanto, 
baseados na teoria evolucionista (Darwin, 1859/1981, Skinner, 1938/1966), os analistas do comportamento consideram que as leis básicas do comportamento são as mesmas para os organismos que ocupam diferentes posições dentro da escala da filogenia. Conseqüentemente, com a compreensão dos processos comportamentais básicos de uma espécie, espera-se aumentar a compreensão do comportamento das demais espécies.

Segundo Willner (1991a), os modelos animais são amplamente utilizados para investigar, em laboratório, aspectos de psicopatologia humana. Esses modelos são procedimentos que buscam mimetizar uma psicopatologia e, para que eles sejam comparados, o modelo deve apresentar semelhanças com alguns aspectos da patologia, tais como etiologia, bases bioquímicas, sintomatologia e tratamento. O desamparo aprendido, estudado em animais, foi sugerido como passível de compor um modelo experimental de depressão humana (Seligman, 1975/1977), pois se assemelha a essa psicopatologia quanto aos aspectos apontados anteriormente.

\section{DEPRESSÃO}

Na literatura médica, termos mentalistas, tais como humor deprimido e perda de interesse, permeiam critérios e definições da depressão. De acordo com o DSM-IV ${ }^{1}$, a depressão é denominada Transtorno Depressivo Maior e se enquadra dentro dos Transtornos de Humor. Diversos critérios diagnósticos devem ser preenchidos para a elaboração de um diagnóstico de depressão, levando-se em conta aspectos como a identificação de transtornos psiquiátricos freqüentemente associados, características específicas e prevalência em diferentes culturas/ idades/gênero, reconhecimento de fatores biológicos, entre outros.

\footnotetext{
${ }^{1}$ American Psychiatric Association (1994). Diagnostic and Statistical Manual of Mental Disorders; DSM IV (4 $4^{\text {th }}$ ed.). Washington, DC: APA.
} 
Sistemas de classificação, como o DSM-IV e o CID-10², foram desenvolvidos com a finalidade de fornecer critérios diagnósticos e uniformizar a linguagem utilizada por diferentes profissionais (Wielenska, 2001). Segundo Cavalcante \& Tourinho (1998), os sistemas de classificação representam um esforço no sentido de permitir a padronização, a troca de informações entre profissionais, a predição e o desenvolvimento de estratégias de tratamento, utilizando o enquadramento com base em critérios diagnósticos específicos.

Para os objetivos do presente trabalho, o que é importante considerar sobre os sistemas de classificação é que neles são utilizados conceitos mentalistas para definir determinadas patologias e o enquadramento é feito com base em critérios diagnósticos específicos. O que é avaliado é a topografia do comportamento e não é considerada a função do mesmo. Já o modelo behaviorista radical atenta para a função de determinados comportamentos no contexto onde se inserem, considerando os déficits e excessos comportamentais. Dentro desse modelo, pesquisas básicas sobre esquemas de reforçamento (Ferster \& Skinner, 1957) permitiram uma maior compreensão de alterações no padrão de respostas operantes e, seguindo nessa linha de investigação, Ferster (1973) desenvolveu um trabalho pioneiro de análise funcional da depressão.

Segundo Ferster (1973), a primeira tarefa de uma análise comportamental é definir objetivamente o comportamento, enfatizando classes funcionais de respostas que possam ser observadas e, dessa forma, descobrir tipos de circunstâncias que aumentam ou diminuem a freqüência de determinados comportamentos. Assim, para observar comportamentos que fazem referência à definição clínica de depressão, é preciso atentar para a freqüência dos mesmos, pois a característica mais óbvia de uma pessoa deprimida é a diminuição da freqüência de comportamentos reforçados positivamente, ou seja, a pessoa deprimida sofre basicamente de falta de reforçadores.

${ }^{2}$ Organização Mundial da Saúde. (2003). CID-10: classificação estatística internacional de doenças e problemas relacionados à saúde. 10. ed. São Paulo: Editora da Universidade de São Paulo. 
Sobre esse aspecto, Hunziker (1997) analisa que os relatos verbais de pessoas a respeito de tristeza, pessimismo, passividade, etc, seriam uma tradução mentalista da falta de reforçadores. Sendo assim, para o analista do comportamento são as relações funcionais que definem o comportamento como depressivo e não apenas as características topográficas e, por isso, as classificações tradicionais não são necessárias para essa abordagem da depressão.

Desse ponto de vista, o repertório comportamental do indivíduo dito deprimido é produto dos mesmos processos comportamentais que estão envolvidos na produção de qualquer outro repertório. Skinner (1989/1991) afirma que comportamentos perturbados são gerados pelos mesmos processos que produzem o comportamento dito normal. Desse modo, se uma pessoa apresenta um determinado padrão de respostas, estas respostas são as melhores que ela pode dar frente ao seu ambiente. Isso porque tais respostas foram selecionadas a partir das contingências de reforço às quais aquela pessoa foi submetida, e são essas contingências que continuam mantendo seu comportamento. Portanto, o que é importante é saber qual é a relação funcional entre o comportamento e o ambiente que serve de ocasião, que modela e que mantém o comportamento denominado depressivo.

Ferster (1973) também aponta que é preciso compreender os processos que levam o sujeito a ter essa baixa freqüência de reforçamento e que não basta apenas reconhecer que houve a diminuição da freqüência de comportamentos reforçados positivamente. Ele cita que um desses processos é a extinção, ou seja, a interrupção de reforçamento para respostas que produziam reforçadores anteriormente. A esse respeito, Hunziker (1997) analisa que se acontecem algumas mudanças nas contingências de reforçamento e o repertório do indivíduo não se adequa a elas, as respostas emitidas deixam de ser reforçadas, entram em um processo de extinção (diminuem de freqüência), o que leva a um quadro ainda mais acentuado de pouco reforçamento, característico da depressão. Já a proposta do desamparo aprendido (Seligman, 1975/1977), como modelo de depressão, destaca o fato de que o indivíduo pode 
aprender, a partir de determinadas circunstâncias, que aspectos de seu ambiente não estão sob seu controle e conseqüentemente, frente a novas situações, ele deixa de emitir respostas, mesmo sem experimentar a extinção. Dessa forma, o indivíduo emite menos respostas, seu comportamento é pouco reforçado, estabelecendo um padrão de falta de reforçadores.

O fato da Análise do Comportamento abordar a depressão a partir de contingências do ambiente não significa a exclusão das características do organismo que se comporta. Os estudos sobre a bioquímica da depressão contribuem para a investigação básica de alguns comportamentos. Por exemplo, a identificação de que a sensibilidade a reforçadores é mediada por alguns neurotransmissores está relacionada ao repertório deprimido, pois mesmo com reforçadores disponíveis um indivíduo que tenha disfunções nesses sistemas de neurotransmissão pode não ser sensível a esses reforçadores e, como conseqüência, seus comportamentos podem não ser mantidos. Dessa forma, a baixa freqüência de respostas pode ser devida tanto à falta de reforçadores como à insensibilidade do organismo aos potenciais reforçadores disponíveis. Mesmo que essa insensibilidade se deva a fatores bioquímicos, estes não podem ser considerados as causas primeiras da depressão, pois se sabe que uma disfunção bioquímica pode ser decorrente das interações do indivíduo com o ambiente, o que mostram alguns trabalhos experimentais, como o de Weiss, Stone e Harrell (1970). Portanto, a indicação de fatores ambientais ou bioquímicos no estudo das causas da depressão é apenas uma questão do nível de análise que está sendo feita: eles não são excludentes, mas, ao contrário, interagem entre si. 


\section{DESAMPARO APRENDIDO: UM MODELO ANIMAL DE DEPRESSÃO}

O desamparo aprendido foi descrito por Overmier e Leaf (1965), Overmier e Seligman (1967) e Seligman e Maier (1967), sendo inicialmente chamado de efeito de interferência, e posteriormente substituído pela atual denominação.

Conforme Hunziker (1993), o estudo do desamparo se destaca pela análise da história passada como evento crítico na determinação do comportamento emitido no presente. A dificuldade de aprendizagem é avaliada na comparação do comportamento emitido diante de contingências operantes (fuga ou esquiva), apresentados por sujeitos submetidos previamente a eventos aversivos (geralmente choques elétricos) controláveis ou incontroláveis ou nenhum choque. Nessa comparação, maiores latências de respostas de fuga/esquiva, que indica dificuldade ou não aprendizagem dessas respostas, caracterizam o desamparo.

Um procedimento típico do desamparo aprendido envolve três grupos de animais que são colocados em caixas experimentais idênticas, onde ficam durante uma sessão. Dois deles recebem choques de uma mesma fonte e um terceiro não recebe choques. Dos dois animais tratados com choque, apenas um deles pode emitir uma resposta que o desliga, controlando a duração dos choques para si e para seu parceiro, cujas respostas não alteram a duração dos choques, caracterizando-os como incontroláveis. Essa tríade permite a análise tanto dos efeitos dos choques em si, como dos efeitos da possibilidade (ou não) de controle sobre os mesmos. Após 24 horas dessa sessão, os animais são expostos à contingência de fuga ou esquiva. O resultado padrão é uma maior latência da resposta de fuga/esquiva apresentada pelos animais previamente submetidos aos choques incontroláveis, sendo que tanto os animais previamente expostos aos choques controláveis quanto os não submetidos aos choques, aprendem igualmente a resposta que está sob reforçamento negativo. 
Duas hipóteses associativas foram formuladas para explicar os processos de aprendizagem envolvidos no desamparo. Uma delas, chamada de hipótese da inatividade aprendida defende que o desamparo é função de contingências acidentais que selecionam a baixa atividade motora. Por exemplo, os primeiros choques eliciam a alta movimentação corporal que coincide com a continuidade dos mesmos, estabelecendo uma contingência acidental de punição da alta atividade motora (Bracewell \& Black, 1974). Uma segunda contingência acidental seria a de reforçamento negativo da inatividade, baseada na observação de que a movimentação corporal tende a se reduzir após alguns segundos de choque, possibilitando que o término do choque coincida com a baixa atividade motora (Glazer \& Weiss, 1976a, b). Portanto, ambos os processos acidentais que se instalariam durante os choques incontroláveis, levariam a um resultado comum que seria a baixa atividade motora.

A segunda hipótese, denominada hipótese do desamparo aprendido, propõe que os choques incontroláveis geram uma expectativa no indivíduo de que ele não pode controlar o ambiente, e que é essa expectativa de não controle que determina a dificuldade de aprendizagem posterior (Maier \& Seligman, 1976). Excluindo-se essa interpretação mentalista sobre a "expectativa”, pode-se dizer que a hipótese do desamparo aprendido estabelece que os sujeitos são sensíveis à condição de impossibilidade de controle, e que essa ausência de relação funcional, aprendida durante os choques incontroláveis, se generaliza para condições futuras onde a contingência operante existe, dificultando a nova aprendizagem (Hunziker, 2005).

Além dessas hipóteses comportamentais, há outras que se baseiam exclusivamente em análises de processos neuroquímicos. Alguns pesquisadores como Glazer e Weiss (1976a, b), também defendem a hipótese de que o desamparo se deve à baixa atividade motora do sujeito após o tratamento com a incontrolabilidade, com a diferença de que eles atribuem essa baixa atividade motora diretamente à depleção de neurotransmissores 
do sistema nervoso central (SNC), tais como a noradrenalina e dopamina: com esses neurotransmissores em baixa, os sujeitos estariam fisiologicamente menos aptos a se movimentarem, o que dificultaria a emissão da resposta de fuga/esquiva que, geralmente, envolve grande movimentação corporal. Outro estudo (Takase \& cols., 2005) mostra que a administração de um número alto de choques incontroláveis leva a mudanças em neurônios serotonérgicos e noradrenérgicos de sistemas neuroquímicos cerebrais e ao desamparo aprendido, sendo esse resultado consistente com a hipótese de que a ativação dos neurônios serotonérgicos e noradrenérgicos, além de um certo limiar, pode ser um fator crítico para o desenvolvimento do desamparo aprendido. Alguns pesquisadores, como Jackson, Maier e Coon (1979), também identificaram que a exposição a choques incontroláveis leva a uma maior liberação de endorfinas e essa maior quantidade de endorfinas circulantes gera estados analgésicos tão potentes quanto os induzidos por uma dose moderadamente alta de morfina, deixando os sujeitos menos sensíveis a estímulos dolorosos.

Tanto as hipóteses associativas quanto as neuroquímicas lidam com a baixa atividade motora e/ou com a insensibilidade ao reforço. Elas diferem no que diz respeito às variáveis dependentes analisadas: enquanto que no primeiro caso são medidos comportamentos voltados ao meio ambiente, no segundo são comportamentos intraorganismos (liberação de neurotransmissores). Entretanto, as variáveis independentes são as mesmas para ambos os conjuntos de hipóteses: as relações probabilísticas entre a emissão da reposta e as mudanças no ambiente, ou seja, a possibilidade ou não de controle sobre os eventos aversivos apresentados ao sujeito. Dessa forma, ambos os conjuntos de interpretações teóricas podem ser complementares. (Hunziker, 2003).

É importante ressaltar que, ao se fazer um paralelo entre o modelo animal do desamparo aprendido e a depressão humana, pode-se observar muitas semelhanças. Segundo Hunziker (2005), o procedimento de estudo do desamparo aprendido mimetiza histórias de 
vida que envolvem muita aversividade e que acabam reduzindo, como conseqüência, a atuação do sujeito sobre seu meio (passividade). Essa passividade impede o contato com reforçadores disponíveis, pois há uma baixa iniciativa comportamental, e também leva a uma redução da função reforçadora dos estímulos disponíveis, os quais são normalmente reforçadores para a espécie ou para o próprio sujeito antes da experiência com a incontrolabilidade. Ambos os efeitos levam à queda de reforçamento para o sujeito, condição característica da depressão.

Algumas das outras semelhanças entre o modelo e a depressão humana seriam:

1) A baixa freqüência de respostas ou insensibilidade aos reforçadores (Petterson, Maier \& Seligman, 1993; Ferster, 1973). No desamparo aprendido, os animais que passaram por um tratamento com choques incontroláveis apresentam, na sessão de teste, uma baixa freqüência de respostas e, mesmo experimentando a contingência de fuga ao responder e eliminar o choque em algumas tentativas, essa resposta não se mantém. No ser humano, percebe-se uma diminuição na freqüência de respostas reforçadas positivamente, tais como respostas relacionadas ao lazer, contatos sociais, afetivos, etc;

2) Os eventos aversivos incontroláveis muitas vezes são também identificáveis como desencadeadores de alguns comportamentos depressivos em humanos (Seligman, 1975/1977);

3) As alterações bioquímicas encontradas em pessoas depressivas se assemelham, ao menos parcialmente, às identificadas em animais que apresentaram o desamparo, tais como a depleção de noradrenalina e serotonina no SNC (Willner, 1991b);

4) Drogas com comprovado efeito antidepressivo em humanos, quando administradas após choques incontroláveis, impedem o aparecimento do desamparo em animais, como por exemplo, a imipramina (Gouveia Jr, 2001; Petty \& Sherman, 1979; Sherman, Sacquitine \& Petty, 1982), sendo que esses paralelos farmacológicos justificam o estudo do 
desamparo aprendido em animais para a identificação de novos fármacos com potencial antidepressivo em humanos (Willner, 1991b).

Avaliando a adequação de modelos animais de depressão, Willner (1984) realizou uma análise de 18 modelos disponíveis na literatura. Nessa avaliação, o critério era que o modelo deveria se assemelhar à condição modelada em sua etiologia, base bioquímica, sintomatologia e tratamento. Foram considerados três tipos de validade, cada uma com seus critérios: 1) validade preditiva: implica que conhecidas manipulações que influenciam o estado patológico no ser humano devem ter efeitos similares no modelo, sendo avaliada também por tratamentos antidepressivos de diversos tipos farmacológicos; 2) validade de face: significa que existem similaridades de sintomas entre o modelo e a condição humana e 3) validade de contructo: significa que o modelo tem uma sólida racional teórica. Os resultados obtidos por Willner mostraram que o desamparo foi um dos quatro modelos que atingiram a mais alta validade global: ele tem uma boa validade preditiva, pois responde a uma ampla variedade de tratamentos efetivos clinicamente; o grande número de sintomas induzidos pelo choque incontrolável, e suas óbvias similaridades com a sintomatologia da depressão, parecem dar ao modelo uma considerável validade de face. Por fim, considerou-se que existe boa validade de constructo, mesmo existindo controvérsias, sendo as racionais teóricas do modelo as que seguem: (1) animais expostos a eventos aversivos incontroláveis tornam-se desamparados, (2) um estado similar é induzido pela incontrolabilidade em pessoas e (3) o desamparo em pessoas é o sintoma central da depressão.

Baseado nesse trabalho de Willner (1984), pode-se considerar que o desamparo aprendido é um modelo animal de depressão com boa validade geral, o que o habilita a ser utilizado inclusive no teste de determinadas substâncias potencialmente antidepressivas. 


\section{AGENTES FARMACOLÓGICOS NO ESTUDO DA DEPRESSÃO}

Segundo Blackman (1987), psicólogos experimentais têm desenvolvido métodos confiáveis que permitem a coleção de dados empíricos válidos, e têm procurado manipular de uma forma sistemática aquelas variáveis que poderiam afetar o comportamento. Em experimentos controlados com animais, a administração de drogas é uma das variáveis independentes que pode resultar em efeitos sistemáticos sobre o comportamento. Assim, em condições de laboratório tem sido demonstrado que o maior determinante do comportamento dos animais provém das condições ambientais às quais esses animais são ou têm sido expostos, sendo que os efeitos de tais variáveis são sutis e de variedade infinita, mas são ordenados e fidedignos, e uma grande parte da análise experimental do comportamento tem sido dedicada a explorá-los. Thompson e Boren (1977) também afirmam que as técnicas operantes estão entre as mais sensíveis para medir a ação comportamental das drogas, pois um sistema comportamental é sensível à manipulação de variáveis independentes e, neste caso, a administração de drogas é uma delas. Entretanto, apontam que um problema fundamental em analisar as formas pelas quais as drogas alteram o comportamento é determinar o grau em que os efeitos observados são específicos da droga ou do conjunto de condições investigadas. Isso porque as drogas, como variáveis independentes, interagem com todas as outras variáveis para determinar o resultado comportamental particular.

Para estudar o efeito de drogas psicotrópicas (drogas que alteram o comportamento), a farmacologia comportamental utiliza processos comportamentais investigados pela análise experimental do comportamento (Blackman \& Pellon, 1993). Diversos modelos animais de depressão foram e são utilizados para avaliar o efeito de várias substâncias antidepressivas, tanto alopáticas (Graeff, 1991; Graeff, Graeff \& Hunziker, 1991; Petty \& Sherman, 1979; De Vry, Maurel, Schreiber, de Beun \& Jentzch, 1999; Gouveia Jr, 
2001; Takamori, Yoshida \& Okuyama, 2001) quanto fitoterápicas (Gambarana \& cols., 1999; Usai \& cols, 2003; De Vry \& cols, 1999; Bach-Rojecky, Kalodera \& Samarzija, 2004; Goulart, 2004; Guilhermano, Ortiz, Ferigolo \& Barros, 2004 ) e homeopáticas (Goulart, 2004).

A classificação das substâncias como alopáticas, homeopáticas ou fitoterápicas depende, segundo Fontes (2001), do fato de que na medicina ocidental existem duas correntes terapêuticas fundamentadas em dois princípios distintos: o princípio dos contrários (contraria contrariis curantur) e o dos semelhantes (similia similibus curantur). O princípio dos contrários é empregado pela alopatia tradicional para combater as doenças por meio de substâncias que atuam contrariamente aos sintomas como, por exemplo, antiinflamatórios e antitérmicos. Essas substâncias podem ser naturais, sintéticas ou semi-sintéticas, sendo formuladas a partir do princípio ativo. Portanto, na alopatia, mesmo que o medicamento seja derivado de substâncias naturais, ele utiliza apenas o princípio ativo da planta que interessa ao tratamento e não o extrato da planta em si. A fitoterapia também emprega o princípio dos contrários, sendo nesse ponto semelhante ao método alopático de tratamento, porém difere da alopatia, pois utiliza diretamente o extrato de plantas medicinais possuidoras de um ou vários princípios ativos que agirão conjuntamente (Bhattaram, Graefe, Kohlert, Veit \& Derendorf, 2002). Diferentemente das anteriores, a homeopatia baseia-se no princípio dos semelhantes, apoiando-se no fato de que toda substância capaz de provocar determinados sintomas em um indivíduo sadio é capaz de curar um doente que apresente sintomas semelhantes, desde que em doses adequadas. Como característica básica, os medicamentos homeopáticos são preparados a partir de minerais, vegetais ou substâncias obtidas a partir de organismos vivos, sendo crítico o processo de dinamização dessa substância, ou seja, diluições e agitações sucessivas em um veículo supostamente inerte (Moritz \& Almeida, 2003). 
Muitas substâncias alopáticas para o tratamento da depressão já foram testadas em laboratório, com modelos animais, o que permite um certo grau de conhecimento sobre seus mecanismos de ação. Segundo McKim (2003), os antidepressivos geralmente aumentam a atividade do sistema monoaminérgico no cérebro e existem diversas formas pelas quais isso é feito. Dentre as drogas referidas como antidepressivos de primeira geração, estão os inibidores da mono-amino-oxidase (iMAOs), tais como como iproniazide, fenelzide, tranilcipromine e maclobemide. A classificação dessas drogas é feita pela forma como agem, ou seja, por inibirem a MAO, uma enzima que inativa a dopamina (DA), noradrenalina (NA) e serotonina (5-HT). Outras drogas, tais como os antidepressivos tricíclicos (TCAs), são assim chamados pelo fato de suas estruturas moleculares conterem três anéis, tais como a imipramina, amitriptilina, desipramina, e nortriptilina. Elas agem por meio da prevenção da recaptação de monoaminas após elas terem sido liberadas na fenda sináptica. Drogas que foram desenvolvidas mais recentemente, e não pertencem a essas categorias, são denominadas de antidepressivos de segunda geração. São inibidores de recaptação, agonistas ou bloqueadores de receptores de monoaminas, sendo alguns deles: maprotilina, amoxapina, trazodona, miaserin, bupropiona e nomifensina. Esse grupo também inclui os inibidores de recaptação seletiva da serotonina (SSRIs), como a fluoxetina, a fluvoxamina, a sertralina e a paroxetina.

O efeito de algumas dessas substâncias já foram avaliados comportamentalmente em modelos animais de depressão, dentre eles o desamparo aprendido. Por exemplo, alguns trabalhos foram realizados para verificar se o desamparo aprendido seria sensível ao tratamento com uma droga amplamente utilizada na clínica, a imipramina. Hunziker, Buonomano e Moura (1986) verificaram que a administração de dose baixa (1.0 mg/Kg) e única, i.p., de imipramina após os choques incontroláveis, 30 min antes da sessão de teste, impediu o desenvolvimento do desamparo aprendido. Esses resultados foram 
posteriormente replicados por outros autores (Graeff \& cols., 1991; Gouveia Jr, 2001). Outro estudo (Takamori \& cols., 2001) também verificou, em um dos experimentos, o efeito sobre o desamparo aprendido em ratos de um tratamento de oito dias com imipramina $(10 \mathrm{mg} / \mathrm{kg})$, fluvoxamina (1,25 mg/kg) e tranilcipromina $(1,25 \mathrm{mg} / \mathrm{kg})$ administradas por via oral (v.o.) ${ }^{3}$. O resultado foi uma significante redução do número de falhas na resposta de fuga, ou seja, não ocorrência do desamparo.

O estudo de Gouveia Jr (2001) procurou verificar os efeitos dose-dependente da imipramina sobre o desamparo aprendido e se esse efeito diferia em ratos machos e fêmeas. Os ratos foram distribuídos de acordo com o sexo (machos e fêmeas), o tratamento (choque incontrolável ou não choque) e dose de imipramina (0; 4; 8; 16 ou 32 mg/kg). Os animais foram submetidos à sessão de treino (tratamento com choque incontrolável ou não choque) e após 24 horas cada sujeito recebeu injeção via i.p. de veículo $(0 \mathrm{mg} / \mathrm{kg})$ ou imipramina (4; 8; 16 ou $32 \mathrm{mg} / \mathrm{kg})$. Após 30 minutos dessa injeção, os animais foram submetidos à sessão de teste de aprendizagem de fuga. Os resultados mostraram que: 1) os animais que receberam veículo e que foram submetidos aos choques incontroláveis foram os que apresentaram maior taxa de falhas e maior latência de respostas, ou seja, dificuldade de aprendizagem de fuga (desamparo); 2) a administração aguda da imipramina foi eficaz para inibir a ocorrência do desamparo, sendo esse efeito dose-dependente e 3) apesar do desamparo ser igualmente verificado em ratos machos e fêmeas, o efeito da droga sofreu interferência do sexo do sujeito, ou seja, o maior efeito se deu em diferentes doses a depender do sexo do sujeito.

Os resultados desse estudo, bem como os dos estudos citados anteriormente, fortalecem a suposição de que o desamparo aprendido se mostrou eficiente e sensível ao tratamento com substâncias alopáticas que são utilizadas na clínica para o tratamento da

\footnotetext{
${ }^{3}$ Toda administração v.o. citada aqui é feita pelo método gavagem: introdução de uma cânula no estômago do animal, por meio da qual a substância é administrada.
} 
depressão. Será que o mesmo tipo de resultado pode ser obtido com substâncias antidepressivas fitoterápicas e homeopáticas em modelos animais? Alguns estudos, bem como as particularidades de cada área, serão discutidos com mais detalhes a seguir.

\section{FITOTERAPIA E O HYPERICUM PERFORATUM, EM EXTRATO BRUTO, NO ESTUDO DA DEPRESSÃO}

O tratamento de doenças com medicamentos originários de plantas é utilizado por várias culturas do mundo, há muitos séculos. Aproximadamente $80 \%$ da população mundial usa medicamentos que são direta ou indiretamente derivados de plantas. Mesmo equivocada, a crença de que medicamentos naturais são muito mais seguros que os sintéticos tem ganhado popularidade em anos recentes, o que leva a um tremendo crescimento da utilização desses (Bhattaram \& cols., 2002).

Dentre os fitoterápicos, o Hypericum perforatum (Hp) é utilizado na clínica médica para o tratamento da depressão (Williams \& Holsinger, 2005). O Hp, também conhecido como Erva de São João, é uma planta medicinal pertencente à família das Hypericaceae (sinonímia: guttiferae) (Teedrogen, Bisset \& Wichtl, 1994). Segundo Bahls (2001), existem evidências científicas para a indicação do extrato de Hp em casos de depressões de intensidade leve e moderada, sendo que a substância apresenta um perfil bastante favorável quanto à sua tolerabilidade.

Ainda não se conhece completamente os mecanismos de ação dessa substância, nem quais são os componentes do extrato que apresentam eficácia antidepressiva. (Noriega, 1999; Vitiello, 1999; Bahls, 2001; Hammerness \& cols., 2003; Caccia, 2005). Porém, vários estudos foram realizados para uma melhor compreensão dessa substância, dos constituintes e 
dos prováveis mecanismos de ação (Noriega \& Soares, 1998; Chatterjee, Bhattacharya, Wonnemann, Singer \& Müller, 1998; Calapai \& cols., 1999; Noriega, 1999; Cervo \& cols., 2002; Hirano \& cols., 2004).

De acordo com a Medical Economic Company (PDR for Herbal Medicines) (2000), alguns elementos constituintes do Hp são: derivados antraceno (naftodiantronas, especialmente hipericina e pseudo-hipericina); flavonóides (hiperosido, quercitina, rutina, isoquercitina e alguns biflavonoides, incluindo amentoflavona); xantonas (1,3,6,7,tetrahidroxi-xantona); acilfloroglucinóis (hiperforina com pequena quantidade de adhiperforina); óleo volátil; oligômeros; procianidinas e derivados do ácido caféico. Segundo Bahls (2001), não se sabe exatamente se um ou mais desses componentes são os responsáveis pela eficácia antidepressiva, ou se sua ação terapêutica se deve à somatória das várias substâncias. "Todavia, a maioria dos estudos sobre o Hypericum perforatum admite que seu principal componente ativo com propriedade antidepressiva é a hipericina, havendo, entretanto, alguns autores que também propõem a hiperforina como capaz de apresentar ação antidepressiva” (p. 391).

Por ser uma substância extraída de plantas, fatores como período de colheita, temperatura, umidade, processo de secagem e armazenagem, influenciam na constituição do composto que é disponível comercialmente. Para o tratamento da depressão, os extratos são padronizados e formulados em cápsulas, comprimidos e xaropes para administração oral. Geralmente, os extratos comerciais de Hp são padronizados em hipericina, por volta de 0,10,3\%, e/ou hiperforina, 1-6\%. (Vitiello, 1999).

\section{Farmacodinâmica do Hp em preparação fitoterápica}

Alguns artigos que revisam a literatura da área citam possíveis ações farmacodinâmicas do Hp, embora seja admitido que o seu mecanismo de ação não esteja 
completamente elucidado (Chatterjee \& cols., 1998; Bahls, 2001; Bilia, Gallori \& Vincieri, 2002; Rodríguez-Landa \& Contreras, 2003; Butterweck, 2003; Muller, 2003; Hammerness \& cols., 2003; Mennini \& Gobbi, 2004). Dentre os estudos que buscam verificar o mecanismo de ação do Hp, está o de Calapai e cols. (1999) que avaliou o efeito da administração de dois extratos de Hp: 1) LI160 (0,3\% de hipericina e 6\% de flavonóides) e 2) Ph-50 (0,3\% de hipericina e 50\% de flavonóides). O nível de neurotransmissores em algumas regiões dos cérebros de ratos foi medido uma e 24 horas após a administração dos dois extratos, nas doses de 25-250mg/kg v.o. Os resultados apontaram que: 1) ambos os extratos induziram a um significante aumento de serotonina no córtex; 2) apenas o segundo extrato provocou um aumento dos níveis de serotonina e ácido 5-hidroxindolacético no diencéfalo e aumento dos níveis de noradrenalina, dopamina e serotonina no tronco encefálico e 3) ambos aumentaram o nível de noradrenalina e dopamina no diencéfalo. Assim, os autores concluem que a administração do Hp modifica os níveis dos neurotransmissores que estão envolvidos em distúrbios do humor. Em outro artigo recente, Butterweck (2003) fez uma revisão da literatura, relatando que estudos bioquímicos iniciais demonstram que o Hp é um fraco inibidor da atividade da MAO-A e -B, além de inibir a recaptação sináptica de serotonina, dopamina e noradrenalina. Entretanto, outros estudo in vitro demonstraram significante afinidade por adenosina, GABA(A), GABA(B) e receptores de glutamato. Já in vivo, estudos mostram que o Hp produz downregulation de receptores beta-adrenérgicos, upregulation de receptores de serotonina no córtex frontal do rato e causa mudanças na concentração de neurotransmissores em áreas cerebrais que estão envolvidas na depressão. Com isso, concluise que apesar do Hp ser submetido a extensos estudos científicos na última década, ainda há muitas questões em aberto sobre a farmacologia e o mecanismo de ação do Hp. 


\section{Estudos clínicos sobre a eficácia antidepressiva do Hp fitoterápico}

Em relação aos estudos clínicos, Linde e cols. (1996) realizaram uma revisão sistemática e uma meta-análise ${ }^{4}$ de 23 experimentos, incluindo um total de 1757 pacientes com desordens depressivas leves a moderadamente severas. O objetivo foi investigar se o extrato de Hp era mais efetivo que o placebo no tratamento da depressão, se era tão efetivo quanto tratamentos antidepressivos convencionais, e se tinha menores efeitos colaterais que as drogas antidepressivas convencionais. Quinze experimentos foram controlados com placebo (1008 pacientes) e oito compararam o hypericum com outra droga (749 pacientes). Os resultados mostraram que o extrato do $\mathrm{Hp}$ foi significativamente superior ao placebo e similarmente efetivo aos antidepressivos convencionais. Efeitos colaterais ocorreram em 19,8\% dos pacientes que receberam $\mathrm{Hp}$ e em 52,8\% daqueles que receberam os outros antidepressivos. Assim, o Hp pareceu ter menores efeitos colaterais a curto prazo em relação aos outros antidepressivos convencionais. Os autores acreditam que há uma boa evidência de que o Hp é melhor que o placebo em tratar algumas desordens depressivas, porém não puderam concluir se o Hp é melhor para tratar certas desordens do que outras, e nem se diferentes preparações são igualmente efetivas. Além disso, a classificação de depressão não foi uniforme e em alguns estudos foi bastante vaga. Como limitação desse estudo, os próprios autores apontam que é insuficiente a evidência de que o Hp é tão eficaz quanto outros antidepressivos convencionais, pois consideram que o número de pacientes ( $\mathrm{n}=749$ ), avaliados em oito experimentos, é limitado para se fazer tal afirmação.

Stevinson e Ernst (1999) fizeram uma revisão de seis experimentos publicados entre 1995 e 1997. Quatro deles, que compararam o Hp com placebo, evidenciaram que o Hp é mais efetivo que o placebo para tratar desordens depressivas leves e moderadas. Dois deles, que compararam o Hp com antidepressivos convencionais, não proveram evidência

\footnotetext{
${ }^{4}$ Análise dos estudos publicados.
} 
convincente de eficácia similar. Os autores apontam a necessidade de se realizarem mais estudos.

Na revisão de Williams e cols. (2000) é apontada uma comprovada eficácia clínica do Hp tanto em relação ao placebo quanto comparada aos antidepressivos convencionais. Entretanto, afirmam que a evidência da eficácia é incompleta, pois as preparações utilizadas podem não ser representativas das que vêm sendo utilizadas comercialmente.

Recentemente, Linde, Mulrow, Berner e Egger (2005), em uma revisão de literatura, concluíram que as evidências da eficácia do Hp são inconsistentes e confusas. Enquanto alguns estudos sugerem que o Hp tem mínimos efeitos antidepressivos, outros sugerem que o Hp tem efeitos antidepressivos similares aos antidepressivos convencionais. Os autores destacam que as preparações disponíveis no mercado podem variar consideravelmente quanto à qualidade farmacêutica, o que dificulta a generalização desses dados. Portanto, segundo eles, esses resultados se aplicam somente aos produtos testados nos estudos que foram incluídos nessa revisão.

\section{Estudos em animais sobre os efeitos do Hp fitoterápico}

De modo geral, pode-se perceber que alguns estudos clínicos demonstram, ao menos, a eficácia do Hp em relação ao placebo. Além de estudos com humanos, os efeitos do Hp também vêm sendo investigados em modelos animais de depressão (De Vry \& cols., 1999; Gambarana \& cols., 1999; Usai \& cols., 2003; Butterweck \& cols., 2003; Guilhermano \& cols., 2004; Goulart, 2004; Bach-Rojecky \& cols., 2004). Por exemplo, o efeito do Hp, na forma de extrato bruto, foi verificado no estudo de Bach-Rojecky e cols. (2004) em testes de nado forçado e retirada da cauda com camundongos. As doses utilizadas (0, 7, 35 e 70mg/kg), em um volume de $0,5 \mathrm{ml} / \mathrm{kg}$ foram administradas uma única vez por via intraperitoneal (i.p.), 
30 minutos antes do teste. Os resultados mostraram efeitos antidepressivos dose-dependente: quanto maior a dose, maior foi o efeito.

De Vry e cols. (1999) verificaram o efeito comportamental de dois extratos de Hp (Ze 117 - Remotiv, da Suíça; e LI 160 - Jarsin, da Alemanha), administrados nas doses 0, 5, 10, 20 e 40 mg/kg, i.p., 5 ml/kg, em ratos Wistar. Em uma sessão de pré-teste, o animal era colocado em um cilindro de água por 20 minutos, onde ele poderia nadar ou adotar uma posição de imobilidade que o mantinha com o focinho fora d'água (chamado teste de Porsolt). Após 24 horas, ele era colocado novamente no cilindro por 5 minutos e a duração total da imobilidade foi registrada durante esse teste. Os extratos do Hp foram administrados 23, 5 e 1 hora antes do segundo teste de nado forçado, num intervalo de 24 horas entre o primeiro e o segundo teste. Os resultados mostram que, para ambos os extratos, o efeito antidepressivo máximo foi obtido na dose de $20 \mathrm{mg} / \mathrm{kg}$, resultando em $41 \%$ da redução da imobilidade para o extrato Ze 117 e 32\% para o LI 160. Para o extrato Ze 117, a dose de 40 mg/kg também induziu a um significante efeito antidepressivo (35\% de redução da imobilidade), enquanto que para o extrato LI 160, apenas a dose de 20 mg/kg alcançou significância estatística.

Goulart (2004) buscou comparar o efeito de diferentes formas farmacêuticas do Hp (tanto na forma de extrato bruto como dinamizado) em modelos comportamentais em ratos: seus efeitos foram avaliados no teste de Porsolt, labirinto em cruz-elevado, esquiva passiva e campo aberto. A dose de extrato bruto do Hp utilizada foi 300mg/kg, v.o. Os resultados foram: 1) no teste de Porsolt, essa dose reduziu o tempo de imobilidade, mostrando efeito antidepressivo; 2) no labirinto em cruz elevado, essa dose aumentou a porcentagem de entrada e tempo nos braços abertos, mostrando efeito ansiolítico e 3) nos testes de esquiva passiva e atividade geral no campo aberto, não foram observados efeitos significativos com essa dose. 
Gambarana e cols. (1999) verificaram o efeito do Hp nas doses 0, 250, 500, 1000 e 1500 mg/kg, v.o., em administração única (60 minutos antes do treino) e 0, 250, 500 e $1000 \mathrm{mg} / \mathrm{kg}$ em administração repetida (15 dias) no modelo do desamparo aprendido. Os resultados dos animais que receberam administração única das doses de 1000 e 1500 mg/kg diferiram estatisticamente, ( $\mathrm{p}<0,05$ e $\mathrm{p}<0,01$, respectivamente) daqueles que receberam $\mathrm{o}$ veículo, ou seja, apresentaram um maior número de respostas de fuga no teste (efeito antidepressivo). As outras doses não mostraram diferenças significativas em relação ao grupo que recebeu o veículo. No tratamento repetido, apenas as doses 500 e 1000 mg/kg mostraram efeitos estatisticamente significantes ( $\mathrm{p}<0,05$ e $\mathrm{p}<0,01$ respectivamente), ou seja, os animais que receberam essa dose apresentaram um número maior de respostas de fuga no teste (efeito antidepressivo). Dessa forma, foi concluído que quanto maior a dose, maior é o efeito do Hp tanto em administração única quanto repetida.

O estudo de Guilhermano e cols. (2004) procurou verificar, no teste de Porsolt, o efeito de dois extratos de Hp disponíveis comercialmente (Extrato 1 - importado e Extrato 2 - produzido no Brasil), padronizados para conter 0,3\% de hipericina, no teste de nado forçado em ratos. Foram administradas doses de 0, 125, 250 e $375 \mathrm{mg} / \mathrm{kg}$ em um volume de $1 \mathrm{ml} / \mathrm{kg}$, sendo que o Extrato 1 foi administrado por v.o. e o Extrato 2 via i.p. Os resultados mostraram que o Extrato 1 não modificou o comportamento dos ratos no teste, enquanto o Extrato 2 aumentou significativamente o tempo de imobilidade, mostrando um efeito tipo depressivo, quando comparados ao grupo controle. Assim, esses dois extratos disponíveis comercialmente no Brasil não mostraram efeitos antidepressivos no teste e, ao contrário, o Extrato 2 ainda promoveu um efeito tipo depressivo nos animais. Portanto, estes extratos disponíveis para a população podem diferir de outros extratos utilizados em experimentos que mostraram efeitos antidepressivos. Conseqüentemente, são necessárias mais avaliações de extratos individuais - 
por meio de quantificação de constituintes, testes experimentais e estudos clínicos -, para se verificar quão comparáveis farmacologicamente são essas substâncias.

Em relação às doses utilizadas nos estudos, geralmente, quando a administração é feita v.o. são utilizadas doses maiores, como 300 mg/kg (Goulart, 2004); 250 e 500mg/kg (Butterweck \& cols., 2003) e 250, 500, 1000 e 1500 mg/kg (Gambarana \& cols., 1999), enquanto em estudos que fazem a administração i.p. as doses são menores: 0-40 mg/kg (De Vry \& cols., 1999); 0-100 mg/kg (Coleta, Campos, Cotrim \& Proença da Cunha, 2001); 0-70mg/kg (Back-Rojecky \& cols., 2004). Essa escolha das doses pode ser devido ao efeito de metabolização e absorção da substância, pois, na administração via oral a droga passa pelo trato gastrodigestivo antes de atingir seu local de ação e, já pela via intraperitoneal, a absorção é mais rápida devido à grande quantidade de vasos sanguíneos na região (McKim, 2003).

Os intervalos de administração também variam muito de estudo para estudo. Alguns o fazem em administração única (Coleta \& cols., 2001; Back-Rojecky \& cols., 2004), outros utilizam administrações repetidas (De Vry \& cols., 1999; Goulart, 2004; Guilhermano \& cols., 2004) e outros ainda realizam experimentos com as duas formas de administração (Gambarana \& cols., 1999; Usai \& cols., 2003).

Conforme se demonstrou, há uma grande variedade de resultados nos estudos que utilizaram o Hp em modelos animais de depressão, sendo que um dos estudos aponta a ineficácia de sua utilização. Além disso, há uma grande variedade de dosagem utilizada, formas e intervalos de administração. Esses fatos indicam a necessidade de mais investigações, com padronização de procedimento, sobre o efeito do Hp. A utilização de um modelo animal com boa validação prévia (como a obtida pelo desamparo aprendido) pode favorecer essa padronização. Além da importância científica dessas investigações, elas atendem, também, interesses de aplicação clínica uma vez que o Hp é uma substância que se 
encontra disponível comercialmente, sendo recomendada e utilizada para o tratamento da depressão.

\section{HOMEOPATIA E O HYPERICUM PERFORATUM NO ESTUDO DA DEPRESSÂO}

A homeopatia, como acontece nas demais ciências, está embasada em conhecimentos antecedentes. Em seu tempo, Hipócrates advogava, em termos de tratamento, que dois métodos terapêuticos poderiam ser utilizados com sucesso: a "cura pelos contrários" (Contraria Contrariis Curentur), consolidada por Galeno (129-199 d.C.) e Avicena (9801037), sendo a base da medicina alopática; e a "cura pelos semelhantes" (Similia Similibus Curentur), revista no século XVI por Paracelso (1493-1591) e consolidada pelo médico alemão Samuel Hahnemann (1755 - 1843), quando este criou a Homeopatia. Para Hipócrates, essas duas formas de tratamento eram eficazes no restabelecimento da saúde, não se opondo a elas em seu pensamento (Corrêa, Siqueira-Batista \& Quintas, 1997).

A homeopatia apresenta alguns princípios básicos. A lei dos semelhantes ou princípio da similitude é baseada na lei similia similibus curantur, que quer dizer: o semelhante será curado pelo semelhante. Nessa perspectiva, a droga e a doença provocam sintomas semelhantes produzindo um aumento sincrônico da reação orgânica, que levará à melhora ou à cura do paciente. Assim, o “efeito primário dos medicamentos” causaria alterações nos diversos sistemas orgânicos e o “efeito secundário do organismo” (reação vital; reação homeostática), atuaria como uma resposta orgânica neutralizadora àqueles distúrbios ocasionados pelos fármacos, na tentativa de manter o equilíbrio do meio interno (homeostase). A experimentação no homem sadio, também chamada de experimentação homeopática ou pura, é o método para se conhecer as propriedades curativas das substâncias, 
é o procedimento de testar substâncias medicinais em indivíduos sadios para elucidar os sintomas que irão refletir sua ação. O medicamento dinamizado (doses mínimas, infinitesimais ou ultradiluições) é utilizado como método de preparação dos medicamentos homeopáticos. A substância é diluída e agitada sucessivamente, transmitindo ao diluente a “informação” de suas propriedades, com a propriedade de atuar na esfera física, psíquica e emocional. (Teixeira, 2001).

A lei do remédio único também era aplicada por Hahnemann, que administrava os medicamentos isoladamente, um por vez, por ser mais racional e para impedir as interações entre os diferentes medicamentos, condenando quem fazia o contrário (Machado, 2000; Fontes, 2001).

Em relação à preparação dos medicamentos, o processo farmacotécnico conhecido como dinamização se caracteriza por diluição do insumo ativo sempre intercalado pelas sucussões (agitações), obedecendo a uma progressão geométrica (Fontes, 2001). Para exemplificar: a dinamização $1 \mathrm{CH}$ é feita a partir de uma parte do insumo ativo, mais 99 partes do insumo inerte, mais sucussões; a dinamização $2 \mathrm{CH}$ é feita a partir de uma parte da $1 \mathrm{CH}$, mais 99 partes do insumo inerte, mais sucussões; a dinamização 3CH é feita a partir de uma parte da 2CH, mais 99 partes do insumo inerte, mais sucussões, e assim por diante. Assim, quanto maior a potência ou dinamização do medicamento menor a probabilidade de se encontrar moléculas da droga original na solução. A dinamização sempre vem descrita na forma de um número e a letra $\mathrm{C}$ ou $\mathrm{CH}$. O número que acompanha a letra indica o grau de dinamização do medicamento, e a letra $\mathrm{C}$ ou $\mathrm{CH}$ indica que o medicamento foi preparado na escala centesimal hahnemanneana (proposta por Hahneman). Por exemplo, $1 \mathrm{CH}$ se refere a $1^{\mathrm{a}}$ dinamização centesimal hahnemanneana, uma diluição de $1 / 100,12 \mathrm{CH}$ se refere a $12^{\mathrm{a}}$ dinamização centesimal hahnemanneana, diluição de $1 / 1.10^{23}$. 
Segundo Machado (2000), a escolha da dinamização a ser empregada segue, em geral, as seguintes normas: as baixas dinamizações convêm às lesões, as médias às funções e as altas ao mental. Dinamizações baixas são, por exemplo: C1, C3; médias C5, C7; e altas: C12, C30, C100. Entretanto, Fontes (2001) afirma que o conceito de potência alta ou baixa não encontrou padronização internacional.

A administração do medicamento homeopático pode ser pelas mucosas, epiderme e vias aéreas superiores e inferiores. O método mais empregado pelos homeopatas é a administração via oral. Os medicamentos homeopáticos não devem ser engolidos, mas deixados na boca para que sejam absorvidos pela mucosa bucal. Essa mucosa absorve bem o medicamento e evita que eles recebam influências do estômago e do fígado. A zona perilingual é a mais indicada para receber o medicamento homeopático (Machado, 2000; Fontes, 2001).

Nos últimos tempos vêm aumentando a discussão sobre a eficácia dos medicamentos homeopáticos, bem como o número investigações nessa área. Quando a homeopatia surgiu, consistia em uma técnica terapêutica revolucionária, ainda que de embasamento antigo, que utilizava um método de testar no próprio organismo humano um medicamento para determinar sua atuação. A difusão dos conhecimentos homeopáticos se deu por boa parte do mundo. Entretanto, após a morte de Hahnemann, em 1843, foi mantida a mesma linguagem usada em sua época e os mesmos princípios persistiram até a atualidade. Dessa forma, a homeopatia não pode ser considerada sob o enfoque das novas perspectivas científicas emergentes, sendo difícil comprovar os fundamentos deste ramo da medicina. Apesar dos relatos de que os medicamentos homeopáticos apresentavam efeitos significativos, a homeopatia começou a ser questionada por não conseguir identificar um mecanismo de ação plausível. Provavelmente, este foi o fator que mais contribuiu para seu declínio em relação à alopatia. Atualmente, a homeopatia vem evoluindo por meio de estudos que utilizam o 
método científico, almejando a melhor compreensão de seus mecanismos terapêuticos (Corrêa \& cols., 1997).

\section{Farmacodinâmica do Hp em preparação homeopática}

Segundo Bellavite (2000), os princípios da homeopatia podem ser reavaliados sob a luz da moderna biologia e do conhecimento biofísico e imunológico. Contudo, uma teoria completa de como as drogas homeopáticas podem funcionar no corpo (mecanismos de ação) ainda está faltando. A razão dessa lacuna de conhecimento pode ser devido ao fato de que os fenômenos das doses ultradiluídas e da lei dos semelhantes não podem ser compreendidos pela abordagem utilizada para a investigação de drogas convencionais e de alta dosagem, que considera o organismo, a célula e o mecanismo molecular únicos. Bellavite aponta que a homeopatia é uma abordagem holística, que leva em consideração todos os níveis de organização do corpo.

\section{Estudos clínicos sobre a eficácia antidepressiva do Hp homeopático}

Apesar de não ter se encontrado ainda, dentro da abordagem científica atual, uma explicação dos mecanismos de ação dos medicamentos homeopáticos, muitos estudos vêm sendo realizados com o objetivo de observar os efeitos desses medicamentos sobre algumas doenças em seres humanos. Baker, Myers, Howden, e Brooks (2003), por exemplo, procuraram investigar a eficácia da substância Argentum nitricum sobre a redução da ansiedade, avaliada em escalas de ansiedade com estudantes universitários que tomaram a substância duas vezes ao dia por um período de quatro dias. Os resultados desse estudo demonstraram que a substância homeopática não reduziu a ansiedade, avaliada pela escala, nessa população. 
Outro estudo, desenvolvido por Davidson, Morrison, Shore, Davidson, e Bedayn (1997), procurou relatar o uso de tratamento homeopático em pacientes com depressão e ansiedade. Os medicamentos foram selecionados individualmente, de acordo com o tratamento de doze pacientes com depressão maior, fobia social ou pânico. A duração do tratamento foi de sete a oitenta semanas e as respostas foram monitoradas pelo uso de três tipos de escalas: clinical global scale, self-rated SCL-90 scale e brief social phobia scale. Os resultados apontaram que, com base na primeira escala, 7 dos 12 pacientes (58\%) responderam ao tratamento homeopático e nas outras duas escalas, 6 (50\%) dos 12 pacientes responderam ao tratamento. Apesar de esses resultados sugerirem que a homeopatia pode ser útil no tratamento de alguns pacientes com essas desordens, os próprios autores apontaram limitações nesse estudo uma vez que não foi feito o controle com placebo. Com isso, não foi possível determinar se a melhora foi devido à remissão espontânea, ao efeito placebo, aos efeitos psicoterapêuticos da entrevista homeopática, etc.

Em uma meta-análise, Linde e cols. (1997) procuraram avaliar se os efeitos clínicos relatados em experimentos que utilizaram remédios homeopáticos são equivalentes aos relatados por placebo. Foram avaliados 89 estudos e os resultados não são compatíveis à hipótese de que os efeitos da homeopatia são completamente devido ao efeito placebo. Entretanto, foram encontradas evidências insuficientes, a partir desses estudos, para afirmar que a homeopatia é claramente eficaz para qualquer condição clínica.

Moritz e Almeida (2003) realizaram uma revisão crítica da literatura para avaliar o recente progresso de pesquisas em homeopatia. A homeopatia foi avaliada a partir de pesquisas clínicas, in vitro e fundamentos físicos. Foi realizada uma ampla revisão e uma análise crítica da literatura científica dos últimos dez anos, a partir da base de dados Medline e contato direto com alguns autores listados nas referências. Os resultados mostram que os estudos clínicos apontam para a ineficácia da homeopatia, sendo que alguns poucos estudos 
com resultados positivos são questionáveis devido a problemas de qualidade e falta de controle experimental adequado. Outro resultado foi de que as pesquisas homeopáticas clínicas com resultados positivos não têm sido replicadas por pesquisadores independentes. Estudos dos fundamentos físicos e pesquisas in vitro também mostram uma clara relação entre baixa qualidade metodológica e resultados positivos. Assim, um mecanismo plausível de atuação das substâncias homeopáticas, e sua formulação, não foi, ainda, identificado. Dessa forma, parece não haver evidências clínicas e experimentais suficientes para sustentar uma afirmação de que substâncias homeopáticas têm efeito terapêutico.

Em uma revisão mais recente (Shang \& cols., 2005), foram comparados os efeitos da homeopatia e de remédios convencionais em experimentos controlados com placebo. Os autores presumem que os efeitos observados nos experimentos de homeopatia poderiam ser explicados por uma combinação de deficiências metodológicas e relatos enviesados. Inversamente, mesmo existindo vieses nos experimentos com remédios convencionais, estes vieses não podem explicar os efeitos observados. Os resultados afirmam que, quando a análise foi restrita a grandes experimentos de alta qualidade, não houve evidência convincente de que a homeopatia foi superior ao placebo, enquanto que para os remédios convencionais um efeito importante permaneceu nesses experimentos. Assim, isso provê suporte para a hipótese de que efeitos clínicos da homeopatia, mas não de remédios convencionais, são efeitos placebos não específicos ou efeitos contextuais.

Dessa forma, esses estudos mostram que, quando os efeitos dos tratamentos homeopáticos são positivos, atribui-se a eles o viés e as deficiências metodológicas e, com isso, a dificuldade de uma avaliação mais fidedigna de tais efeitos. Contudo, mesmo que as revisões de literatura encontradas demonstrem pouca eficácia para esse tipo de tratamento, sabe-se que isso não tem impedido a indicação e a utilização clínica de tais medicamentos. Segundo Davidson e cols. (1997), o interesse pela homeopatia por profissionais bem- 
qualificados e sérios é grande, incluindo nesse interesse o tratamento da depressão e da ansiedade, desordens que envolvem um gasto público significante e que também são tratadas em contextos de medicina alternativa.

\section{Estudos em animais sobre os efeitos do Hp homeopático}

Já foi apontada, anteriormente, a significância do teste de substâncias potencialmente antidepressivas em modelos animais de depressão. De acordo com livros de homeopatia, referentes à Matéria Médica (Kent, 1985; Hering, 1989; Allen, 2000; Clarke, 1998), a substância Hypericum perforatum (Hp), em preparação homeopática, tem indicação para alguns sintomas observados em pessoas com depressão, tais como grande ansiedade, melancolia, tristeza, etc., o que justifica o seu teste em modelos animais.

Nos estudos dos efeitos do Hp com modelos animais de depressão, a maioria utiliza essa substância na forma de extrato bruto (preparação fitoterápica), sendo encontrado apenas o trabalho de Goulart (2004) que utilizou o Hp também na preparação homeopática. Esse estudo buscou comparar o efeito de diferentes formas farmacêuticas do Hp (tanto na forma de extrato bruto como dinamizado) em modelos comportamentais em ratos: teste de Porsolt, labirinto em cruz-elevado, esquiva passiva e campo aberto. Os resultados referentes à homeopatia, cuja administração foi v.o. com conta-gotas, mostraram que: 1) dentre as doses na preparação homeopática (30, 100 e 200CH), a única que mostrou efeitos significativos, em relação ao grupo controle, nos diversos modelos comportamentais avaliados, foi a Hp 200CH e 2) o veículo utilizado (solução hidroalcóolica a 5\% dinamizado 200CH) não mostrou diferenças significativas em relação ao grupo controle (água destilada).

Como o estudo de Goulart (2004) foi o único encontrado que investigou, em alguns modelos animais, o efeito de uma substância homeopática indicada para a depressão em humanos, fica patente a necessidade de mais investigações que comprovem a eficácia 
dessa substância, bem como das dinamizações utilizadas, em outros modelos não utilizados nesse estudo, tais como o desamparo aprendido, que tem boa validação dentre os modelos animais de depressão (Willner, 1984). 


\section{OBJETIVO GERAL}

O atual trabalho buscou verificar o efeito do Hypericum perforatum (Hp), preparado de acordo com a fitoterapia (extrato bruto) e com a homeopatia (dinamizado), sobre o desamparo aprendido em ratos. 


\section{EXPERIMENTO 1}

\section{Objetivo específico}

O objetivo desse estudo foi verificar o efeito do Hypericum perforatum em preparação homeopática, nas dinamizações 30CH e 200CH, sobre o desamparo aprendido, em ratos.

\section{MÉTODO}

\section{Sujeitos}

Foram utilizados 96 ratos, machos, albinos, descendentes de Wistar, provenientes do Biotério Central da Fundação Butantan, São Paulo, SP. Os animais eram experimentalmente ingênuos, com aproximadamente 120 dias de idade no início do experimento. No Biotério do Departamento de Psicologia Experimental da USP, os animais foram alojados em gaiolas individuais, com alimento (ração balanceada) e água ad libitum. A iluminação foi automaticamente controlada, mantendo ciclo $12 \mathrm{~h}$ claro/escuro, sendo que a coleta de dados foi realizada no período de luz. A coleta somente era iniciada após um período de, no mínimo, uma semana de permanência dos animais nesse biotério.

\section{Equipamento}

Foram utilizados duas caixas experimentais, sendo uma cúbica e outra alongada (shuttlebox).

A caixa de condicionamento cúbica media 21,5 X 21,5 X 21,5 cm (comprimento, largura e altura), tendo a parte frontal de acrílico transparente e as demais em alumínio. Na parede direita, dispunha de um orifício de $3 \mathrm{~cm}$ de diâmetro, localizado a $6 \mathrm{~cm}$ 
acima do piso, chamado de focinhador. Esse orifício era conectado a uma cuba cilíndrica de alumínio, de igual diâmetro e 3 cm de profundidade, presa no lado externo da caixa. A 1,5 cm da borda dessa cuba havia um feixe luminoso que incidia sobre uma célula foto-elétrica, cuja interrupção era registrada automaticamente. A introdução do focinho do animal no focinhador interrompia o feixe luminoso, registrando uma resposta de focinhar. O piso era composto de barras de latão cilíndricas, de 0,3 mm de diâmetro, distando 1,3 cm entre si, por meio do qual eram administrados os choques elétricos de corrente alternada (AC), com alternador de polaridade, marca Lehing Valey 113-33 (Solid State Shocker/Scrabler).

A caixa alongada media 50,0 X 15,5 X 20,0 cm (comprimento, largura e altura), era composta de acrílico preto fosco, com exceção da parede frontal que era transparente. A caixa era dividida, em seu comprimento, em dois compartimentos iguais por uma parede também de acrílico, contendo um orifício de 7,5 cm de altura e 6,0 cm de largura, a uma distância de $8 \mathrm{~cm}$ do piso (como uma "janela”) que possibilitava ao animal passar de um compartimento ao outro por meio da resposta de saltar. O assoalho de cada compartimento era composto por barras de latão cilíndricas, de 0,3 mm de diâmetro e distantes 1,3 cm entre si, por meio do qual eram administrados os choques elétricos de corrente alternada (AC) provenientes de geradores ligados a alternadores de polaridades (shock scrambler), de fabricação BRS Foringer, modelo 901. Duas barras iguais às do piso se situavam na base do orifício da parede divisória, sendo igualmente eletrificadas. Os choques eram liberados apenas nas barras do orifício central e no assoalho do compartimento onde o sujeito estivesse ao iniciarem esses estímulos. Os assoalhos dos compartimentos eram independentes entre si e dotados de um sistema de molas que promovia a inclinação do piso quando o sujeito se situava em um deles. Essa inclinação ativava um microwitch que registrava automaticamente a presença do sujeito em um dos lados da caixa. 
O controle e os registros de dados foram feitos por um microcomputador e um software especialmente desenvolvido para este tipo de pesquisa.

Substâncias

As substâncias utilizadas foram:

1. O Hypericum perforatum, nas dinamizações homeopáticas $30 \mathrm{CH}$ e $200 \mathrm{CH}$, preparado em solução hidroalcóolica a 5\%, conforme metodologia homeopática. As diluições foram preparadas a partir do extrato de Hypericum perforatum padronizado: extrato seco contendo no mínimo 0,4\% de hipericina e no mínimo 3,0\% de hiperforina (Farma Flora Farmácia Homeopática).

2. Solução hidroalcóolica a 5\% (Farmácia Universitária da USP).

As embalagens com as substâncias foram mantidas em vidro âmbar, ao abrigo da luz e em temperatura ambiente, colocadas em uma sala do biotério onde os animais que receberam essas substâncias ficaram alojados. Nessa sala constavam apenas esses animais e a substância, sendo que aparelhos eletromagnéticos (computador, celular, rádio...), substâncias alopáticas e outros animais não eram colocados no mesmo ambiente.

As dinamizações $30 \mathrm{CH}$ e $200 \mathrm{CH}$ do $\mathrm{Hp}$ foram recomendadas por Goulart (comunicação pessoal, 30 de agosto de 2004 e 24 de setembro de 2005), em função do resultado obtido em seus estudos prévios: a dinamização $200 \mathrm{CH}$ do Hp foi a única a ter efeito significativo em um dos seus experimentos (Goulart, 2004), enquanto a dinamização 30CH foi escolhida para que se pudesse comparar o efeito de uma dinamização mais baixa em relação à mais alta. 


\section{Procedimento}

Os animais foram subdivididos aleatoriamente em doze grupos ( $\mathrm{n}=8)$, cada um exposto a três fases experimentais (choque, droga e teste), sendo o intervalo entre a primeira e a última fase de $24 \mathrm{~h}$.

Fase choque - A fase inicial foi realizada na caixa cúbica, onde quatro grupos de sujeitos foram expostos a um dentre os seguintes tratamentos: choques controláveis (grupos C), choques incontroláveis (grupos I) ou a nenhum choque (grupos N). Aos sujeitos dos grupos $\mathrm{C}$ foram administrados 60 choques de $1 \mathrm{~mA}$ de intensidade, 10s de duração máxima, apresentados em VT 60s (amplitude de variação de 10-110s). Os animais podiam interromper a apresentação do choque emitindo a resposta de introduzir o focinho na cuba da parede (resposta de fuga). Se eles não emitissem essa resposta, o choque era interrompido após 10s de seu início. Cada choque apresentado correspondia a uma tentativa. A latência da resposta de fuga (tempo de duração do choque) era registrada a cada tentativa. A não emissão da resposta de fuga era computada como falha, considerando-se a latência máxima de 10s.

Os animais dos grupos I eram acoplados, aos pares, aos do grupo (C) e recebiam o mesmo número, intensidade e duração de choques, porém, nenhuma resposta desses sujeitos tinha qualquer conseqüência sobre os choques. Com esse procedimento, os animais receberam o mesmo tratamento de choques, com a diferença de que apenas os sujeitos dos grupos C podiam exercer controle sobre a duração dos choques, enquanto que os dos grupos I receberam choques incontroláveis.

Os sujeitos dos grupos $\mathrm{N}$ foram colocados na caixa experimental, permanecendo nela durante o mesmo tempo da sessão dos demais grupos, porém sem receber choques. 
Fase droga - Terminada a fase anterior, os animais foram reconduzidos ao biotério e submetidos à administração da droga. Nessa fase, os sujeitos foram agrupados em quatro tríades, compostas por grupos de animais previamente designados como N, C e I, cada uma submetida a um dos seguintes tratamentos farmacológicos: $\mathrm{Hp} 30 \mathrm{CH}$, Hp 200CH, solução hidroalcóolica a 5\% (0CH), e uma tríade permaneceu no biotério sem droga (sd). Em cada administração, foram fornecidas 5 gotas, liberadas com um conta-gotas diretamente na boca do sujeito. Foram feitas três administrações das substâncias, obedecendo aos seguintes intervalos após o término da primeira fase: 0, 19 e 23 h. Portanto, a primeira dose foi administrada imediatamente após o término da fase de choques, e a última dose foi administrada uma hora antes da sessão de teste (seguindo os intervalos utilizados por Goulart, 2004).

Fase teste - Na sessão de teste, todos os sujeitos foram submetidos a uma contingência de fuga na shuttlebox. Durante a sessão, foram administrados 30 choques controláveis, de 1mA, 10s de duração máxima, apresentados em VT60s (amplitude da variação de 10-110s). O choque era automaticamente desligado após a emissão da resposta de saltar de um compartimento para outro (resposta de fuga). Caso essa resposta não fosse emitida, o choque era interrompido após a passagem de 10s, sendo, neste caso, computada uma falha e a latência de 10s.

O Quadro 1 resume o procedimento do Experimento 1. 
Quadro 1. Resumo esquemático do procedimento utilizado no Experimento 1, sendo: sd indicativo de "sem droga"; $0 \mathrm{CH}=$ solução hidroalcóolica a $5 \%$; $\mathrm{Hp}=$ hypericum perforatum; $\mathrm{CH}=$ dinamização, nos valores de 0 , 30 e $200 \mathrm{CH}$ O intervalo entre o final do tratamento com choques e o início do teste foi de 24 horas.

\begin{tabular}{|c|c|c|c|}
\hline $\begin{array}{l}\text { Grupos } \\
(n=8)\end{array}$ & $\begin{array}{c}\text { Choque } \\
\text { (60 tentativas) } \\
\text { (R de Fuga }=\text { focinhar) }\end{array}$ & $\begin{array}{c}\text { Droga } \\
5 \text { gotas v.o. } \\
(0,19 \text { e } 23 \mathrm{~h})\end{array}$ & $\begin{array}{c}\text { Teste } \\
\text { (30 tentativas) } \\
\text { ( } \mathrm{R} \text { de fuga }=\text { saltar) }\end{array}$ \\
\hline C sd & Choque Controlável (C) & & \multirow{12}{*}{ Choque Controlável (C) } \\
\hline I sd & Choque Incontrolável (I) & sem droga & \\
\hline $\mathrm{N}$ sd & Nenhum Choque (N) & & \\
\hline $\mathrm{C} \mathrm{OCH}$ & Choque Controlável (C) & & \\
\hline I $0 \mathrm{CH}$ & Choque Incontrolável (I) & $\mathrm{OCH}$ & \\
\hline $\mathrm{N} \mathrm{OCH}$ & Nenhum Choque (N) & Sol. hidroalc. 5\% & \\
\hline $\mathrm{C} 30 \mathrm{CH}$ & Choque Controlável (C) & \multirow{3}{*}{ Hp 30СH } & \\
\hline I $30 \mathrm{CH}$ & Choque Incontrolável (I) & & \\
\hline N 30CH & Nenhum Choque (N) & & \\
\hline C 200CH & Choque Controlável (C) & \multirow{3}{*}{ Hр 200CH } & \\
\hline I $200 \mathrm{CH}$ & Choque Incontrolável (I) & & \\
\hline N 200CH & Nenhum Choque (N) & & \\
\hline
\end{tabular}

Os animais eram pesados na fase pré-experimental e antes de iniciar cada sessão, com o objetivo de controle da saúde dos mesmos, considerando-se que a estabilidade do peso é indicadora de boa saúde. Entre uma sessão e outra, a caixa experimental era limpa, retirando-se detritos. Para isso, foram utilizados toalhas de papel, água e álcool. Isso era importante para evitar interferência na eletrificação do piso e para minimizar odores exalados pelos ratos durante os choques, os quais poderiam ter função de estímulo sinalizador aversivo para os ratos seguintes. Um desumidificador (Marca Arsec, Modelo 160M3-U), mantinha a umidade relativa do ar dentro do laboratório em níveis que não ultrapassavam 70\%.

Foram analisados os dados de latência e falha, tanto para os sujeitos individuais quanto para os grupos. Para a análise estatística dos dados de grupo, foram utilizados 
ANOVA two-way para medidas repetidas; e teste Tukey HSD para a análise das diferenças entre duplas. Os resultados foram considerados estatisticamente significantes para um mínimo de $\mathrm{p}<0,05$. Já para um valor de $\mathrm{p}$ entre 0,05 e 0,10 , os resultados foram considerados limítrofes, indicadores de tendência a diferenças. 


\section{RESULTADO}

Os dados desse experimento estão apresentados na Figura 1, onde cada gráfico representa a média dos oito sujeitos de cada grupo (N, C e I) de cada tríade (sd, 0CH, Hp 30CH e Hp 200CH), referente às latências médias (em segundo) da resposta de fuga (saltar) na sessão de teste, calculado a cada bloco de 5 tentativas.

sd

$\mathbf{O C H}$

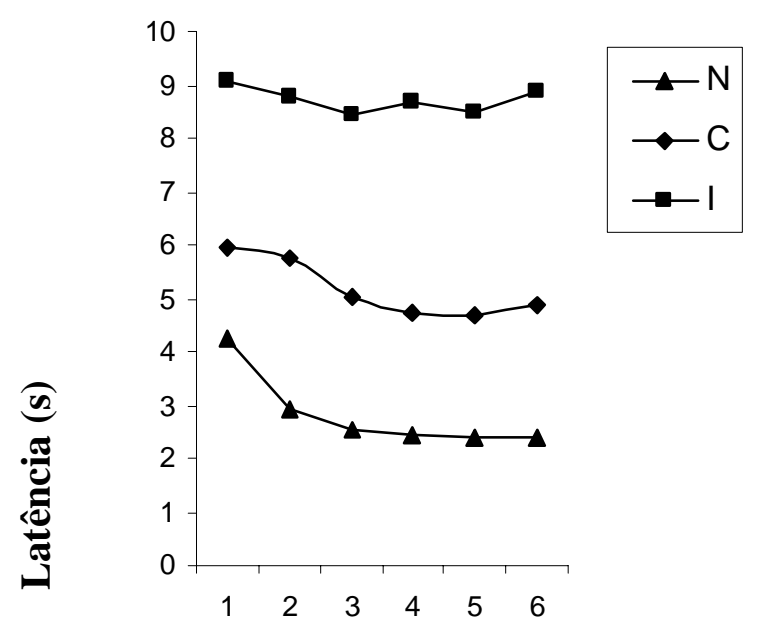

$\mathrm{Hp} 30 \mathrm{CH}$

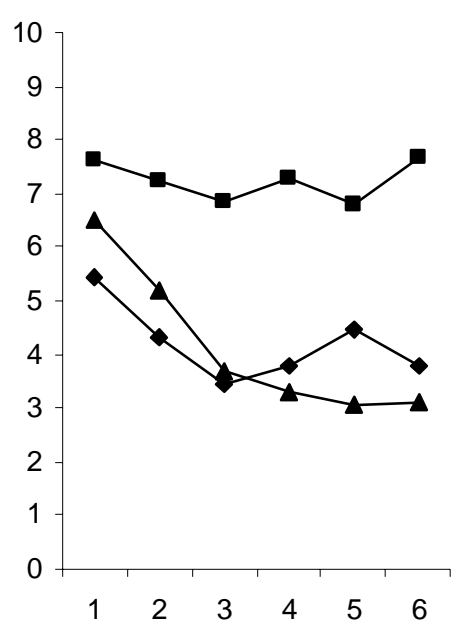

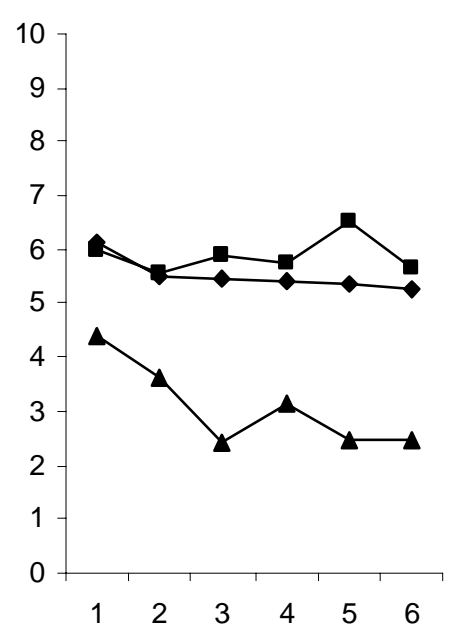

$\mathrm{Hp200CH}$

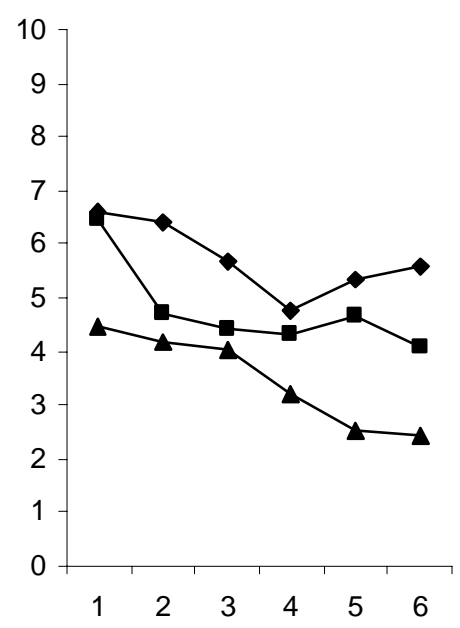

Blocos de 5 tentativas

Figura 1. Médias das latências (em segundos) da resposta de fuga (saltar) na sessão de teste, em blocos de 5 tentativas, apresentadas pelos grupos $(\mathrm{N}=$ nenhum choque, $\mathrm{C}=$ choque controlável e I = choque incontrolável) de cada tríade (Sem droga - sd; Solução hidroalcóolica 5\% - 0CH; Hypericum perforatum $30 \mathrm{CH}$ - Hp30CH e Hypericum perforatum 200CH - Hp200CH). 
Na tríade não exposta a tratamento com droga (sd), pode-se observar que o Grupo $\mathrm{N}$ foi o que apresentou as menores latências, que declinaram até o $4^{\circ}$ bloco e se mantiveram estáveis nos blocos sucessivos. O grupo C teve padrão semelhante, embora com latências um pouco mais elevadas. Já o Grupo I foi o que apresentou as maiores latências na sessão de teste, com pouca alteração das mesmas ao longo da sessão. A análise de variância indicou que as diferenças foram estatisticamente significantes em função das tentativas $(\mathrm{F}(5,105)=3,847, \mathrm{p}<0,05)$ e dos grupos $(\mathrm{F}(2,21)=12,526, \mathrm{p}<0,05)$, sendo que o teste Tukey indicou que grupo I diferiu dos demais $(\mathrm{p}<0,05)$, que não diferiram entre si.

A análise da Tríade 0CH (veículo - solução hidroalcóolica 5\%) mostra que o Grupo N apresentou curva decrescente ao longo da sessão, com latências visivelmente inferiores os grupos C e I, que apresentaram desempenho muito semelhante entre si: as latências apresentadas por ambos tiveram pouco declínio ao longo da sessão. A análise de variância indicou que não houve diferença estatisticamente significante entre os grupos, mas indicou tendência à diferença, $(\mathrm{F}(2,21)=2,891, \mathrm{p}=0,08)$. O teste Tukey indicou que apenas o grupo I mostrou tendência de diferir do N (p=0,09).

Dentre os grupos tratados com $\mathrm{Hp} 30 \mathrm{CH}$, tanto o Grupo $\mathrm{N}$ como o C apresentaram latências decrescentes ao longo da sessão, bastante semelhantes entre si. Diferentemente, o Grupo I apresentou latências mais altas durante toda a sessão, sem decréscimos ao longo dos blocos de tentativas. As diferenças foram significantes em função das tentativas $(\mathrm{F}(5,105)=6,285, \mathrm{p}<0,05)$, havendo interação entre grupos e tentativas $(\mathrm{F}(10,105)=1,999, \mathrm{p}<0,05)$. As diferenças entre grupos mostraram tendência à diferença $(\mathrm{F}(3,28)=2,795, \mathrm{p}=0,06)$. O teste Tukey mostrou que houve tendência à diferença entre os grupos N e I $(p=0,06)$ e entre os grupos C e I $(p=0,07)$. 
Sob o tratamento com Hp 200CH, os três grupos tiveram desempenhos bastante parecidos entre si, com latências decrescentes ao longo da sessão. As diferenças foram estatisticamente significantes apenas em função das tentativas $(F(5,105)=5,799$, $\mathrm{p}<0,05)$.

Os dados apresentados na Figura 1 mostraram que o desempenho dos grupos variou ao longo da sessão. Como o declínio das latências ao longo da exposição ao reforçamento negativo, no teste, é a medida crítica para se analisar a aprendizagem de fuga, os mesmos dados são reapresentados na Figura 2, destacando-se apenas o desempenho inicial e final de cada grupo na sessão de teste, ou seja, nos blocos 1 e 6, respectivamente. Pode-se verificar que todos os grupos apresentam declínio das latências no bloco final, com exceção dos animais dos grupos I. Dentre estes, apenas o exposto a tratamento com Hp 200CH apresentou declínio das latências no bloco final, equiparando-se, sob essa perspectiva, aos demais grupos. 

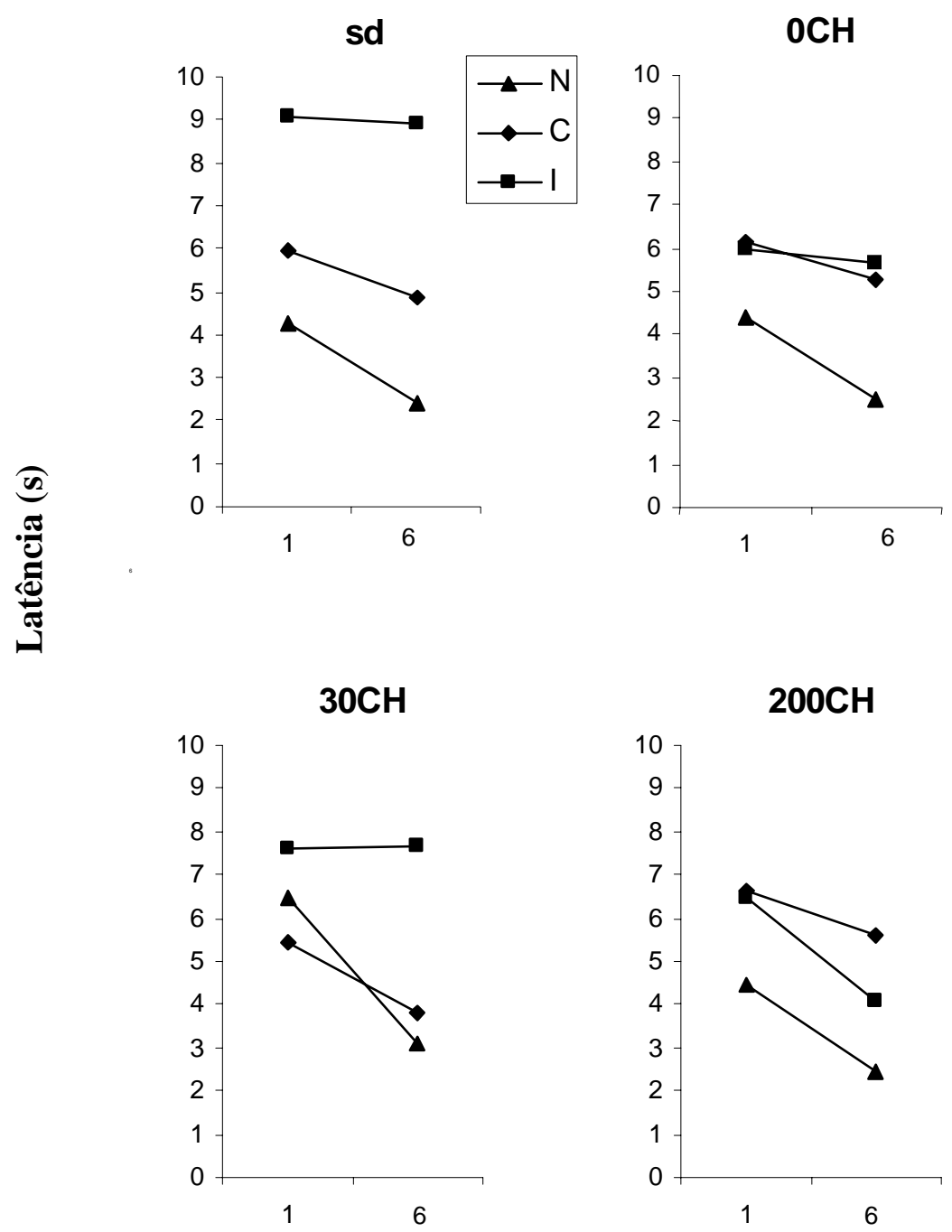

Blocos de 5 tentativas

Figura 2. Médias das latências (em segundos) da resposta de fuga (saltar) do primeiro e último blocos na sessão de teste, apresentadas pelos grupos $(\mathrm{N}=$ nenhum choque, $\mathrm{C}=$ choque controlável e I = choque incontrolável) de cada tríade (Sem droga - sd; Solução hidroalcóolica 5\% - 0CH; Hypericum perforatum 30CH - Hp30CH e Hypericum perforatum 200CH - Hp200CH).

Para exemplificar o desempenho individual dos sujeitos, serão apresentados, na Figura 3, os gráficos de todos os sujeitos da tríade que não recebeu droga (sd) na sessão de teste (Os dados individuais das demais tríades do presente experimento estão apresentados no Anexo I). Pode-se verificar que os desempenhos individuais diferem bastante entre os grupos. No Grupo N as latências são mais baixas que nos demais desde o início da sessão, declinando durante os blocos de tentativas. Nesse grupo, apenas uma exceção: o sujeito 2 não apresentou 
queda da latência de fuga em função da exposição ao reforçamento negativo. No Grupo C, três sujeitos não apresentaram esse declínio das latências (sujeitos 5 e 7 não emitiram nenhuma vez a resposta, e o sujeito 6 passou a responder com latências mais altas nos blocos finais). No Grupo I, apenas um sujeito (o de número 6) apresentou uma curva de latência decrescente. Os demais sujeitos mostraram padrão inalterado ao longo da sessão ou padrão irregular (sujeito 1), terminando a sessão com latência igual à inicial.

Nenhum Choque (N)

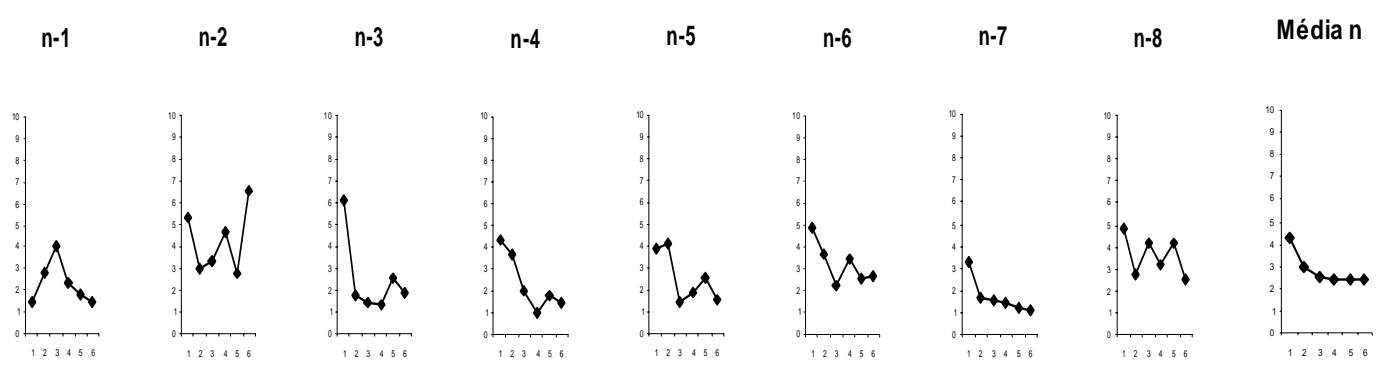

Choque Controlável (C)
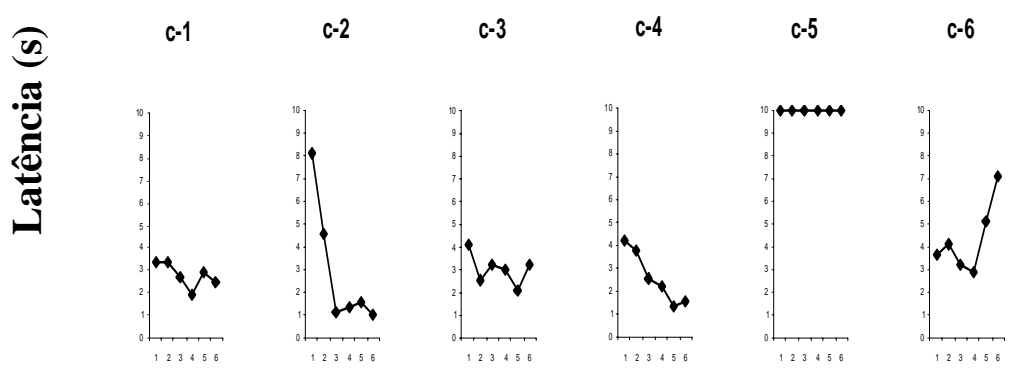

$c-7$

$c-8$

Média c
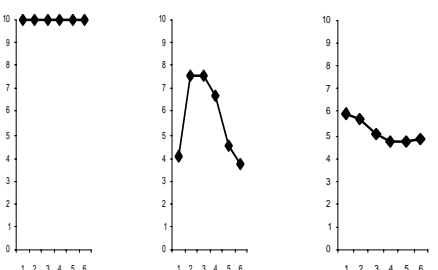

Choque Incontrolável (I)
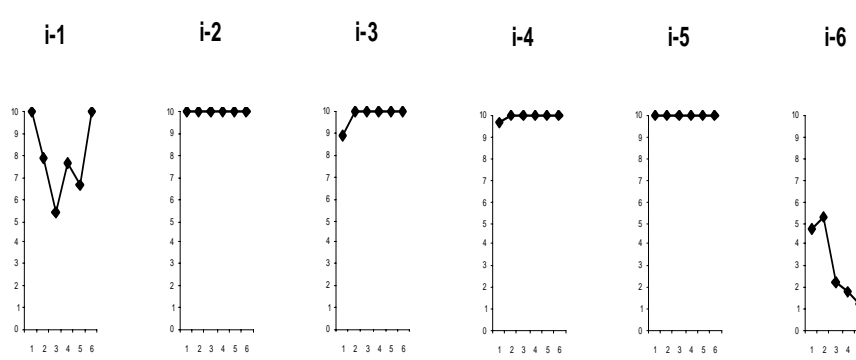

i-7

i-8

Média i
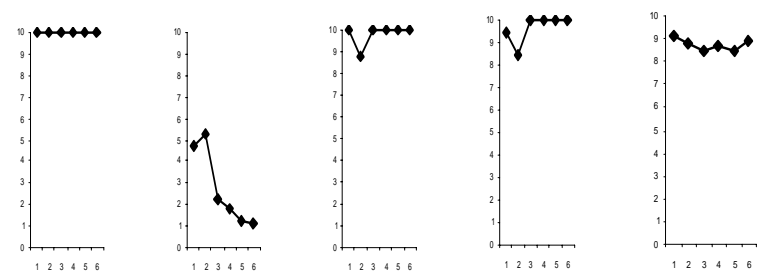

\section{Blocos de 5 tentativas}

Figura 3. Médias das latências (em segundos) da resposta de fuga (saltar) na sessão de teste, em blocos de 5 tentativas, apresentadas pelos sujeitos dos grupos que passaram por nenhum choque (N), choque controlável (C) e choque incontrolável (I) da tríade que não recebeu droga (sd). 
Para uma melhor visualização da diferença de desempenho dos grupos em relação às diferentes substâncias administradas, a Figura 4 mostra os dados agrupados em função dos tratamentos com choque (N, C ou I), de cada tríade tratada com as diferentes administrações de droga. Em comparação com o grupo que não recebeu droga (sd), as substâncias 0CH, Hp 30CH e Hp 200CH, não exerceram efeito sobre os grupos que não passaram por choques (N) ou que passaram por choques controláveis (C) na sessão de tratamento: os desempenhos médios desses grupos na sessão de teste foram muito semelhantes entre si, sem diferença estatisticamente significante. Já entre os grupos que passaram por choque incontrolável (I) na fase choque, o tratamento com o Hp produziu desempenhos bastante diferentes entre si, sendo maior a latência dos animais sem droga e menor dos que receberam Hp 200CH. A análise da variância indicou que houve diferença estatisticamente significante entre grupos $(\mathrm{F}(3,28)=3,294, \mathrm{p}<0,05)$. O teste Tukey mostrou que há diferença estatisticamente significante entre os grupos sd e Hp 200CH (p<0,05).
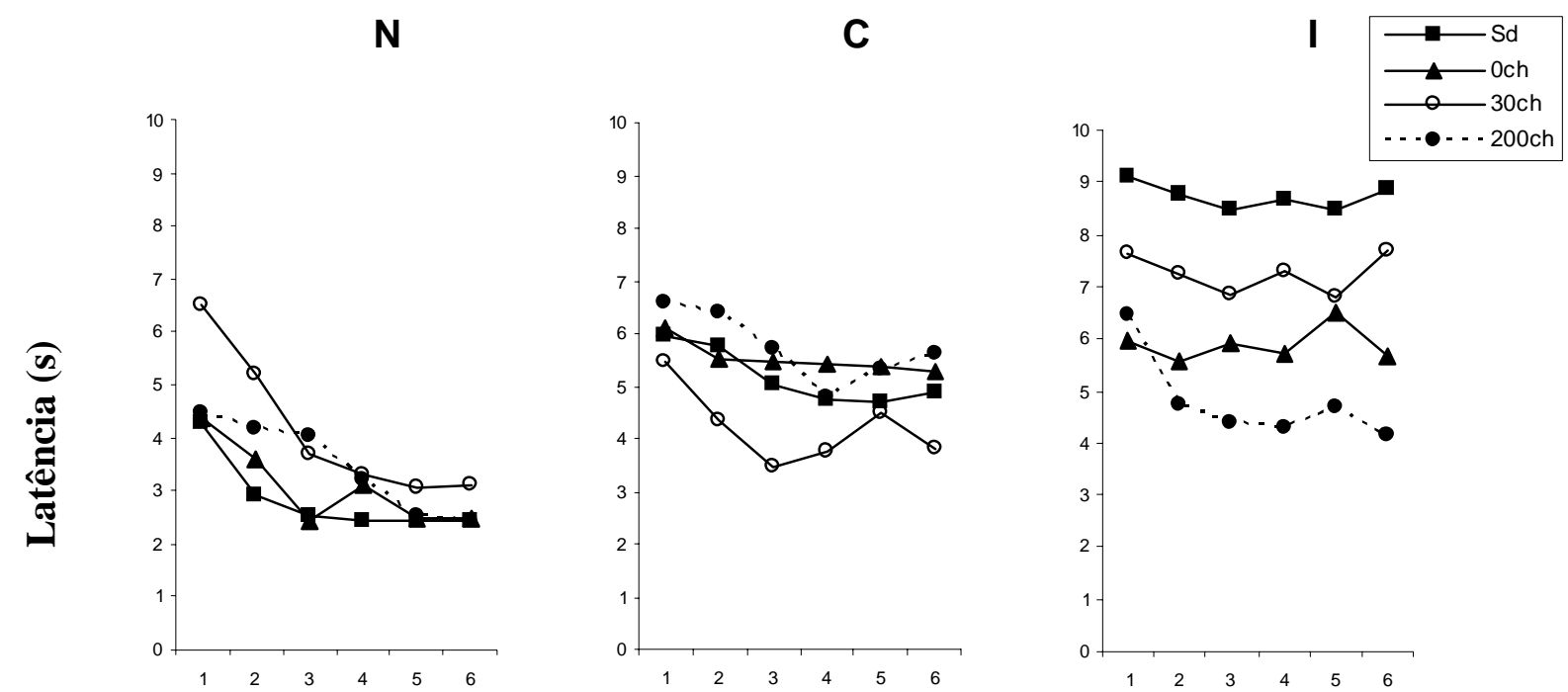

Blocos de 5 tentativas

Figura 4. Médias das latências (em segundos) da resposta de fuga (saltar) na sessão de teste, em blocos de 5 tentativas, apresentadas pelos grupos que passaram por nenhum choque $(\mathrm{N})$, choque controlável (C) e choque incontrolável (I) e que receberam as diferentes substâncias (Sem droga - sd; Solução hidroalcóolica 5\% - 0CH; Hypericum perforatum 30CH - 30CH e Hypericum perforatum $200 \mathrm{CH}-200 \mathrm{CH}$ ). 


\section{DISCUSSÃO}

A partir dos resultados apresentados, pode-se dizer que o tratamento com o Hp (30CH e 200CH) e veículo (0CH) não produziu efeito sobre o desempenho dos grupos que não receberam choque (Grupo N) e daqueles que receberam choque controlável (Grupo C), pois os desempenhos desses grupos foram muito semelhantes entre si e não apresentaram diferença em relação aos mesmos grupos que não receberam droga (sd). Todos esses grupos apresentaram, sem exceção, declínio das latências ao longo dos blocos de tentativas, o que mostra que todos aprenderam fuga. Os resultados mostraram que a droga só produziu efeito nos grupos I, sendo que, dentre as administrações feitas nesse estudo, a que apresentou efeitos mais significativos na redução do desamparo aprendido foi a de Hp 200CH. Esse tratamento com droga equiparou o grupo $\mathrm{I}$ aos grupos $\mathrm{C}$ e $\mathrm{N}$, tanto no que diz respeito às pequenas diferenças de latências entre eles, como na apresentação do padrão de declínio das mesmas ao longo da sessão, efeito característico de aprendizagem de fuga. Portanto, dentre os grupos I, apenas os tratados com Hp 200CH apresentaram padrão de fuga, ou seja, ausência de desamparo.

Chama atenção o fato de que o tratamento de $0 \mathrm{CH}$, correspondente apenas ao veículo (solução hidroalcóolica a 5\%, supostamente inerte), produziu uma pequena redução das latências gerais no grupo I, embora não suficiente para abolir o padrão de desamparo. Nesse sentido, a solução hidroalcóolica não teve efeito comparável ao Hp 200CH, mas teve um efeito limítrofe, sugerindo não ser essa substância tão inócua como seria de se esperar de um veículo em estudos farmacológicos. Tal efeito sugere que estudos futuros devam ser realizados para detectar o grau de ação farmacológica dessa substância, o que dará mais fundamento científico para afirmar a influência desse veículo nesse tipo de investigação. 
Esses resultados se assemelham aos do estudo de Goulart (2004), no qual dentre as três dinamizações de $\mathrm{Hp}$ utilizadas (30CH, 100CH e 200CH) em animais submetidos aos testes de Porsolt, labirinto em cruz-elevado, esquiva passiva e campo aberto, a que apresentou efeitos mais significativos foi a 200CH. Nesse estudo também foi realizada uma comparação entre o veículo utilizado pela homeopatia (solução hidroalcóolica 5\%), na dinamização 200CH, e água destilada. Nessa comparação, verificou-se que o veículo não apresentou efeito sobre o desempenho dos animais nos modelos investigados, ou seja, não houve diferença significativa entre o desempenho do grupo que recebeu solução hidroalcóolica 5\%, dinamizada a $200 \mathrm{CH}$ ) e o grupo que recebeu água destilada. Os resultados do presente estudo mostraram que só a solução hidroalcóolica $5 \%(0 \mathrm{CH})$, não dinamizada ${ }^{5}$, já foi capaz de produzir uma redução da latência das respostas de fuga na sessão de teste, mesmo que tal redução tenha sido pequena.

Como no atual estudo o veículo não havia sido dinamizado, uma interpretação possível dos resultados do grupo 0CH poderia apontar para a falta da dinamização do veículo. Contudo, testes realizados com um Grupo I, tratado com solução hidroalcóolica 5\% preparada na dinamização 30CH, mostrou que esse procedimento não produziu qualquer modificação nos resultados: esse grupo não diferiu estatisticamente dos demais grupos I aqui testados, e, quando comparado ao Grupo $\mathrm{N}$ da Tríade $0 \mathrm{CH}$, ao qual foi acoplado, ele mostrou valores limítrofes de desamparo $(\mathrm{p}=0,053)^{6}$. Portanto, esse resultado do veículo com dinamização a 30CH, associado aos obtidos com a dinamização a 200CH, apresentados por Goulart (2004), sugerem que a dinamização do veículo não é um fator crítico na alteração do comportamento.

Pode-se também supor que a mera manipulação para a administração da substância, que envolvia uma situação de contenção corporal, pudesse ter exercido influência sobre o desempenho dos animais, mesmo aqueles que receberam apenas o veículo. Entretanto,

\footnotetext{
${ }^{5}$ Em relação ao fato do veículo ser dinamizado ou não, a diferença está na agitação da substância e não na composição da mesma (ambas são solução hidroalcóolica 5\%).

${ }^{6} \mathrm{O}$ procedimento utilizado e os resultados desse grupo estão apresentados em Anexo II.
} 
ao se analisar todos os grupos, percebe-se que a diferença de desempenho existiu entre os grupos I, mas não entre os grupos C e N, que receberam algum tipo de substância e os que não receberam (conseqüentemente, que foram tratados com e sem essa manipulação, respectivamente).

Como a diferença de desempenho entre os grupos só ocorreu entre aqueles que passaram por choque incontrolável na fase choque, pode-se afirmar que a história também pode ser sido uma variável que influenciou o efeito das substâncias sobre o comportamento dos animais na fase de teste. Segundo Blackman e Pellon (1993), a história comportamental do sujeito é uma variável que tem sido estudada em farmacologia comportamental, pois os efeitos da droga sobre o comportamento podem ser modulados pela história comportamental do sujeito.

A partir dessas análises, pode-se afirmar que a soma da manipulação para a administração da substância (que envolve contenção corporal), ao choque incontrolável (para os grupos que passaram por esse tratamento na fase choque), e às substâncias administradas, pode ter produzido o efeito final de redução da latência das respostas na sessão de teste. Pois, como afirmam Thompson e Boren (1977), um problema fundamental em analisar as formas pelas quais as drogas alteram o comportamento é determinar o grau em que os efeitos observados são específicos da droga ou do conjunto de condições investigadas. Isso porque as drogas, como variáveis independentes, interagem com todas as outras variáveis para determinar o resultado comportamental particular. No entanto, todos os grupos I, que receberam tratamento com substâncias, foram submetidos às mesmas variáveis, sendo que a única diferença entre eles foram as substâncias em si.

Assim, os resultados do atual estudo apontam que o $\mathrm{Hp} 200 \mathrm{CH}$ aboliu o desamparo aprendido em ratos, efeito esse que se assemelha ao de diversas drogas alopáticas de uso antidepressivo. 


\section{EXPERIMENTO 2}

\section{Objetivo específico}

O objetivo do Experimento 2 foi verificar se o extrato seco do Hypericum perforatum, disponível comercialmente como preparação fitoterápica, produz efeito sobre o desamparo aprendido.

\section{MÉTODO}

\section{Sujeitos}

Foram utilizados 72 ratos, com as mesmas características, procedência e tratamento dos animais do Experimento 1. A tríade de 24 ratos que não recebeu nenhuma substância (sd), o qual foi descrito no Experimento 1, foi utilizado para comparação com os demais grupos desse experimento também.

\section{Equipamento}

Os equipamentos utilizados nesse experimento foram os mesmos do Experimento 1.

Substâncias

As substâncias utilizadas foram:

1. Extrato de Hypericum perforatum L., Hypericaceae, disponível comercialmente (Herbarium Laboratório Botânico Ltda) em cápsulas de 300 mg, padronizado em 
0,3\% de hipericina (0,9 mg), sendo utilizada a parte aérea da planta. O extrato era preparado pela manhã, antes da administração aos animais, como suspensão em água destilada e álcool a 5\% (solução hidroalcóolica), em um volume final de 15 e 30 $\mathrm{mg} / \mathrm{ml}$.

2. O veículo utilizado foi a solução hidroalcóolica a 5\% (Farmácia Universitária da USP).

As cápsulas, a solução hidroalcóolica e o Hp (depois de ter sido preparado) eram mantidos em temperatura ambiente e ao abrigo da luz. As embalagens, da solução hidroalcóolica e aquela na qual era preparado o Hp, era em vidro âmbar.

O veículo e o $\mathrm{Hp}$ nas doses 15 e 30mg/kg, eram administrados via intraperitoneal.

\section{Procedimento}

O procedimento foi semelhante ao do Experimento 1, com diferenças apenas na fase de administração da droga, que foi administrada i.p., nas seguintes doses: Hp 15mg/kg, Hp 30mg/kg, solução hidroalcóolica a 5\% (Hp 0mg/kg). O volume final foi de $1 \mathrm{ml} / \mathrm{kg}$ do animal. As doses foram administradas 22 horas após o término da sessão de choques, ou seja, duas horas antes da sessão de teste.

O Quadro 2 exemplifica o procedimento utilizado nesse experimento, acrescida da tríade que não recebeu nenhuma substância (sd) no Experimento 1, aqui utilizada como controle geral para os demais grupos tratados farmacologicamente. 
Quadro 2. Resumo esquemático do procedimento utilizado no Experimento 2. Doses do hypericum perforatum: 0 (solução hidroalcóolica a $5 \%$ ), 15 ou $30 \mathrm{mg} / \mathrm{kg}$. O intervalo entre as sessões de choque e teste foi de 24 horas. Os três primeiros grupos, em itálico, são os mesmos utilizados no Experimento 1.

\begin{tabular}{|c|c|c|c|}
\hline $\begin{array}{l}\text { Grupos } \\
(n=8)\end{array}$ & $\begin{array}{c}\text { Choque } \\
\text { (60 tentativas) } \\
\text { (R de Fuga }=\text { focinhar) }\end{array}$ & $\begin{array}{c}\text { Droga } \\
1 \mathrm{ml} / \mathrm{kg} \text { (i.p.) } \\
22 \text { h pós choque }\end{array}$ & $\begin{array}{c}\text { Teste } \\
\text { (30 tentativas) } \\
\text { (R de Fuga }=\text { saltar) }\end{array}$ \\
\hline $\begin{array}{l}C s d \\
I s d \\
N s d\end{array}$ & $\begin{array}{l}\text { Choque Controlável (C) } \\
\text { Choque Incontrolável (I) } \\
\text { Nenhum Choque (N) }\end{array}$ & sem droga & \\
\hline $\begin{array}{l}\text { C } 0 \\
\text { I } 0 \\
\text { N } 0\end{array}$ & $\begin{array}{l}\text { Choque Controlável (C) } \\
\text { Choque Incontrolável (I) } \\
\text { Nenhum Choque (N) }\end{array}$ & $\begin{array}{c}\text { Hp 0mg/kg } \\
\text { (Sol. hidroalc. 5\%) }\end{array}$ & $\begin{array}{l}\text { Choque Controlável } \\
\text { (C) }\end{array}$ \\
\hline $\begin{array}{l}\text { C } 15 \\
\text { I } 15 \\
\text { N } 15\end{array}$ & $\begin{array}{l}\text { Choque Controlável (C) } \\
\text { Choque Incontrolável (I) } \\
\text { Nenhum Choque (N) }\end{array}$ & Hp 15mg/kg & \\
\hline $\begin{array}{l}\text { C } 30 \\
\text { I } 30 \\
\text { N } 30\end{array}$ & $\begin{array}{l}\text { Choque Controlável (C) } \\
\text { Choque Incontrolável (I) } \\
\text { Nenhum Choque (N) }\end{array}$ & Hp 30mg/kg & \\
\hline
\end{tabular}

Os dados foram analisados da mesma forma descrita no Experimento 1. 


\section{RESULTADO}

Os dados desse experimento estão apresentados na Figura 5, onde cada gráfico representa a média dos oito sujeitos de cada grupo (N, C e I) de cada tríade (sd, Hp 0mg/kg, Hp 15mg/kg e Hp 30mg/kg), referente às latências médias (em segundo) da resposta de fuga (saltar) na sessão de teste, calculado a cada bloco de 5 tentativas.

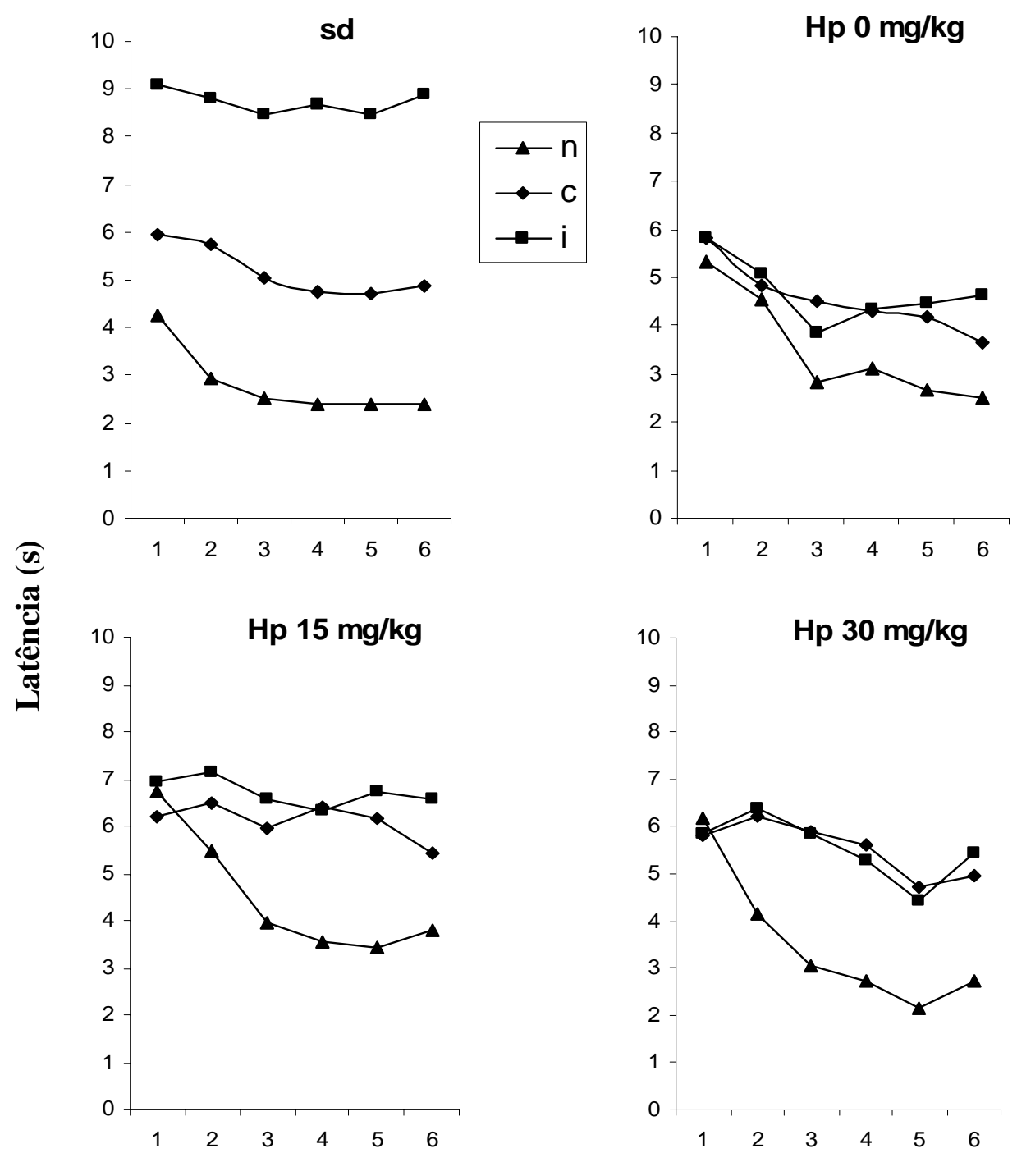

Blocos de 5 tentativas

Figura 5. Médias das latências (em segundos) da resposta de fuga (saltar) na sessão de teste, em blocos de 5 tentativas, apresentadas pelos grupos $(\mathrm{N}=$ nenhum choque, $\mathrm{C}=$ choque controlável e I = choque incontrolável) de cada tríade (Sem droga - sd; Solução hidroalcóolica 5\% - Hp 0mg/kg; Hypericum perforatum 15mg/kg - Hp 15mg/kg e Hypericum perforatum 30mg/kg - Hp 30mg/kg). 
Os resultados da tríade não exposta a tratamento com droga (sd) são os mesmos já descritos no Experimento 1.

A análise dos resultados do tratamento com Hp 0mg/kg (veículo - solução hidroalcóolica 5\%) mostra que os três grupos apresentaram valores de latências próximos entre si, com latências decrescentes ao longo da sessão. Apenas o Grupo I apresentou latências sistematicamente decrescentes até o $3^{\circ}$ bloco, com pequeno aumento das mesmas nos blocos seguintes. A análise da variância indicou que os grupos são iguais entre si, havendo diferenças estatisticamente significantes apenas em função das tentativas $(F(5,105)=$ 7,734, $\mathrm{p}<0,05)$.

O tratamento com $\mathrm{Hp} 15 \mathrm{mg} / \mathrm{kg}$ e $30 \mathrm{mg} / \mathrm{kg}$ não produziu efeito nos desempenhos dos grupos $\mathrm{N}$ e C, mas sim um sensível rebaixamento das latências nos grupos I, comparativamente aos animais dos grupos sd. Com isso, obteve-se que os grupos $\mathrm{N}$ apresentaram curvas decrescentes ao longo da sessão, com latências inferiores às dos grupos C e I, que apresentaram valores de latência próximos entre si, sem declínio das mesmas ao longo da sessão para a Tríade Hp 15mg/kg e com leve declínio para a Tríade Hp 30mg/kg. As diferenças obtidas nos grupos tratados com Hp 15mg/kg foram estatisticamente significantes em função das tentativas $(\mathrm{F}(5,105)=4,832, \mathrm{p}<0,05)$, havendo interação entre grupos e tentativas $(\mathrm{F}(10,105)=2,414, \mathrm{p}<0,05)$ e não houve diferença estatisticamente significante entre os grupos. Em relação aos grupos tratados com Hp 30mg/kg, a análise da variância mostrou que as diferenças foram estatisticamente significantes em função das tentativas $(\mathrm{F}(5,105)=8,573, \mathrm{p}<0,05)$, houve interação entre grupos e tentativas $(\mathrm{F}(10,105)=2,118$, $\mathrm{p}<0,05)$ e houve indicação de tendência à diferença entre os grupos $(\mathrm{F}(2,21)=2,915, \mathrm{p}=0,08)$. Entretanto, apesar da diferença na inspeção visual, que mostra diferença de desempenho do Grupo N em relação aos grupos C e I, que não diferiram entre si, o teste Tukey não apontou 
valores sequer limítrofes $(p=0,12)$, sugerindo que tais diferenças não têm relevância estatística.

A Figura 6, referente à análise dos dados iniciais e finais, mostra que todos os grupos apresentaram declínio das latências entre começo e final da sessão, porém com inclinações mais acentuadas nos grupos N. Os grupos C e I apresentam, no geral, pouco declínio das latências no bloco final (padrão mais horizontal nos grupos I), com exceção dos grupos expostos a tratamento $\mathrm{Hp} 0 \mathrm{~m} / \mathrm{kg}$, que apresentaram declínio um pouco mais acentuado.

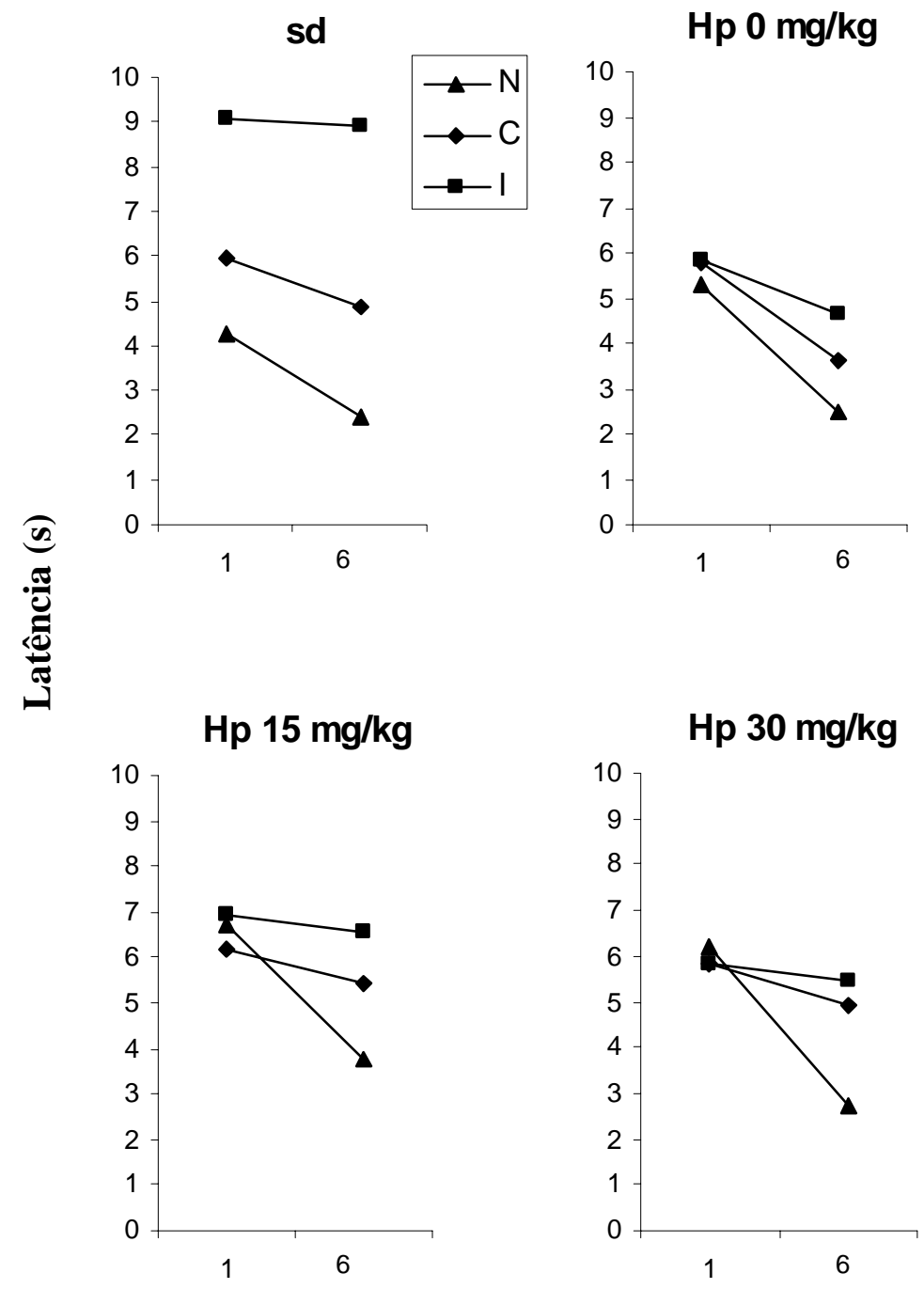

Blocos de 5 tentativas

Figura 6. Médias das latências (em segundos) da resposta de fuga (saltar) do primeiro e último $\left(6^{\circ}\right)$ blocos na sessão de teste, apresentadas pelos grupos $(\mathrm{N}=$ nenhum choque, $\mathrm{C}=$ choque controlável e I = choque incontrolável) de cada tríade (Sem droga - sd; Solução 
hidroalcóolica 5\% - Hp 0 mg/kg; Hypericum perforatum 15 mg/kg - Hp 15 mg/kg e Hypericum perforatum $30 \mathrm{mg} / \mathrm{kg}$ - Hp $30 \mathrm{mg} / \mathrm{kg}$ ).

Os gráficos referentes ao desempenho individual dos sujeitos de todas as tríades, do presente experimento, estão apresentados no Anexo III.

Para uma melhor visualização da diferença de desempenho dos grupos em relação às diferentes substâncias administradas, a Figura 7 mostra os dados agrupados em função dos tratamentos com choque (N, C ou I), de cada tríade tratada com as diferentes administrações de droga. Praticamente não há diferença de desempenho entre os grupos $\mathrm{N}$ e C, todos apresentando redução sistemática das latências ao longo das sessões. Dentre os grupos N, o tratado com $\mathrm{Hp} 15 \mathrm{mg} / \mathrm{kg}$ mostrou as latências gerais mais elevadas. Estatisticamente, as diferenças foram decorrentes das tentativas $(F(5,140)=33,557, \mathrm{p}<0,05)$, havendo tendência de diferença entre os grupos $(F(3,28)=2,553, p=0,08)$ que, segundo o teste Tukey, se situou entre os grupos sd e Hp 15mg/kg ( $\mathrm{p}<0,05)$. Nos grupos C, não foram obtidas quaisquer diferenças estatisticamente significantes. Já entre os grupos que passaram por choque incontrolável na sessão de tratamento (I), o tratamento com o Hp produziu desempenhos bastante diferentes entre si, sendo as maiores latências apresentadas pelos animais que não receberam droga (sd) e as menores pelos que receberam $\mathrm{Hp} 0 \mathrm{mg} / \mathrm{kg}$. A análise da variância indicou que houve diferença ao longo das tentativas $(F(5,140)=2,286$, $\mathrm{p}<0,05)$ e entre os grupos $(\mathrm{F}(3,28)=3,944, \mathrm{p}<0,05)$. O teste Tukey mostra diferença entre os grupos sd e Hp 0mg/kg ( $\mathrm{p}<0,05)$, e uma tendência à diferença entre os grupos sd e Hp $30 \mathrm{mg} / \mathrm{kg}(\mathrm{p}=0,07)$. 

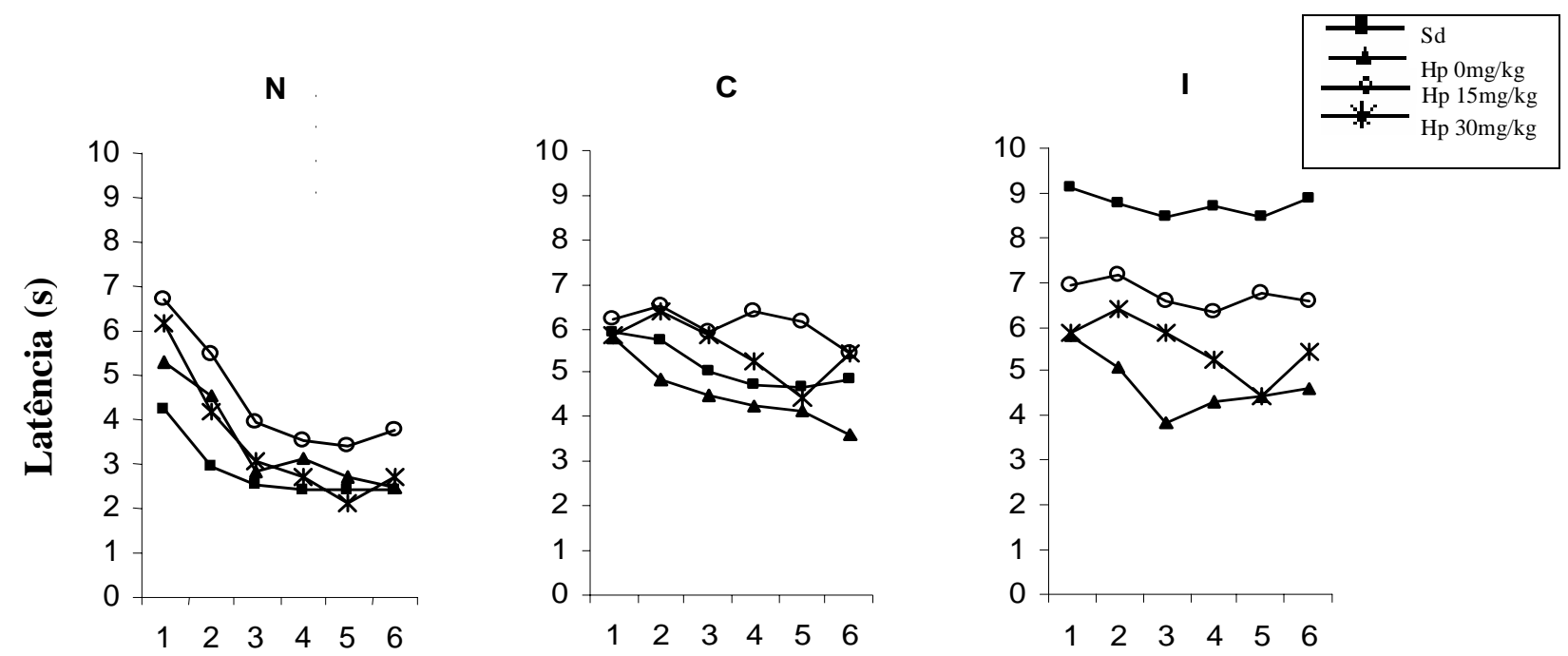

\section{Blocos de 5 tentativas}

Figura 7. Médias das latências (em segundos) da resposta de fuga (saltar) na sessão de teste, em blocos de 5 tentativas, apresentadas pelos grupos que passaram por nenhum choque $(\mathrm{N})$, choque controlável (C) e choque incontrolável (I) e que receberam as diferentes substâncias (Sem droga - sd; Solução hidroalcóolica 5\% - Hp 0 mg/kg; Hypericum perforatum 15 mg/kg - Hp 15 mg/kg e Hypericum perforatum 30 mg/kg - Hp 30 mg/kg). 


\section{DISCUSSÃO}

Os resultados apresentados mostram que tanto o $\mathrm{Hp}$, nas doses de 15 e 30mg/kg, como o seu veículo (Hp $0 \mathrm{mg} / \mathrm{kg}$ ) não apresentou efeito sobre os grupos que receberam choque controlável na sessão de tratamento (grupos C), nem naqueles que não foram expostos a choques previamente $(\mathrm{N})$. Contudo, o tratamento farmacológico aqui testado produziu efeitos diferenciados nos grupos I, sendo o efeito aparentemente dose-dependente em relação à dose do Hp administrada. Contudo, o mais surpreendente foi que o efeito mais acentuado de redução do desamparo se deu no grupo tratado com Hp 0mg/kg (veículo solução hidroalcóolica 5\%).

Esse resultado sugere que o veículo utilizado não era farmacologicamente inerte, o que compromete todos os demais resultados da substância Hp. A que atribuir a redução do desamparo: ao Hp ou ao seu veículo?

Importante apontar que essa diferença de desempenho com tratamento com veículo ocorreu apenas entre os grupos I. Uma hipótese para explicar esses resultados, que não seja a ação farmacológica do veículo, sugere que a manipulação para a administração da substância - que envolvia uma situação de contenção corporal e a administração intraperitoneal (i.p.) -, pode ter interferido com a história de incontrolabilidade de choques e ao efeito das drogas para determinar o desempenho dos animais do Grupo I na sessão de teste. Para testar essa hipótese foi realizado um teste paralelo a esse estudo onde sujeitos previamente tratados com choques incontroláveis foram tratados da mesma forma que o grupo Hp 0mg/kg, com exceção da droga administrada que foi salina (soro fisiológico a 5\%). Os resultados, apresentados no Anexo IV, mostram que esse grupo apresentou desamparo aprendido, com latências crescentes a partir do $2^{\circ}$ bloco até o término da sessão. Com esse 
resultado pode-se dizer que a mera manipulação do animal para administração i.p. não foi suficiente para abolir o desamparo aprendido.

Dessa forma, questiona-se o quanto a composição do veículo em si (álcool a 5\%) possa ter contribuído para o efeito obtido no presente estudo dentre os grupos injetados com Hp 15 e 30 mg/kg. A respeito disso, McKim (2003) relata que diversos pesquisadores têm encontrado, de uma forma geral, resultados em experimentos que mostram que o etanol aumenta a taxa de respostas que eram suprimidas anteriormente por uma contingência de choque. Essa situação é semelhante ao que ocorre no desamparo aprendido, sendo que, na sessão de tratamento o choque incontrolável pode coincidir com várias das respostas dos animais que são suprimidas até o ponto em que ele fica parado recebendo choque, com poucas reações ao mesmo. Como o Grupo I, tratado com veículo, apresentou latências de respostas menores do que aquelas do grupo I que não recebeu droga, pode-se suspeitar que o veículo em si tenha sido o responsável pelos efeitos do Hp aqui apresentados, sendo impossível, nesse estudo, dissociar o efeito dessas variáveis. Para que o efeito do Hp possa ser verificado sem a interferência dessas varáveis sugere-se que novos estudos sejam realizados com a utilização de outros veículos e com outras formas de administração. Dessa forma, poder-se-á verificar de forma mais acurada o efeito do Hypericum perforatum, preparado fitoterapicamente, sobre o desamparo aprendido, modelo animal de depressão. 


\section{DISCUSSÃO GERAL}

Tratamentos alternativos para a depressão são realizados, dentre outras formas, pela fitoterapia e pela homeopatia (Davidson \& cols., 1997, Williams \& Holsinger, 2005). Esses modos de tratamento são utilizados na clínica médica mesmo sem uma completa comprovação científica da sua eficácia. Uma das formas de verificar a eficácia de tais substâncias se dá pela observação de seus efeitos em modelos animais de psicopatologias humanas, que sejam bem validados.

O modelo de desamparo aprendido em animais tem mostrado boa sensibilidade ao tratamento com drogas alopáticas de uso antidepressivo (Hunziker \& cols., 1986; Graeff \& cols., 1991; Gouveia Jr, 2001; Takamori \& cols., 2001). Daí que é razoável supor que o mesmo modelo pode ser um bom instrumento para testar os efeitos do Hp.

Os resultados do presente trabalho parecem confirmar um efeito tipo antidepressivo do Hp, em preparação homeopática na dinamização 200CH, mas teve resultados inconclusivos quanto aos efeitos da preparação fitoterápica. Esse efeito relacionado à preparação homeopática do Hp mostra algumas semelhanças aos resultados encontrados por Goulart (2004), no qual dentre as três dinamizações de Hp utilizadas (30CH, 100CH e 200CH) em animais submetidos aos testes de Porsolt, labirinto em cruz-elevado, esquiva passiva e campo aberto, a que apresentou efeitos significativos foi a $200 \mathrm{CH}$.

No entanto, o veículo utilizado na preparação homeopática (solução hidroalcóolica 5\%) também produziu uma pequena redução das latências gerais. Tal efeito sugere que ou a substancia não era farmacologicamente inerte, ou que a manipulação do animal produziu, por si, algum efeito, podendo caracterizar um placebo ou efeito placebo. Defini-se como placebo qualquer procedimento terapêutico desprovido de qualquer atividade específica para a condição que está sendo tratada (Shapiro, 1964). Já o efeito placebo é 
definido como qualquer efeito atribuído ao procedimento de uso de drogas, desde que não à farmacodinâmica ou propriedades específicas da mesma (Wolf, 1959). Uma explicação do funcionamento do placebo envolve o condicionamento clássico, também chamado de respondente ou pavloviano (Zorzetto, 2004; Jin Cho, 2005). Condicionamento respondente seria a modificação do comportamento por contingências estímulo-estímulo, ou seja, refere-se ao processo em que um estímulo anteriormente neutro (estímulo condicionado) adquire o poder de eliciar a resposta que originalmente era eliciada por outro estímulo (estímulo incondicionado) (Catania, 1979/1999). Dessa forma, o efeito placebo seria uma resposta condicionada devido a repetidas associações entre um estímulo condicionado (procedimento utilizado para a administração) e um estímulo incondicionado (elemento farmacologicamente ativo capaz de eliciar respostas terapêuticas, que seriam as respostas incondicionadas). Como o uso do veículo não envolve, por princípio, pareamento do procedimento de administração com a droga, não se pode supor que esse procedimento adquiriu propriedades condicionadas semelhantes às do Hp. Assim, pode-se concluir que, se o conceito de placebo envolve necessariamente condicionamento respondente, os resultados do presente estudo não podem ser atribuídos ao efeito placebo.

Resultados semelhantes aos do presente estudo, quanto ao fato do veículo produzir efeito sobre o desempenho de animais, foram encontrados em um estudo realizado por Drago, Nicolosi, Micale e Lo Menzo (2001). Nesse estudo, os autores avaliaram o efeito do veículo (salina), da clomipramina (1, 10 e 50mg/kg) administrados i.p., e de nenhuma manipulação (grupo que não recebeu droga, denominado "grupo intacto") sobre o desempenho de ratos Wistar em dois modelos animais: nado forçado e campo aberto. Os resultados mostraram que, para as doses de clomipramina, houve um efeito dose-dependente no dois modelos animais, ou seja, quanto maior a dose, menor o tempo de imobilidade no teste do nado forçado e menor o número de respostas de levantar-se e de entradas nas 
unidades demarcadas, no teste do campo aberto. Entretanto, quando se compara o desempenho do grupo que recebeu $50 \mathrm{mg} / \mathrm{kg}$ de clomipramina com o grupo que recebeu salina e com o grupo que não passou por manipulação (“grupo intacto”), observa-se que, no teste de nado forçado, o grupo que recebeu salina apresentou um tempo de imobilidade maior do que o grupo que não recebeu droga, sendo que essa diferença foi estatisticamente significante, ou seja, a salina produziu um efeito oposto ao da droga ativa. No teste em campo aberto não houve diferenças. Assim, os autores mostraram que a manipulação para a administração i.p. apresentou efeito sobre o comportamento de ratos, efeito esse contrário ao produzido pela droga, e concluem que estudos com modelos experimentais de depressão, que utilizam procedimentos envolvendo estresse, deveriam incluir, além do grupo com a administração do veículo, um outro grupo controle que não receba a droga e não seja manipulado, conforme fizemos no atual estudo.

O efeito do veículo no presente estudo, ao contrário do descrito por Drago e cols. (2001), foi na mesma direção da substância testada, ou seja, redução do desamparo. Sendo assim, ao que tudo indica, a manipulação do animal para a administração da substância não atuou como um estímulo aversivo que poderia ter se somado ao choque incontrolável na sessão de tratamento, pois se assim fosse, deveria ter acentuado o efeito dos choques incontroláveis. Thompson e Boren (1977) afirmam que uma dificuldade nos estudos de farmacologia comportamental é determinar o grau em que os efeitos observados são específicos da droga ou do conjunto de condições investigadas, pois as drogas são também estímulos que podem interagir com todos os demais estímulos da situação experimental, gerando no seu conjunto, o resultado comportamental descrito. A administração é uma situação indispensável, pois a substância deve estar presente no organismo do animal para que seu efeito possa ser observado sobre o comportamento. Portanto, a administração deve ser realizada de alguma forma e as que foram utilizadas no presente estudo, tanto v.o. (conta- 
gotas) quanto i.p., envolveram uma situação de contenção corporal, supostamente aversiva. A administração v.o., utilizada no Experimento 1, foi realizada três vezes e envolveu segurar o animal e repuxar sua pele, de modo a abrir sua boca para que as gotas fossem pingadas. A administração i.p., utilizada no Experimento 2, foi realizada uma vez e envolveu segurar o animal, repuxando a pele na região do peritônio para que a agulha da injeção fosse inserida e a substância administrada. Será que tais manipulações bastam para produzir algum efeito comportamental? Estudos anteriores sobre o desamparo aprendido, realizados no mesmo laboratório que o atual estudo, tem sugerido que a contenção para administração i.p. de salina (soro fisiológico 5\%) não produz nenhum efeito sobre o desamparo (Gouveia Jr, 2001; Hunziker \& cols., 1986; Graeff, Graeff \& Hunziker, 1989). Coerente com esses estudos anteriores, uma investigação paralela aqui realizada também confirmou que a administração i.p. de soro fisiológico (salina) i.p não aboliu o desamparo.

Em relação ao tratamento homeopático, o efeito da manipulação para a administração v.o. do Hp, somado ao choque incontrolável na sessão de tratamento e a substância administrada, não foi diretamente avaliado nesse estudo, mas consideramos ser pouco provável que ela justifique algum tipo de efeito: se a injeção i.p., que envolve manipulação aparentemente mais aversiva (pois envolve dor), não produziu efeito, não há porque supor que algumas gotas colocadas na boca do animal o façam. Contudo, futuros estudos poderiam testar se essa é uma variável relevante na determinação de tais efeitos, somando-se aos grupos anteriores um que receba gotas de água destilada ou soro fisiológico, ambas substâncias farmacologicamente inertes.

A dinamização do veículo também não se mostrou uma variável independente: a solução hidroalcóolica não diferiu em seus efeitos sobre o desempenho dos animais quando era dinamizada ou não. Esses dados coincidem com os de Goulart (2004), que realizou uma comparação dos efeitos do veículo utilizado pela homeopatia (solução hidroalcóolica 5\%), na 
dinamização 200CH, e da água destilada sobre o comportamento de animais submetidos aos teste de Porsolt, labirinto em cruz-elevado, esquiva passiva e campo aberto. Nessa comparação, foi verificado que não houve diferença entre o efeito do veiculo utilizado e da água destilada. Entretanto, Goulart (2004) não testou se ambos os grupos apresentaram diferenças em relação a um grupo não exposto a nenhum procedimento de manipulação para a administração da substância. Nesse sentido, os nossos resultados complementam os de Goulart, fortalecendo a conclusão de que a dinamização não é uma fonte de efeito comportamental.

Deve-se destacar que a solução hidroalcóolica, quando injetada, apresentou efeitos pronunciados, reduzindo substancialmente o desamparo. Esse resultado deriva-se de uma questão técnica que precisa ser solucionada: o Hp é uma substância de difícil dissolução, e a tentativa de usar salina mostrou que o Hp não se dissolveu nesse veículo. Já em solução hidroalcóolica 5\%, mostrou-se solúvel, apresentando uma suspensão homogênea ${ }^{7}$.

Como em ambos os experimentos a solução hidroalcóolica 5\% apresentou efeito de redução geral das latências, mais pronunciado quando administrada via i.p., questiona-se se o álcool a 5\% pode ter algum efeito farmacológico. McKim (2003) relata que diversos pesquisadores têm encontrado resultados em experimentos que mostram que o etanol aumenta a taxa de respostas que eram suprimidas anteriormente por uma contingência de choque. Essa situação é semelhante ao que ocorre no desamparo aprendido, pois a redução do desamparo corresponde, no geral, a um aumento da atividade do sujeito (ele emite a resposta mais rapidamente).

A diferença de efeito do etanol injetado ou colocado diretamente na boca dos animais, sobre o desempenho destes, talvez possa ser explicada por fatores farmacodinâmicos. De acordo com Scivoletto e Malbergier (2003), o etanol é uma substância de baixo peso

\footnotetext{
${ }^{7}$ O procedimento para a preparação e administração do Hp, tanto na forma homeopática quanto fitoterápica, foi orientado pela Dra. Flávia Cristina Goulart, que sugeriu as dinamizações, doses e veículos utilizados.
} 
molecular e hidrossolúvel. Vários fatores podem influenciar a absorção no caso da ingestão oral, como o tempo de esvaziamento gástrico e o início da absorção intestinal. Assim, para atingir o sistema nervoso central (SNC) e atuar sobre o comportamento, o etanol depende de vários fatores, tais como a dose ingerida, velocidade de absorção, vias de administração (que diferem quanto a metabolização e absorção), peso e sensibilidade ao álcool. As duas vias de administração aqui utilizadas diferem quanto a metabolização e absorção de substâncias, pois, na administração via oral a droga passa pelo trato gastrodigestivo antes de atingir seu local de ação e, já pela via intraperitoneal, a absorção é mais rápida devido à grande quantidade de vasos sanguíneos na região (McKim, 2003). Livy, Parnell e West (2003) investigaram a concentração de etanol no sangue de ratos Sprague-Dawley administrado em dose única via intragástrica - gavagem (i.g.) e injeção intraperitoneal (i.p.), em um volume de $21 \%$ de etanol em água destilada. Os resultados mostraram que a concentração de etanol no sangue dos ratos difere nas administrações i.g. e i.p. Após 30 minutos da administração, a concentração de etanol no sangue foi superior na forma i.p., assim como também foi superior a taxa média do pico da concentração de etanol no sangue. Os autores discutem que a administração i.g. produziu significativamente menores concentrações de etanol no sangue do que o observado pela administração i.p., devido à absorção e metabolização.

Amit e Stern (1970) também afirmam que a forma de administração do álcool é uma variável importante na determinação do comportamento. No estudo que realizaram, procuraram verificar os efeitos de duas formas de administração (ingestão oral e infusão intragástrica) do álcool, em um volume de 13\% e 18\% de etanol em água destilada, sobre o comportamento locomotor de ratos em campo aberto. Os resultados mostraram que o efeito do álcool administrado via infusão intragástrica é uma maior atividade locomotora dos animais em campo aberto em relação ao desempenho dos animais em que o álcool foi ingerido oralmente, e que ambos são superiores à salina administrada via infusão intragástrica 
e à água administrada via oral. Não houve diferenças entre o desempenho dos animais que receberam diferentes concentrações de etanol. Os autores concluem que a forma de administração do álcool pode ser uma variável crucial em determinar os efeitos do álcool sobre o comportamento.

No presente estudo, deve-se levar em conta que a concentração de etanol aqui utilizada (5\%) é inferior à utilizada nos estudos citados (21\%, 13\% e 18\%). Mesmo assim não se pode deixar de sugerir que o efeito obtido pode ser devido à ação farmacológica do veículo. Aqui, a administração v.o. foi realizada por meio de um conta-gotas (5 gotas), seguindo o referencial da homeopatia, de acordo com o qual o que importa é que os medicamentos homeopáticos sejam deixados na boca para que sejam absorvidos pela mucosa bucal (Machado, 2000; Fontes, 2001), e não a quantidade da substância ingerida. Já a administração i.p. foi realizada calculando-se $1 \mathrm{ml} / \mathrm{kg}$ para cada animal, sendo que a dose variou em torno de 0,35 ml, ou seja, uma dose superior à administrada v.o., com o adendo de que foi administrada na cavidade peritoneal onde a absorção á mais rápida devido a uma maior quantidade de vasos sanguíneos na região. Devido a isso, pode-se dizer que as diferentes vias de administração utilizadas podem ter sido responsáveis pela diferença de desempenho entre os grupos veículo de ambos os experimentos aqui realizados.

Mesmo que se suponha que a composição do veículo e a manipulação para a administração do Hp tenham influenciado na redução geral das latências, nossos resultados mostram claramente que o efeito homeopático do Hp 200CH foi maior e mais significativo em reduzir o fenômeno do desamparo aprendido. Portanto, pode-se concluir que foram observados resultados positivos em relação ao efeito do Hp preparado de acordo com a homeopatia, na dinamização mais alta (200CH), sobre o desamparo aprendido. 
Algumas revisões de literatura (Moritz \& Almeida, 2003; Shang \& cols., 2005) mostram que, quando os efeitos dos tratamentos homeopáticos são positivos, atribui-se a eles o viés e as deficiências metodológicas e, com isso, a dificuldade de uma avaliação mais fidedigna de tais efeitos. No presente estudo, o modelo utilizado é bem validado experimentalmente para o teste de substâncias potencialmente antidepressivas e todas as medidas e precauções foram tomadas para que problemas metodológicos fossem evitados, tanto do ponto de vista das exigências homeopáticas como as de procedimentos experimentais em laboratório com comportamento animal. Assim, as embalagens com as substâncias foram mantidas em vidro âmbar, ao abrigo da luz e em temperatura ambiente, colocadas em uma sala do biotério onde apenas os animais que receberam essas substâncias ficaram alojados, sendo que aparelhos eletromagnéticos (computador, celular, rádio...), substâncias alopáticas e outros animais não foram colocados no mesmo ambiente. Também foi seguido um controle experimental rigoroso quanto aos cuidados e manipulações com os animais e às sessões de tratamento com choques e teste. Por essas características, consideramos que o presente estudo representa um avanço na avaliação dos reais efeitos de drogas homeopáticas através de modelos animais. Segundo Corrêa e cols. (1997), a homeopatia vem evoluindo por meio de estudos que utilizam o método científico, almejando a melhor compreensão de seus mecanismos terapêuticos.

Segundo Blackman (1987), o estudo científico dos efeitos de drogas em animais não é realizado como um fim em si mesmo, e um objetivo maior é extrapolar os achados experimentais com animais para humanos, com a devida cautela, particularmente quando eles podem parecer relevantes para possíveis inovações terapêuticas. Dessa forma, ao se fazer um paralelo entre os efeitos do Hp preparado de forma homeopática demonstrado no presente estudo com animais e os possíveis efeitos dessa substância em seres humanos, observa-se que existem diferenças que devem ser levadas em consideração ao se fazer uma 
extrapolação dos resultados aqui apresentados. Uma delas se refere à administração das substâncias homeopáticas que, em seres humanos não envolve uma situação de contenção corporal, enquanto que essa situação é necessária para a administração do Hp em animais e pode ter exercido efeito sobre os resultados aqui apresentados. Assim, para que se possa concluir pelos efeitos do Hp preparado de forma homeopática em seres humanos, são necessárias diversas outras investigações.

Quanto aos resultados aqui obtidos com o Hp preparado fitoterapicamente, eles são inconclusivos na medida que o veículo produziu mais efeito que a droga nas suas diferentes doses. Outros estudos que avaliaram o efeito do Hp fitoterápico, administrado i.p. em modelos animais utilizando ratos (Misane \& Ögren, 2001; Guilhermano \& cols., 2004; De Vry \& cols, 1999), utilizaram outros veículos (por exemplo, carboximetilcelulose, água destilada com Tween 80, água destilada ou soro fisiológico com ácido láctico) e relataram ausência de efeitos do veículo em si. Por outro lado, também não relatam o controle experimental realizado com um grupo que não recebeu nenhuma substância. Tais diferenças impedem que se compare o atual resultado com os dos trabalhos citados.

É importante atentar para o fato de que o Hp utilizado nesse estudo pode diferir de outros extratos disponíveis comercialmente (tanto para uso clínico como utilização em pesquisa), pois por ser uma substância extraída de plantas, fatores como período de colheita, temperatura, umidade, processo de secagem e armazenagem, podem influenciar na constituição do composto. Optou-se aqui pelo uso da droga disponível no mercado que é apresentada como tendo padronização de $0,3 \%$ de hipericina, sendo que está dentro do proposto: hipericina, por volta de 0,1-0,3\%, e/ou hiperforina, 1-6\% (Vitiello, 1999). Contudo, a quantidade exata desses compostos, bem como a presença de outros constituintes, podem ser fatores que influenciam o efeito obtido experimentalmente. 
Outros estudos devem ser desenvolvidos para avaliar o efeito do Hp, preparado de acordo com a fitoterapia, utilizando outros veículos, bem como outras formas de administração (v.o. gavagem, por exemplo). Em seres humanos, o Hp fitoterápico é administrado oralmente em formato de comprimidos, cápsulas ou xaropes (Vitiello, 1999). Portanto, difere do atual estudo, pois não envolve uma situação de contenção corporal, nem a administração i.p.. Assim sendo, os possíveis efeitos das variáveis analisadas no presente estudo devem ser levados em consideração ao se fazer a generalização de efeitos do Hp entre ambas as espécies.

De uma forma geral, pode-se concluir que os efeitos de tratamentos farmacológicos alternativos, como a homeopatia e a fitoterapia, ainda precisam ser mais investigados para que uma afirmação da sua eficácia tenha mais confiabilidade.

Embora os resultados farmacológicos não tenham sido muito conclusivos, deve-se destacar um aspecto relevante do atual estudo que foi a demonstração de que a droga não produziu efeito por si, isoladamente, mas ela dependeu de variáveis ambientais: seus efeitos foram identificados apenas nos animais previamente expostos a choques incontroláveis, mas não naqueles que haviam recebido choques iguais, porém controláveis. Assim, a variável incontrolabilidade foi tão crítica para os efeitos estudados do Hp como a forma de preparação, dose ou dinamização. De acordo com Blackman (1987) psicólogos experimentais têm desenvolvido métodos confiáveis que permitem a coleção de dados empíricos válidos, e têm procurado manipular de uma forma sistemática aquelas variáveis que poderiam afetar o comportamento. Em condições de laboratório tem sido demonstrado que o maior determinante do comportamento dos animais provém das condições ambientais às quais esses animais são ou têm sido expostos, sendo que os efeitos de tais variáveis são sutis e de variedade infinita, mas são ordenados e fidedignos, e uma grande parte da análise experimental do comportamento tem sido dedicada a explorá-los. 
Portanto, a busca pela identificação de variáveis ambientais (da história e atuais), associadas às substâncias administradas, deve continuar em trabalhos subseqüentes que busquem uma melhor compreensão de tais fenômenos. Além da importância científica dessas investigações, elas também poderão dar subsídios para uma tentativa de generalização de tais efeitos para a aplicação clínica em seres humanos, uma vez que o Hp é recomendado e utilizado para o tratamento da depressão. 


\section{REFERÊNCIAS BIBLIOGRÁFICAS}

Allen, H. C. (2000). Sintomas-chave da matéria médica homeopática. (J. Batista, Trad.) São Paulo: Synamis Editorial. (Trabalho original publicado em 1995).

American Psychiatric Association (1994). Diagnostic and Statistical Manual of Mental Disorders; DSM IV (4 $4^{\text {th }}$ ed.). Washington, DC: APA.

Amit, Z. \& Stern, M. H. (1970). Ambulatory behavior in the rat as a function of two methods of alcohol administration. Psychon. Sci., 18(5), 273-274.

Bach-Rojecky, L., Kalodera, Z. \& Samarzija, I. (2004). The antidepressant activity of Hypericum perforatum L. measured by two experimental methods in mice. Acta Pharmacologica, 54 (2), 157-162.

Bahls, S. C. (2001). Tratamento fitoterápico da depressão. Jornal Brasileiro de Psiquiatria, 50 (11-12), 389-396.

Baker, D. G., Myers, S. P., Howden, I. \& Brooks, L. (2003). The effects of homeopathic argentum nitricum on test anxiety. Complementary Therapies in Medicine, 11, 65-71.

Bellavite, P. (2000). Basic research on homeopathy. From "life force" to biodynamics and biophysics. Trabalho apresentado em Conference "Homeopathy in the XXI century". Unicamp, Campinas, Brasil.

Bhattaram, V. A., Graefe, U., Kohlert, C., Veit, M. \& Derendorf, H. (2002). Pharmacokinetics and bioavailability of herbal medicinal products [Resumo]. Phytomedicine, 9, (3, Suplemento), 1-33.

Bilia, A. R., Gallori, S. \& Vincieri, F. F. (2002). St. John's wort and depression. Efficacy, safety and tolerability-an update. Life Sciences, 70, 3077-3096. 
Blackman, D. E. (1987). Experimental Psychoparmacology, Past, Present and Future. Em: A. J. Greenshaw \& C. T. Dourish (Orgs.) Experimental Psychopharmacology: Concepts and Methods, (pp.1-25). Clifton, N. J.: Human Press.

Blackman, D. E. \& Pellon, R. (1993). The contributions of B. F. Skinner to the interdisciplinary science of behavioural pharmacology. British Journal of Psychology, 84, $1-25$.

Bracewell, R. J. \& Black, H. T. (1974). The effects of restraint an noncontingent preshock on subsequent escape learning in rat. Learning and Motivation, 5, 53-69.

Butterweck, V. (2003). Mechanism of action of St John's wort in depression: what is know? CNS Drugs, 17(8), 539-562.

Butterweck, V., Christoffel, V., Nahrstedt, A., Petereit, F., Spengler, B. \& Winterhoff, H. (2003). Step by step removal of hyperforin and hypericin: activity profile of different Hypericum preparation in behavioral models. Life Sciences, 73, 627-639.

Caccia, S. (2005). Antidepressant-like components of Hypericum perforatum extracts: an overview of their pharmacokinetics and metabolism. Curr Drug Metab, 6(6), 531-543.

Calapai, G., Crupi, A., Firenzuoli, F., Costantino, G., Inferrera, G., Campo, G. M. \& Caputi, A. P. (1999). Effects of Hypericum perforatum on levels of 5-hydroxytryptamine, noradrenaline and dopamine in the cortex, diencephalon and brainstem of the rat. $J$. Pharm. Pharmacol, 51, 723-728.

Cavalcante, S. N. \& Tourinho, E. Z. (1998). Classificação e diagnóstico na clínica: possibilidades de um modelo analítico-comportamental. Psicologia: Teoria e Pesquisa, $14,139-147$.

Catania, A. C. (1999). Aprendizagem: Comportamento, Linguagem e Cognição. $4^{\mathrm{a}}$. ed. (D. G. Souza, Trad.) Porto Alegre: Artes Médicas Sul. (Trabalho original publicado em 1979). 
Cervo, L., Rozio, M., Ekalle-Soppo, C. B., Guiso, G., Morazzoni, P. \& Caccia, S. (2002). Role of hyperforin in the antidepressant-like activity of Hypericum perforatum extracts. Psychopharmacology, 164, 423-428.

Chatterjee, S. S., Bhattacharya, S. K., Wonnemann, M., Singer, A. \& Müller, W. E. (1998). Hyperforin as a possible antidepressant component of hypericum extracts. Life Sciences, 63(6), 499-510.

Clarke, J. H. (1998). Dicionário de Matéria Médica Homeopática, v. 2. São Paulo: Editorial Homeopática Brasil.

Coleta, M., Campos, M. G., Cotrim, M. D. \& Proença da Cunha, A. (2001). Comparative evaluation of Melissa officinalis L., Tília europaea L., Passiflora edulis Sims. and Hypericum perforatum L. in the elevated plus maze anxiety test. Pharmacopsychiatry, 34, (1, Suplemento), S20-S21.

Corrêa, A.D., Siqueira-Batista, R. \& Quintas, L.E.M. (1997). Similia Similibus Curentur: notação histórica da medicina homeopática. Revista da. Associação Médica Brasileira, 43(4), 347-351.

Darwin, C. (1981) A Origem das Espécies. (A. Soares Trad.) São Paulo; Brasília: Melhoramentos; Editora da Universidade de Brasília. (Trabalho original publicado em 1859).

Davidson, J. R. T., Morrison, R. M., Shore, J., Davidson, R. T. \& Bedayn, G. (1997). Homeopathic treatment of depression and anxiety. Alternative Therapies, 3(1), 46-49.

De Vry, J., Maurel, S., Schreiber, R., de Beun R. \& Jentzch, K. R. (1999). Comparison of hypericum extracts with imipramine and fluoxetine in animal models of depression and alcoholism. European Neuropsychopharmacology, 9, 461-468. 
Drago, F., Nicolosi, A., Micale, V. e Lo Menzo, G. (2001). Placebo affects the performance of rats in models of depression: is it a good control for behavioral experiments? European Neuropsychopharmacology, 11, 209-213.

Ferster, C. B. (1973). A functional analysis of depression. American Psychologist, 28, 857870.

Ferster, C. B. \& Skinner, B. F.(1957). Schedules of reinforcement. New York: AppletonCentury-Crofts.

Fontes, O. L. (2001). Farmácia homeopática: teoria e prática. Barueri, SP: Ed. Manole.

Gambarana, C., Ghiglieri, O., Tolu, P., De Montis, M. G., Giachetti, D., Bombardelli, E. \& Tagliamonte, A. (1999). Efficacy of an Hypericum Perforatum (St. John's Wort) in Preventing and Reverting a Condition of Escape Deficit in Rats. Neuropsychopharmacology, 21(2), 247-257.

Glazer, H. I. \& Weiss, J. M. (1976). Long term and transitory interference effects. Journal of Experimental Psychology: Animal Behavior Processes, 2, 191-201. (a).

Glazer, H. I. \& Weiss, J. M. (1976). Long term interference effects: an alternative to learned helplessness. Journal of Experimental Psychology: Animal Behavior Processes, 2, 202213. (b)

Goulart, F. C. (2004). Estudo comparativo de diferentes formas farmacêuticas do hipérico (Hypericum perforatum) em modelos comportamentais em ratos. Tese de Doutorado. Universidade de São Paulo. São Paulo.

Gouveia Jr, A. (2001). Efeitos da administração aguda de imipramina sobre o desamparo aprendido em ratos machos e fêmeas. Acta Comportamentalia, 9, 19-29.

Graeff, E. O. (1991). Efeito da administração aguda e sub-crônica da ipsapirona e da BAY R 1531 sobre o comportamento de fuga de ratos tratados previamente com choques incontroláveis. Dissertação de mestrado, Universidade de São Paulo, São Paulo. 
Graeff, E. O., Graeff, F. G. \& Hunziker, M. H. L. (1989). Effects of ipsapirone and bay r 1531 on learned helplessness. Brazilian Journal of Medical and Biological Research Ribeirao Preto, 22(9), 1141-1144.

Graeff, E. O., Graeff, F. G. \& Hunziker, M. H. L. (1991). Efeito da administração aguda e sub-crônica de imipramina, ipsapirona e BAY R 1531 sobre o desamparo aprendido em ratos. [Resumo]. Em Núcleo de Pesquisa em Neurociências e Comportamento (Org.), Resumos I Congresso Interno do Núcleo de Pesquisa em Neurociências e Comportamento (p.3.3). São Paulo: NeC.

Guilhermano, L. G., Ortiz, L., Ferigolo, M. \& Barros, H. M. T. (2004). Commercially available Hypericum perforatum extracts do not decrease immobility of rats in the forced swimming test. Progress in Neuro-Psychopharmacology \& Biological Psychiatry, 28, 4955.

Hammerness, P., Basch, E., Ulbricht, C., Barrete, E-P., Foppa, I., Basch, S., Bent, S., Boon, H. \& Ernst, E. (2003). St John's Wort: a systematic review of adverse effects and drug interactions for the consultation psychiatrist. Psychosomatics, 44, 271-282.

Hering, C. (1989). The Guiding Symptoms of our Materia Medica. New Delhi: Jain.

Hirano, K, Kato, Y, Uchida, S., Sugimoto, Y., Yamada, J., Umegaki, K. \& Yamada, S. (2004). Effects of oral administration of extracts of Hypericum perforatum (St John's wort) on brain serotonina transporter, serotonina uptake and behaviour in mice. $J$ Pharm Pharmacol, 56(12), 1589-1595.

Hunziker, M. H. L., Buonomano, D. V. \& Moura, M. D. (1986). Efeito da administração aguda de imipramina sobre o comportamento de ratos [Resumo]. Em: Sociedade Brasileira de Psicologia (Org.), Resumos da XVI Reunião Anual de Psicologia (p. 35). Ribeirão Preto: SBP. 
Hunziker, M. H. L. (1993). Desamparo Aprendido: um modelo animal da depressão? Psicologia: Teoria e Pesquisa, 9(3), 487-498.

Hunziker, M. H. L. (1997). O desamparo aprendido e a análise funcional da depressão. Em: D. R. Zamignani \& cols. (Orgs.) Sobre Comportamento e Cognição, 3 (pp. 141-149), Santo André, SP: ARBytes.

Hunziker, M. H. L. (2003). Desamparo Aprendido. Tese de livre-docência. Universidade de São Paulo, São Paulo.

Hunziker, M. H. L. (2005). O desamparo aprendido revisitado: estudos em animais. Psicologia: Teoria e Pesquisa , 21 (2), 131-139.

Jackson, R. L., Maier, S. F. \& Coon, D. J. (1979). Long-term analgesic effects of inescapable shock and learned helplessness. Science, 206, 91-94.

Jin Cho, H. (2005). Reviving the old sermon of medicine with the placebo effect. Revista Brasileira de Psiquiatria, 27(4), 336-340.

Kent, J. T. (1985). Materia Medica of the Human Mind: a compilation from the chapter on mind of Kent's repertory. Compiled by M. L. Agrawal. Delhi: Pankaj.

Linde, K., Ramirez, G., Mulrow, C., Pauls, A., Weidenhammer, W. \& Melchart, D. (1996). St John's wort for depression - an overview and meta-analysis of randomized clinical trials. BMJ, 313, 253-258.

Linde, K., Clausius, N., Ramirez, D., Melchart, D., Eitel, F., Hedges, L. V. \& Jonas, W. B. (1997). Are the clinical effects of homoepathy placebo effects? A meta-analysis of placebo-controlled trials. The Lancet, 350, 834-843.

Linde, K., Mulrow, C. D., Berner, M. \& Egger, M. (2005). St John’s wort for depression. Cochrane Database Syst Rev (2): CD000448.

Livy, D. F., Parnell, S. E. \& West, J. R. (2003). Blood ethanol concentration profiles: a comparison between rats and mice. Alcohol, 29, 165-171. 
Machado, I. T. (2000). Guia Homeopático. 6a . ed. São Paulo: Robi Editorial.

Maier, S. F. \& Seligman, M. E. P. (1976). Learned helplessness: Theory and evidence. Journal of Experimental Psychology: General, 105, 3-46.

McKim, W. A. (2003). Drugs and behavior: an introduction to behavioral pharmacology. 5a ed. New Jersey: Prentice Hall.

Medical Economic Company. (2000). PDR for Herbal Medicines. New Jerssey: Montvale.

Mennini, T.\& Gobbi, M. (2004). The antidepressant mechanism of Hypericum perforatum. Life Sciences, 75(9), 1021-1027.

Misane, I. \& Ögren, S. O. (2001). Effects of Hypericum perforatum (St. John’s wort) on passive avoidance in the rat: evaluation of potential neurochemical mechanisms underlying its antidepressant activity. Pharmacopsychiatry, 34, Suppl1: S89-S97.

Moritz, R. \& Almeida, V. R. (2003). Uma revisão crítica da literatura relativa aos possíveis benefícios da medicina homeopática. Revista do Hospital das Clínicas, 58(6), 324-331.

Muller, W. E. (2003). Current St. John's wort research from mode of action to clinical efficacy. Pharmacological Research, 47, 101-109.

Noriega, P. M. S. (1999). Formulação e avaliação in vitro de comprimidos de liberação controlada contendo extrato seco de Hypericum perforatum L. Dissertação de Mestrado. Universidade de São Paulo, São Paulo.

Noriega, P. \& Soares, I. C. (1998). Caracterização físico-quimica do extrato de hypericum perforatum. Rev. Farm. Bioquím. Univ. S. Paulo, 34, (2, Suplemento).

Organização Mundial da Saúde. (2003). CID-10: classificação estatística internacional de doenças e problemas relacionados à saúde. 10. ed. São Paulo: Editora da Universidade de São Paulo. 
Overmier, J. B. \& Leaf, R. C. (1965). Effects of discriminative Pavlovian fear conditioning upon previously or subsequently acquired avoidance responding. Journal of Comparative and Physiological Psychology, 60(2), 213-217.

Overmier, J. B. \& Seligman, M. E. P. (1967). Effects of inescapable shock upon subsequent escape and avoidance learning. Journal of Comparative and Physiological Psychology, 63(1), 28-33.

Petterson, C., Maier, S. F. \& Seligman, M. E. P. (1993) “Learned Helplessness”. A theory for the age of personal control. New York: Oxford University Press.

Petty, F. \& Sherman, A. D. (1979). Reversal of learned helplessness by imipramine. Communications in Psychopharmacology, 3, 371-373.

Rodríguez-Landa, J. F. \& Contreras, C. M. (2003). A review of clinical and experimental observations about antidepressant actions and side effects produced by Hypericum perforatum extracts. Phytomedicine, 10, 688-699.

Scivoletto, S. \& Malbergier, A. (2003). Etanol. Em Seizi, O. (Org.), Fundamentos de Toxicologia, $2^{\mathrm{a}}$ ed. São Paulo: Atheneu Editora.

Seligman, M. E. P. (1977). Desamparo: sobre depressão, desenvolvimento e morte. (M. T. A. Silva, Trad.) São Paulo: HUCITEC, Ed. da Universidade de São Paulo. (Trabalho original publicado em 1975)

Seligman, M. E. P. \& Maier, S. F. (1967). Failure to escape traumatic shock. Journal of Experimental Psychology, 74, 1-9.

Shang, A., Huwiler-Müntener, K., Nartey, L., Jüni, P., Dörig, S., Sterne, J. A. C., Pewsner, D. \& Egger, M. (2005). Are the clinical effects of homoepathy placebo effects? Comparative study of placebo-controlled trial of homoepathy and allopathy. The Lancet, 366, 726-732.

Shapiro, A. K. (1964). A historic and heuristic definition of the placebo. Psychiatry, 27, 5258. 
Sherman, A. D., Sacquitine, J. L. \& Petty, F. (1982). Specificity of the learned helplessness model of depression. Pharmacology, Biochemestry and Behaviour, 16, 122-128.

Skinner, B. F. (1966) The behavior of organisms. New York : Appleton-Century-Crofts. (Originalmente publicado em 1938).

Skinner, B. F. (1991). Questões recentes na análise comportamental. (A. L. Néri Trad.) Campinas, SP, Papirus. (Trabalho original publicado em 1989).

Skinner, B. F. (1998). Ciência e Comportamento Humano. 10ª ed. (J. C. Todorov \& R. Azzi, Trad.) São Paulo: Martins Fontes. (Trabalho original publicado em 1953).

Stevinson, C. \& Ernst, E. (1999). Hypericum for depression: an update of the clinical evidence. European Neuropsychopharmacology, 9, 501-505.

Takamori, K., Yoshida, S. \& Okuyama, S. (2001). Repeated treatment with imipramine, fluvoxamine and tranylcypromine decreases the number of escape failures by activating dopaminergic systems in a rat learned helplessness test. Life Sciences, 69, 1919-1926.

Takase, L. F., Nogueira, M. I., Bland, S. T., Baratta, M., Watkins, L. R., Maier, S. F., Fornal, C. A. \& Jacobs, B. L. (2005). Effect of number of tailshocks on learned helplessness and activation of serotonergic and noradrenergic neurons in the rat. Behavioural Brain Research, 162, 299-306.

Teixeira, M. Z. (2001). Pesquisa básica em homeopatia: revisão bibliográfica. Revista de Homeopatia APH, 66(2), 5-26.

Thompson, T. \& Boren, J. J. (1977). Operant behavioral pharmacology. Em: Honig, W. K.; Staddon, J. E. R. (Org.) Handbook of Operant Behavior. (pp. 540-569). New Jersey: Prentice-Hall.

Teedrogen, E., Bisset, N. G. \& Wichtl, M. (1994). Herbal drugs and phytopharmaceuticals: a handbook for practice on a scientific basis. Stuttgart; Boca Raton: Medpharm Scientific Publishers: CRC Press. 
Usai, M., Leggio, B., Grappi, S., Nanni, G., Gambarana, C., Tolu, P., Giachetti, D. \& De Montis, M. G. (2003). Hypericum perforatum subspecies angustifolium shows a protective activity on the consequences of unavoidable stress exposure at lower doses than hypericum perforatum perforatum. Pharmacopsychitary, 36, 283-287.

Vitiello, B. (1999). Hypericum perforatum extracts as potential antidepressants. Journal of Pharmacy Pharmacological, 51, 513-517.

Zorzetto, R. (2004). Remédios imaginários: expectativa e condicionamento explicam por que placebo, às vezes, funciona. Revista Fapesp, $100^{a}$ ed. Retirado em 13/10/2006, de http://www.revistapesquisa. fapesp.br/?art=2484\&bd=1\&pg=1\&Ig.

Weiss, J. M., Stone, E. A. \& Harrell, N. (1970). Coping behavior and brain norepinefrine level in rats. Journal of Comparative and Physiological Psychology, 72, 153-160.

Wielenska, R. C. (2001). Análise funcional da depressão (ou: a qual fenômeno estamos mesmo nos referindo?). Em: Wielenska, R. C. \& cols. (Orgs.) Sobre Comportamento e Cognição, 6, (pp. 271-283). Santo André, SP: ESETec Editores Associados.

Williams, J. W. J., Mulrow, C. D., Chiquette, E., Noël, P. H., Aguilar, C. \& Cornell, J. (2000). A systematic review of newer pharmacotherapies for depression in adults: evidence summary. Annals of Internal Medicine, 132(9), 743-756.

Williams, J. W. J. \& Holsinger, T. (2005). St John’s for depression, worts and all. BMJ, 330, 350-351.

Willner, P. (1984). The validity of animal models of depression. Psychopharmacology, 3, 116.

Willner, P. (1991). Methods for assessing the validity of animal models of human psychopathology. Em Boultom, A. A.; Glen, B. B.; Martin-Iverson, M. T. Neuromethods Animal Models in Psychiatry I. Human Press, Clifton, New Jersey. (a) 
Willner, P. (1991). Behavioral models in psychopharmacology: theorical, industrial and clinical perspectives. New York: Cambridge University Press. (b)

Wolf, S. (1959). The pharmacology of placebos. Pharmacology Review, 11, 689-704. 
ANEXOS 


\section{ANEXO I}
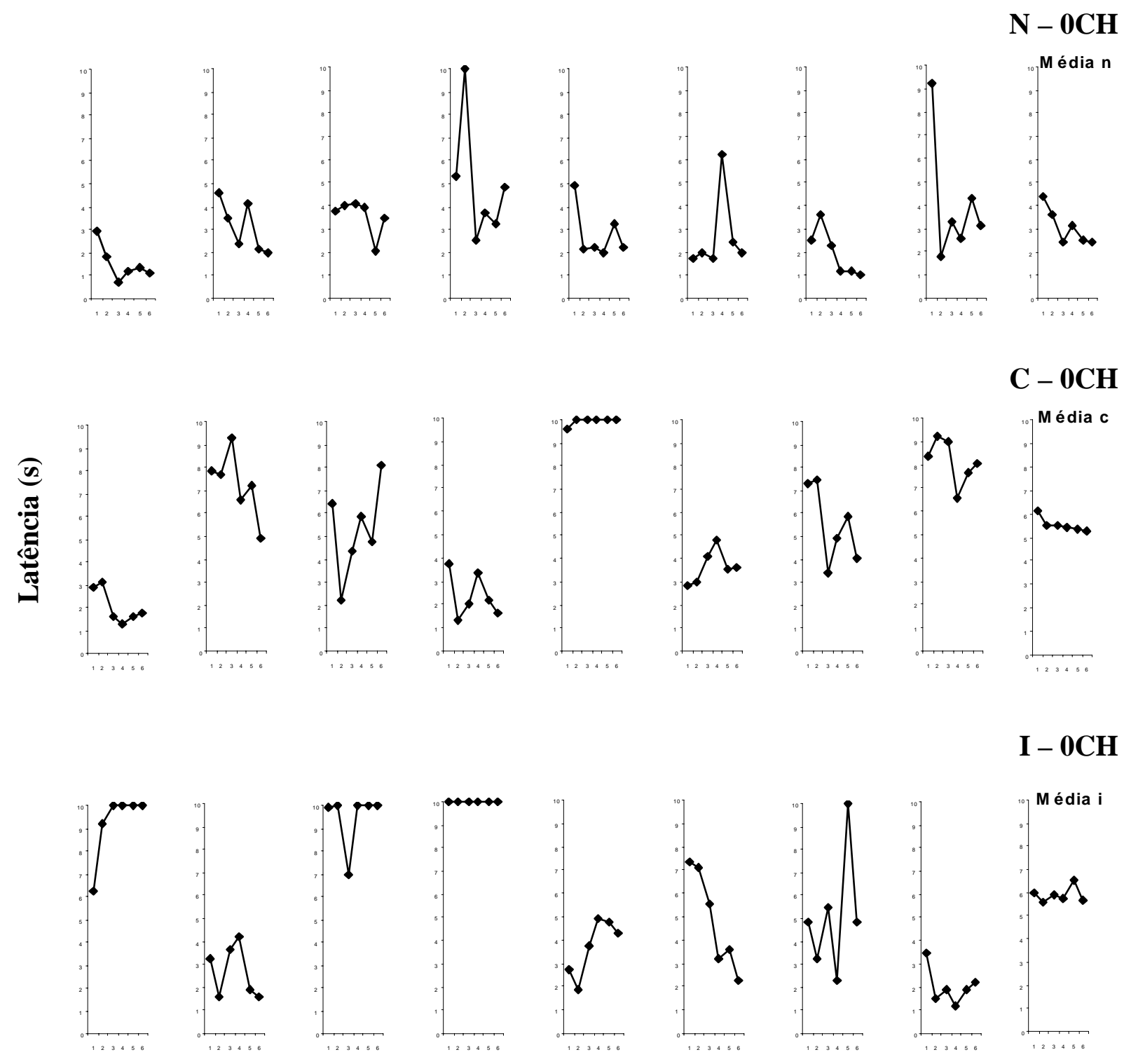

\section{Blocos de 5 tentativas}

Figura 8. Médias das latências (em segundos) da resposta de fuga (saltar) na sessão de teste, em blocos de 5 tentativas, apresentadas pelos sujeitos dos grupos que passaram por nenhum choque (N), choque controlável (C) e choque incontrolável (I) da tríade que recebeu o veículo $(0 \mathrm{CH})$ - solução hidroalcóolica $5 \%$. 

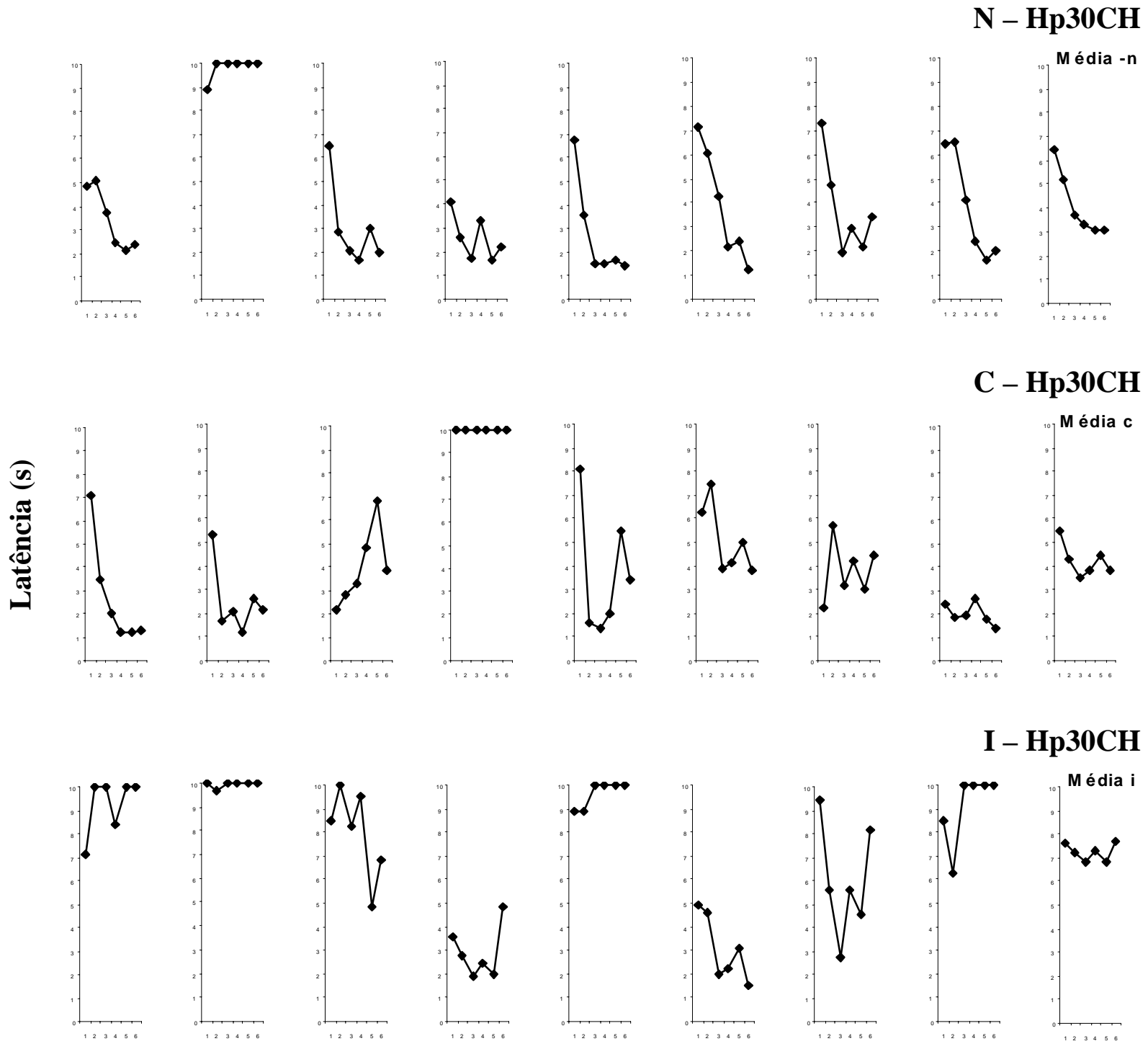

\section{Blocos de 5 tentativas}

Figura 9. Médias das latências (em segundos) da resposta de fuga (saltar) na sessão de teste, em blocos de 5 tentativas, apresentadas pelos sujeitos dos grupos que passaram por nenhum choque $(\mathrm{N})$, choque controlável $(\mathrm{C})$ e choque incontrolável (I) da tríade que recebeu o Hypericum perforatum na dinamização 30CH (Hp30CH). 

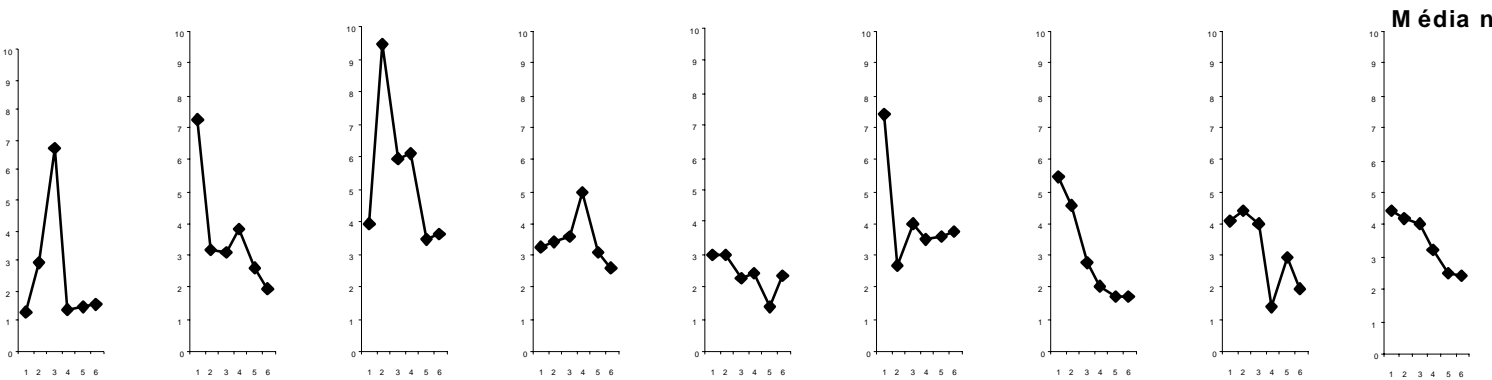

C - Hp200CH
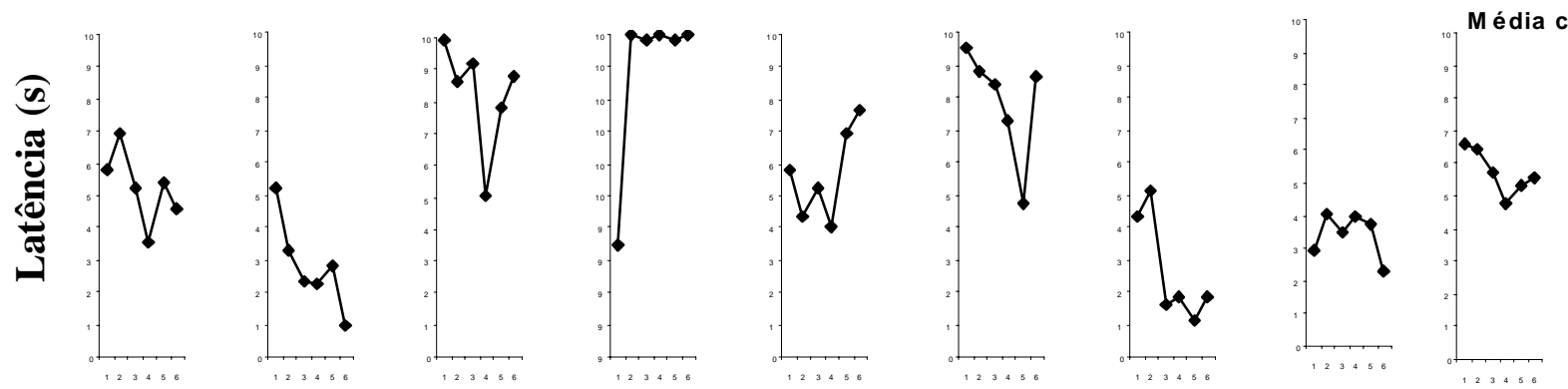

I - Hp200CH
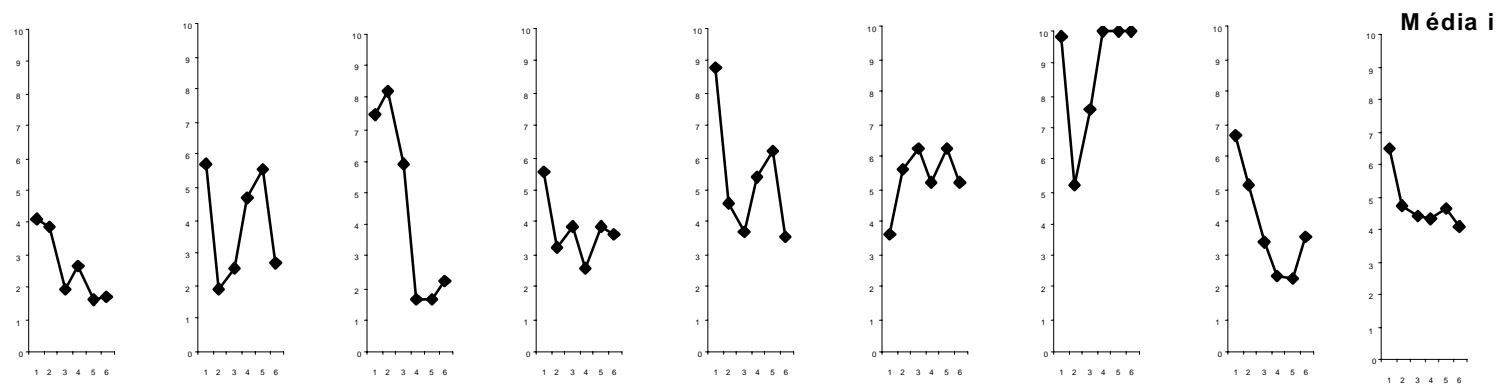

Blocos de 5 tentativas

Figura 10. Médias das latências (em segundos) da resposta de fuga (saltar) na sessão de teste, em blocos de 5 tentativas, apresentadas pelos sujeitos dos grupos que passaram por nenhum choque $(\mathrm{N})$, choque controlável (C) e choque incontrolável (I) da tríade que recebeu o Hypericum perforatum na dinamização 200CH (Hp200CH). 


\begin{abstract}
ANEXO II
Quadro 3. Resumo esquemático do procedimento utilizado como complemento do Experimento 1, com o acréscimo de um Grupo I que recebeu a solução hidroalcóolica 5\% na dinamização $30 \mathrm{CH}$, acoplado à Tríade $0 \mathrm{CH}$. Assim: $0 \mathrm{CH}$ = solução hidroalcóolica a $5 \%$; $30 \mathrm{CH}=$ solução hidroalcóolica $5 \%$ na dinamização $30 \mathrm{CH}$. O intervalo entre o final do tratamento com choques e o início do teste foi de 24 horas.
\end{abstract}

\begin{tabular}{|c|l|c|c|}
\hline $\begin{array}{c}\text { Grupos } \\
(\mathbf{n}=\mathbf{8})\end{array}$ & \multicolumn{1}{|c|}{$\begin{array}{c}\text { Choque } \\
(\mathbf{6 0} \text { tentativas) } \\
\text { (R de Fuga=focinhar) }\end{array}$} & $\begin{array}{c}\text { Droga } \\
5 \text { gotas v.o. } \\
(0,19 \text { e } 23 \mathrm{~h})\end{array}$ & $\begin{array}{c}\text { Teste } \\
\text { (30 tentativas) } \\
\text { (R de fuga = saltar) }\end{array}$ \\
\hline C 0CH & Choque Controlável (C) & Sol. hidroalc. 5\% & Choque Controlável \\
I 0CH & Choque Incontrolável (I) & & (C) \\
N 0CH & Nenhum Choque (N) & & \\
I 30CH & Choque Incontrolável (I) & Sol. hidroalc. 5\% 30CH & \\
\hline
\end{tabular}




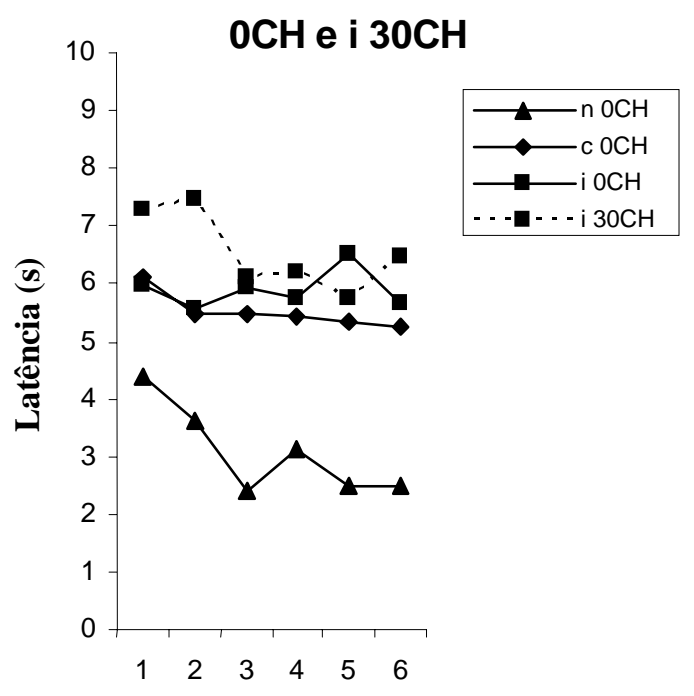

Blocos de 5 tentativas

Figura 11. Médias das latências (em segundos) da resposta de fuga (saltar) na sessão de teste, em blocos de 5 tentativas, apresentadas pelos grupos que passaram por nenhum choque $(\mathrm{N})$, choque controlável (C) e choque incontrolável (I) da tríade que recebeu solução hidroalcóolica $5 \%$ e pelo Grupo I acoplado a essa tríade, mas que recebeu solução hidroalcóolica 5\% na dinamização 30CH (30CH).
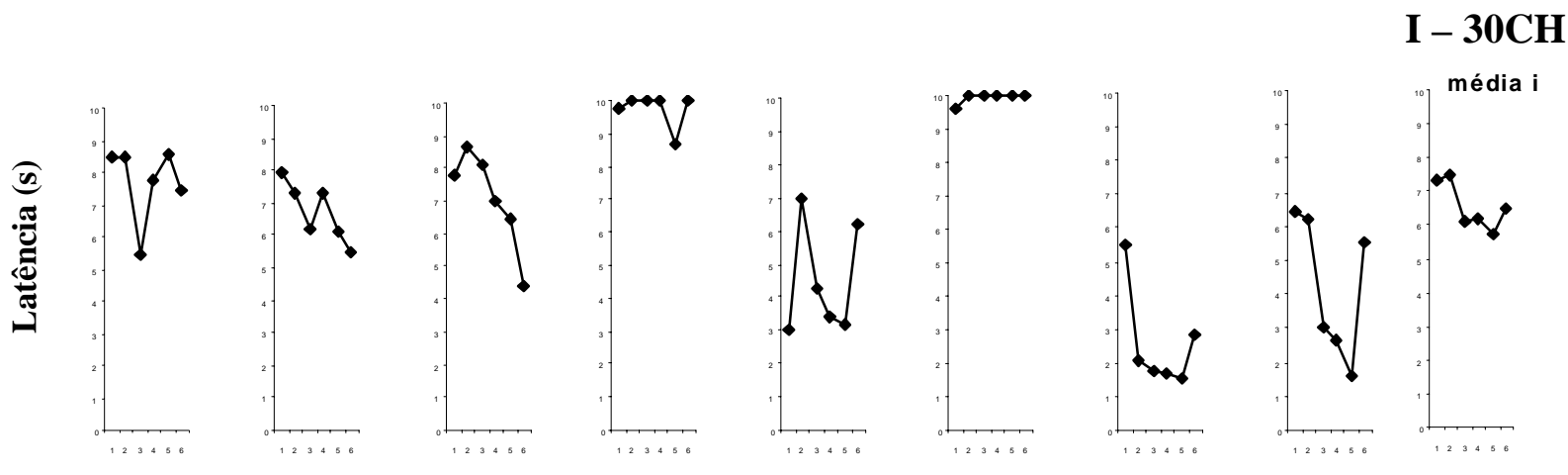

Blocos de 5 tentativas

Figura 12. Médias das latências (em segundos) da resposta de fuga (saltar) na sessão de teste, em blocos de 5 tentativas, apresentadas pelos sujeitos do grupo que passou por choque incontrolável (I), acoplado ao Grupo $\mathrm{C}$ da Tríade $0 \mathrm{CH}$, e que recebeu solução hidroalcóolica $5 \%$ na dinamização $30 \mathrm{CH}(30 \mathrm{CH})$. 

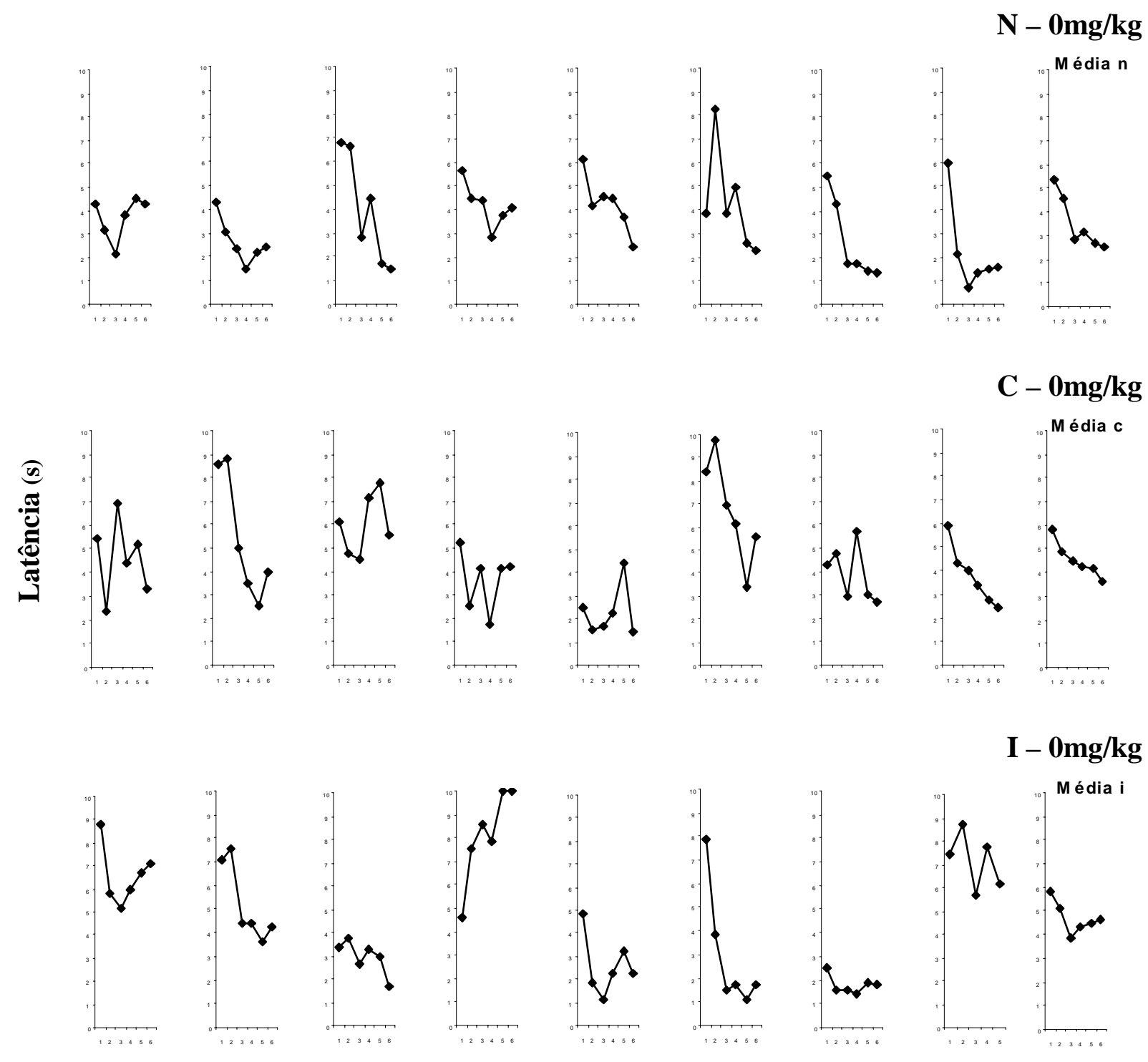

\section{Blocos de 5 tentativas}

Figura 13. Médias das latências (em segundos) da resposta de fuga (saltar) na sessão de teste, em blocos de 5 tentativas, apresentadas pelos sujeitos dos grupos que passaram por nenhum choque (N), choque controlável (C) e choque incontrolável (I) da tríade que recebeu o veículo - solução hidroalcóolica 5\% - (0mg/kg). 

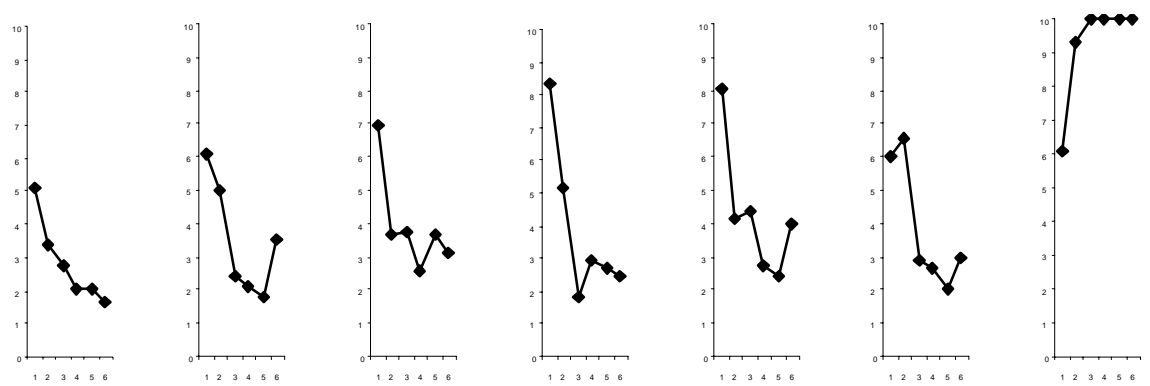

$\mathrm{N}-\mathrm{Hp} 15 \mathrm{mg} / \mathrm{kg}$
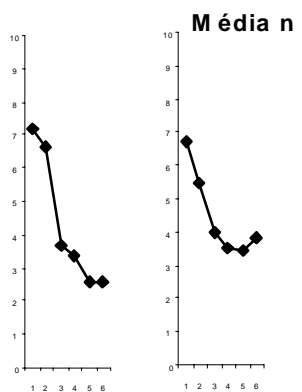

C - Hp 15mg/kg
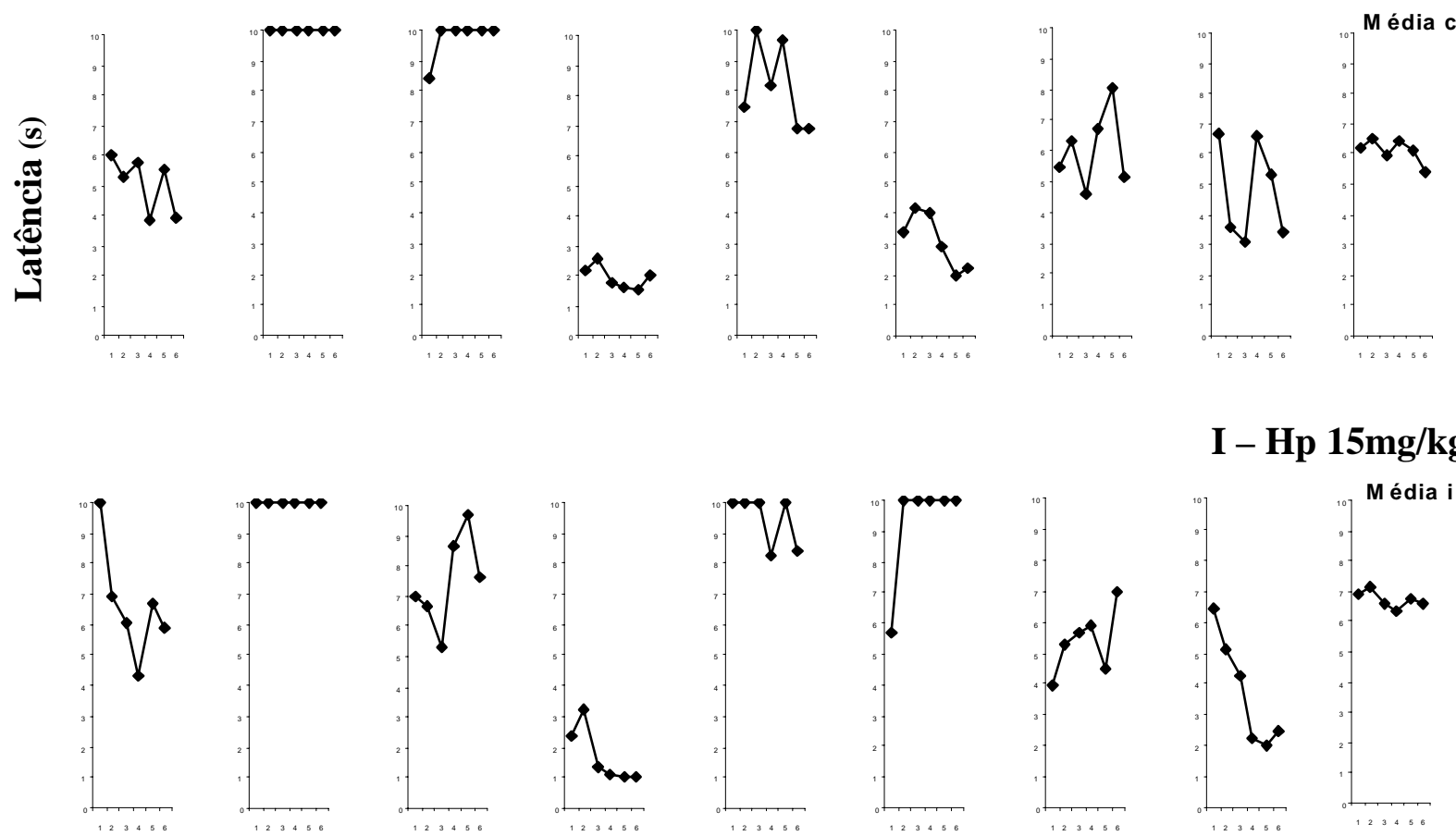

I - Hp 15mg/kg

Blocos de 5 tentativas

Figura 14. Médias das latências (em segundos) da resposta de fuga (saltar) na sessão de teste, em blocos de 5 tentativas, apresentadas pelos sujeitos dos grupos que passaram por nenhum choque $(\mathrm{N})$, choque controlável $(\mathrm{C})$ e choque incontrolável (I) da tríade que recebeu o Hypericum perforatum na dose $15 \mathrm{mg} / \mathrm{kg}$ (Hp 15mg/kg). 

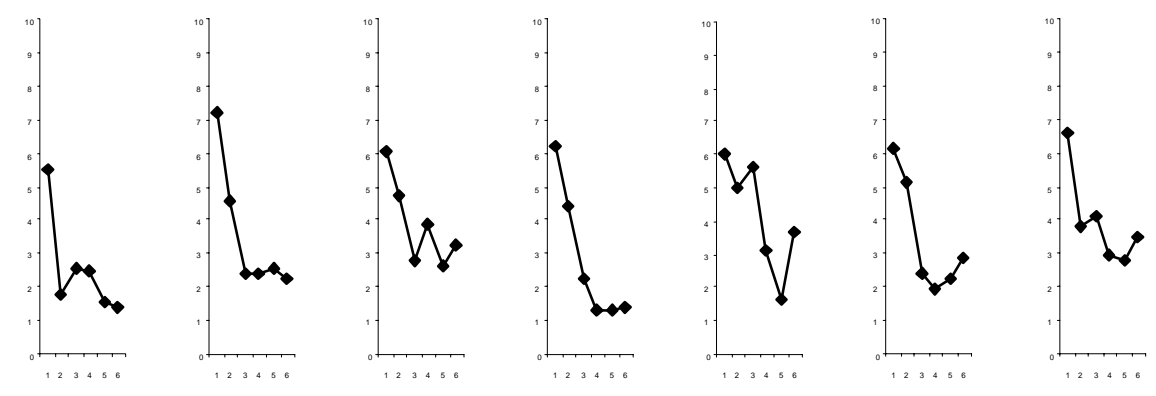

N - Hp 30mg/kg

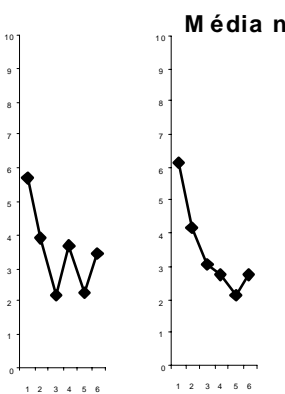

C - Hp 30mg/kg
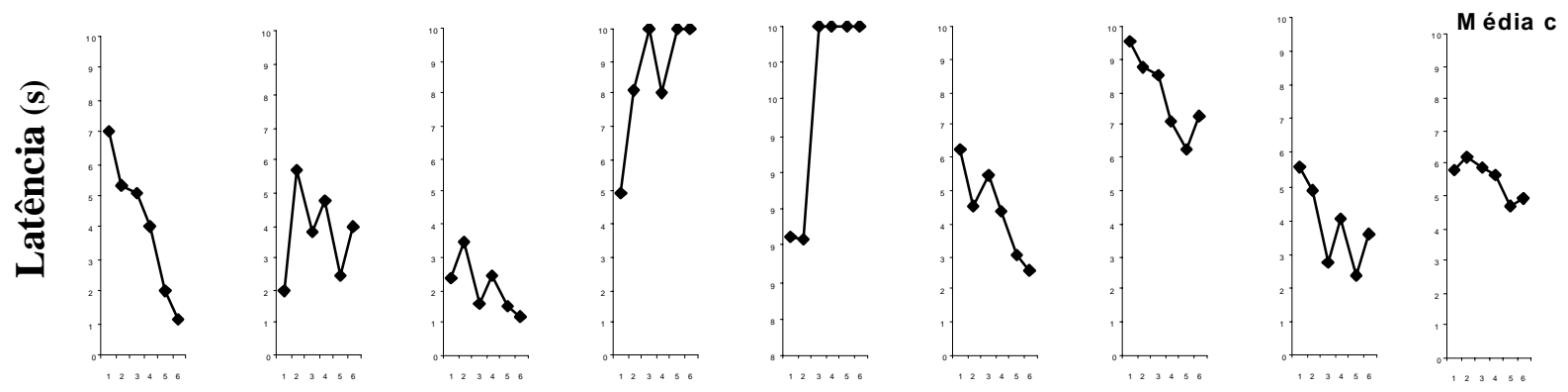

\section{I - Hp 30mg/kg}
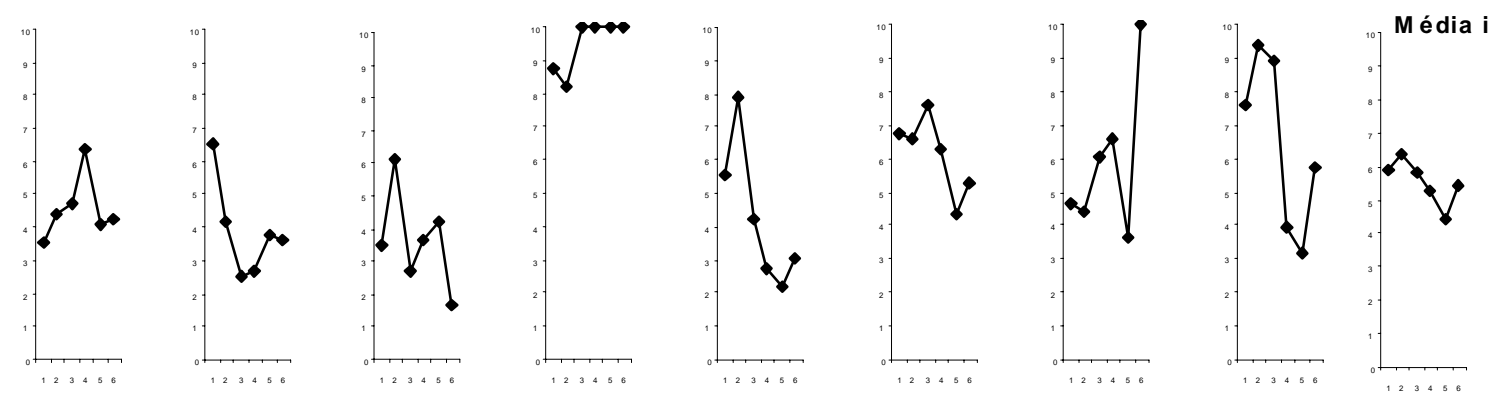

\section{Blocos de 5 tentativas}

Figura 15. Médias das latências (em segundos) da resposta de fuga (saltar) na sessão de teste, em blocos de 5 tentativas, apresentadas pelos sujeitos dos grupos que passaram por nenhum choque $(\mathrm{N})$, choque controlável $(\mathrm{C})$ e choque incontrolável (I) da tríade que recebeu o Hypericum perforatum na dose 30mg/kg (Hp 30mg/kg). 


\section{ANEXO IV}

Quadro 4. Resumo esquemático do procedimento utilizado como complemento do Experimento 2, com o acréscimo de um Grupo I que recebeu salina, acoplado à Tríade 0 $\mathrm{mg} / \mathrm{kg}$. Assim: $0 \mathrm{mg} / \mathrm{kg}$ = solução hidroalcóolica a $5 \%$; Sal = salina ou soro fisiológico. $\mathrm{O}$ intervalo entre as sessões de choque e teste foi de 24 horas.

\begin{tabular}{|c|l|c|c|}
\hline $\begin{array}{c}\text { Grupos } \\
(\mathbf{n = 8 )}\end{array}$ & \multicolumn{1}{|c|}{$\begin{array}{c}\text { Choque } \\
\text { (60 tentativas) } \\
\text { (R de Fuga=focinhar) }\end{array}$} & $\begin{array}{c}\text { Droga } \\
1 \mathrm{ml} / \mathrm{kg} \text { (i.p.) } \\
22 \mathrm{~h} \text { pós choque }\end{array}$ & $\begin{array}{c}\text { Teste } \\
\text { (30 tentativas) } \\
\text { (R de Fuga=saltar) }\end{array}$ \\
\hline C 0 & Choque Controlável (C) & & \\
I 0 & Choque Incontrolável (I) & $0 \mathrm{mg} / \mathrm{kg}$ \\
N 0 & Nenhum Choque (N) & (Sol. hidroalc. 5\%) & $\begin{array}{c}\text { Choque Controlável } \\
\text { (C) }\end{array}$ \\
\hline I Sal & Choque Incontrolável (I) & Salina & \\
\hline
\end{tabular}




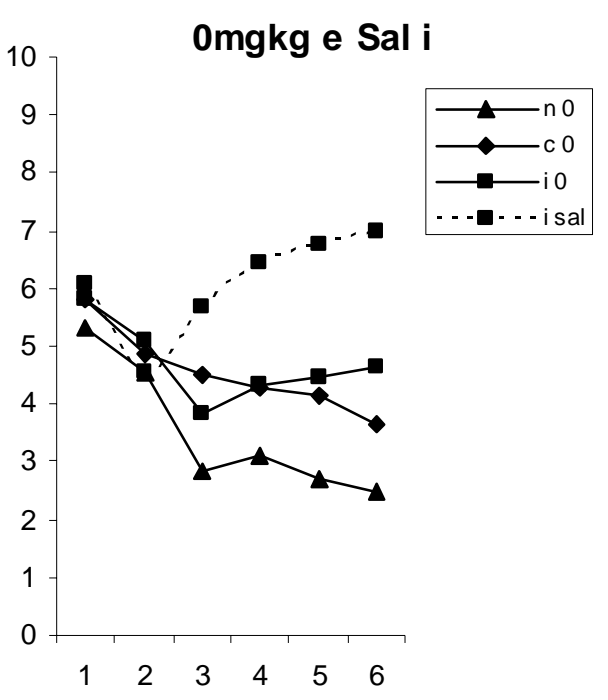

Blocos de 5 tentativas

Figura 16. Médias das latências (em segundos) da resposta de fuga (saltar) na sessão de teste, em blocos de 5 tentativas, apresentadas pelos grupos que passaram por nenhum choque $(\mathrm{N})$, choque controlável (C) e choque incontrolável (I) da Tríade $0 \mathrm{mg} / \mathrm{kg}$ e pelo Grupo I acoplado a essa tríade, que recebeu salina (Sal).

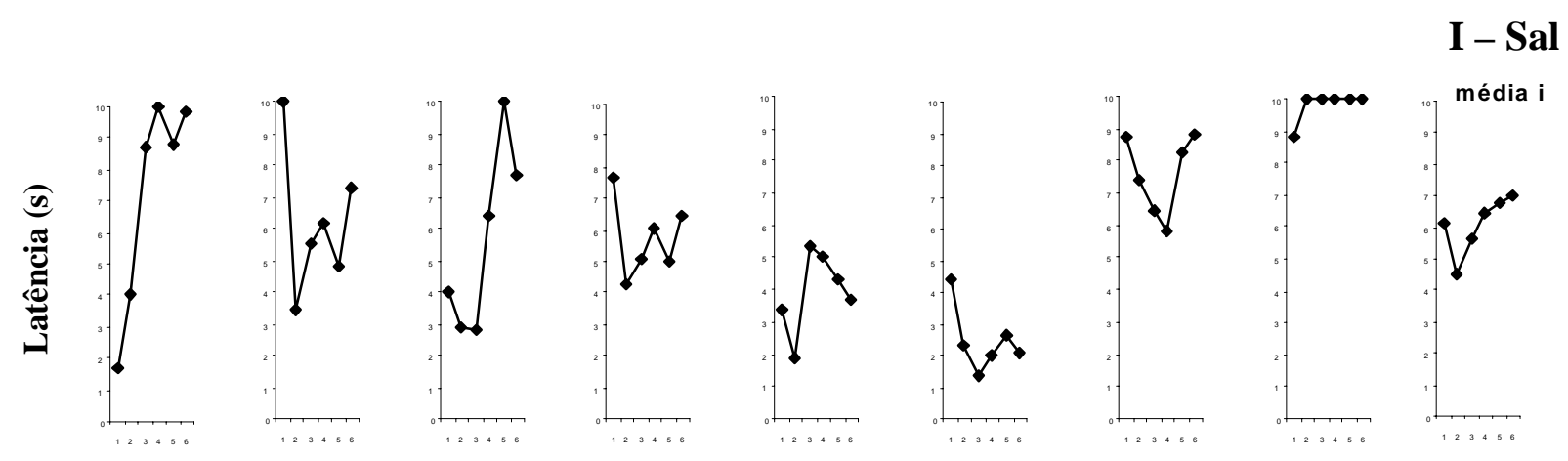

Blocos de 5 tentativas

Figura 17. Médias das latências (em segundos) da resposta de fuga (saltar) na sessão de teste, em blocos de 5 tentativas, apresentadas pelos sujeitos do grupo que passou por choque incontrolável (I), acoplado ao Grupo C da Tríade 0mg/kg, e que recebeu salina (Sal). 